Florida International University

FIU Digital Commons

10-29-2019

\title{
A Visually-Enhanced Approach to Multivariate Calculus Facilitated by a Computer Algebra System
}

\author{
Belarmino Gonzalez \\ Florida International University, bgonz009@fiu.edu
}

Follow this and additional works at: https://digitalcommons.fiu.edu/etd

Part of the Curriculum and Instruction Commons

\section{Recommended Citation}

Gonzalez, Belarmino, "A Visually-Enhanced Approach to Multivariate Calculus Facilitated by a Computer Algebra System" (2019). FIU Electronic Theses and Dissertations. 4288.

https://digitalcommons.fiu.edu/etd/4288

This work is brought to you for free and open access by the University Graduate School at FIU Digital Commons. It has been accepted for inclusion in FIU Electronic Theses and Dissertations by an authorized administrator of FIU Digital Commons. For more information, please contact dcc@fiu.edu. 


\title{
FLORIDA INTERNATIONAL UNIVERSITY
}

Miami, Florida

\section{A VISUALLY-ENHANCED APPROACH TO MULTIVARIATE CALCULUS FACILITATED BY A COMPUTER ALGEBRA SYSTEM}

\author{
A dissertation submitted in partial fulfillment of the \\ requirements for the degree of \\ DOCTOR OF EDUCATION
}

in

CURRICULUM AND INSTRUCTION

by

Belarmino Gonzalez

2019 
To: Dean Michael R. Heithaus

College of Arts, Sciences, and Education

This dissertation, written by Belarmino Gonzalez, and entitled A Visually-Enhanced Approach to Multivariate Calculus Facilitated by a Computer Algebra System, having been approved in respect to style and intellectual content, is referred to you for judgment.

We have read this dissertation and recommend that it be approved.

Haiying Long

Tedi C. Draghici

Mandayam O. Thirunarayanan

Maria L. Fernandez, Major Professor

Date of Defense: October 29, 2019

The dissertation of Belarmino Gonzalez is approved.

Dean Michael R. Heithaus

College of Arts, Sciences, and Education

Andrés G. Gil

Vice President for Research and Economic Development and Dean of the University Graduate School

Florida International University, 2019 
(C) Copyright 2019 by Belarmino Gonzalez

All rights reserved. 


\section{DEDICATION}

To my parents, who fostered and encouraged my curiosity and desire to learn. Whose unconditional love and example as professionals and human beings have guided my journey and put me in the path of success and happiness. 


\section{ACKNOWLEDGMENTS}

The successful completion of this dissertation would not have been possible without the help, support, and encouragement of many people. First, I would like to thank my committee members for their time, effort, and expertise in the completion of this project. Thank you, Dr. Fernandez, for believing in me for so many years, and always letting me know I could do it even when I doubted myself. Thank you, Dr. Long, for your availability and guidance in the methodology and analysis of this study, where difficulty and excitement converged. Thank you, Dr. Draghici, for your invaluable input in the creation of the content knowledge instruments used. Finally, thank you, Dr. Thirunarayanan, for your insights and suggestions to strengthen this work.

I would also like to thank my Mom and Dad, to whom I dedicate this important milestone in my life and whose contributions are far more than I can list here. I would like to thank my wife, Dayana, whose patience and support is almost unbounded, and whose love is even greater. I would like to thank my son; whose very existence and love pushes me to better myself. I would also like to thank my friends and colleagues who have helped me and motivated me to finish my dissertation. 
ABSTRACT OF THE DISSERTATION

A VISUALLY-ENHANCED APPROACH TO MULTIVARIATE CALCULUS FACILITATED BY A COMPUTER ALGEBRA SYSTEM

\author{
by
}

Belarmino Gonzalez

Florida International University, 2019

Miami, Florida

Professor Maria L. Fernandez, Major Professor

This study investigated the effects of a visually-enhanced approached to the teaching of selected multivariate calculus concepts on students' mathematical understanding and visualization. The sample size consisted of 65 undergraduate students from Miami Dade College, a large Hispanic Serving Institution in the Southeast. A pretest - posttest, nonequivalent group design was used. CAS dynamic worksheets containing visualizations and geometric representations were created using a computer algebra system and embedded as part of the lecture in the experimental group. Instructordeveloped instruments were used to measure students' prerequisite knowledge for multivariate calculus, and students' mathematical understanding of selected concepts. Furthermore, Yoon (2011)'s Revised PSVT: R was used to measure students' spatial ability. Results from the statistical tests supported the hypothesis that enhancing the visual/geometric aspects of selected multivariate calculus concepts have a positive effect on students' mathematical understanding and spatial ability. 


\section{TABLE OF CONTENTS}

CHAPTER

PAGE

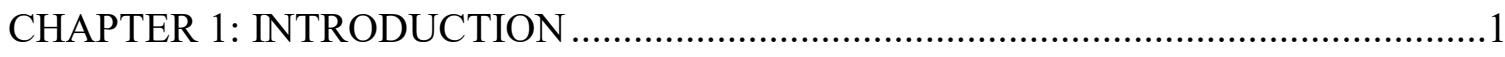

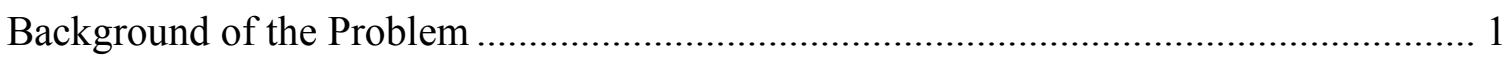

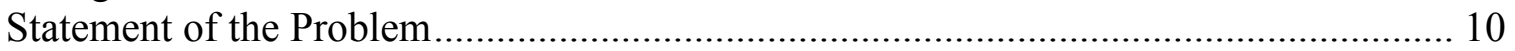

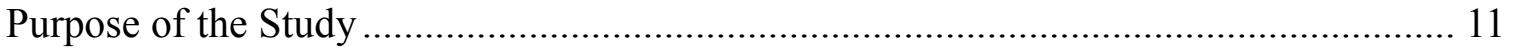

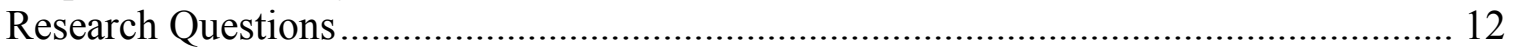

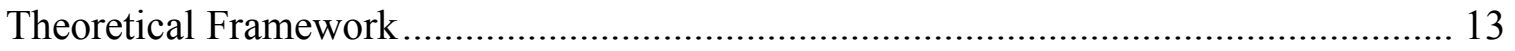

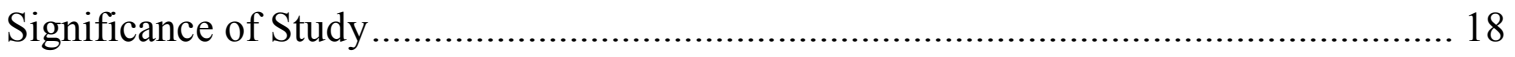

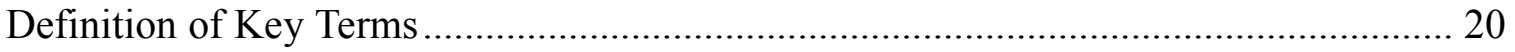

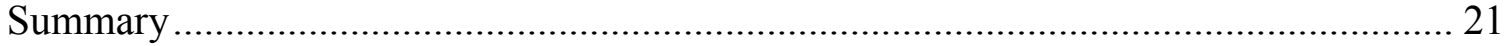

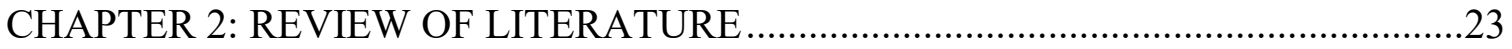

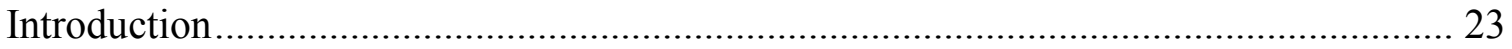

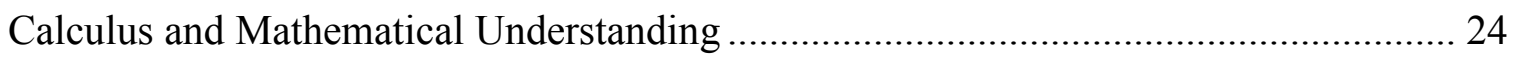

Role of Technology in the Teaching and Learning of Calculus ...................................... 28

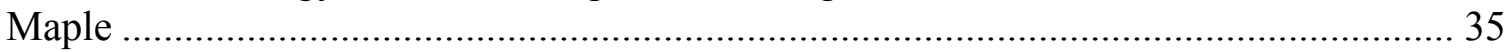

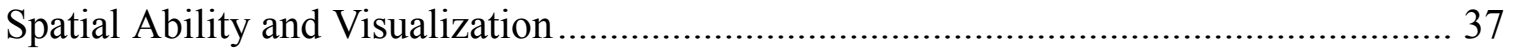

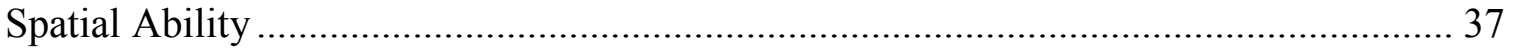

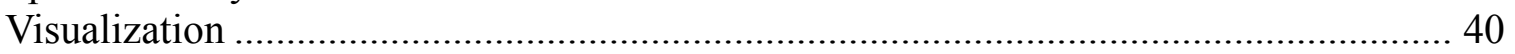

Visualization and Mathematical Understanding in Calculus......................................... 45

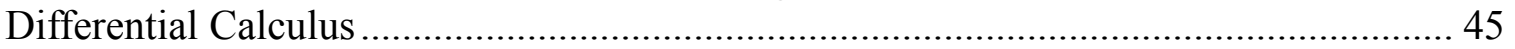

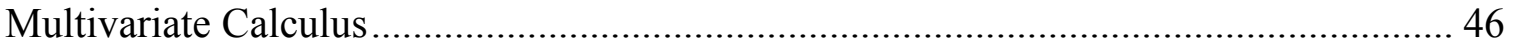

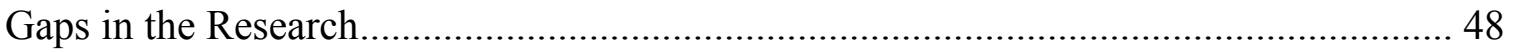

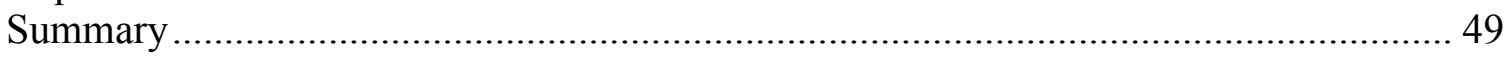

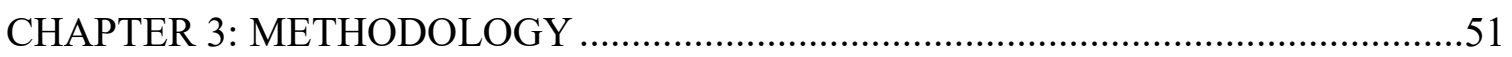

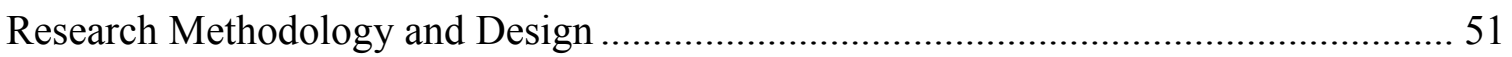

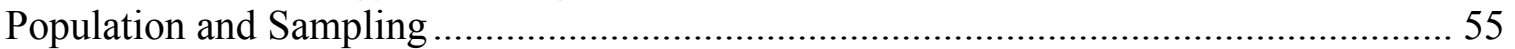

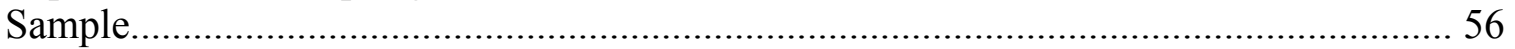

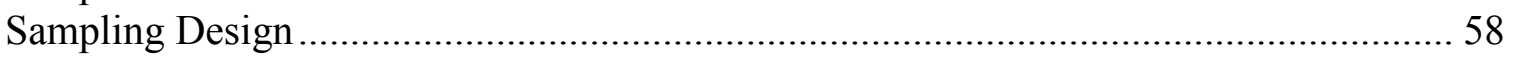

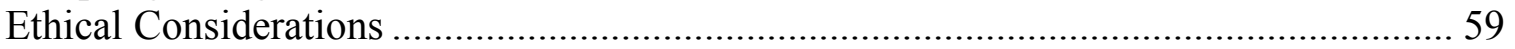

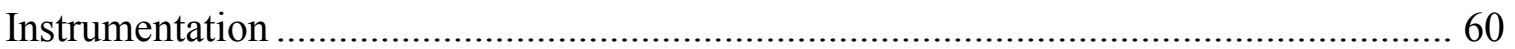

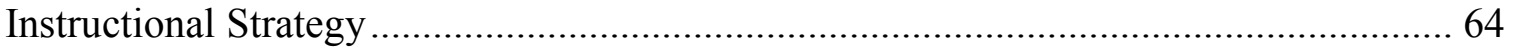

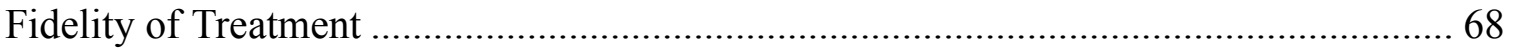

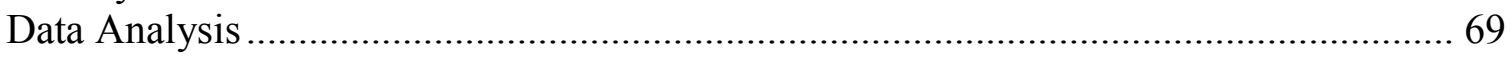

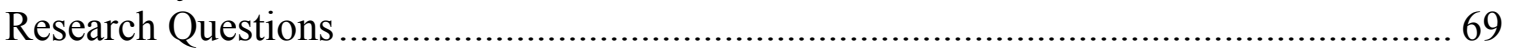

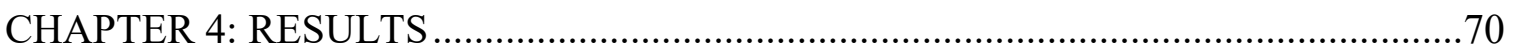




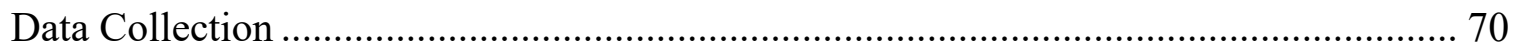

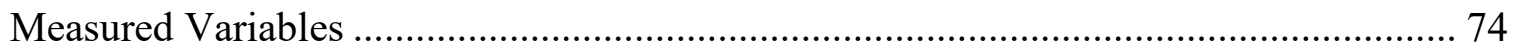

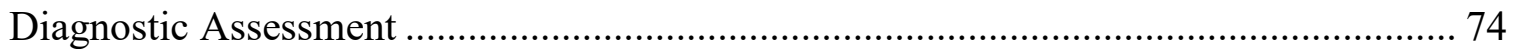

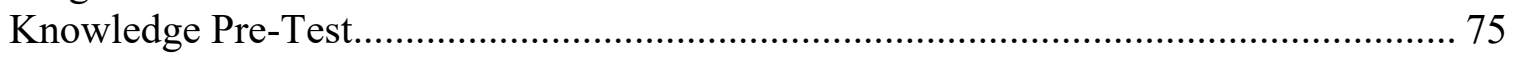

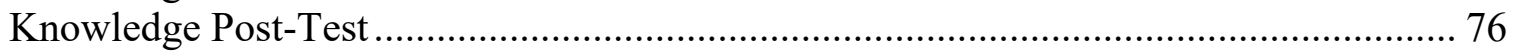

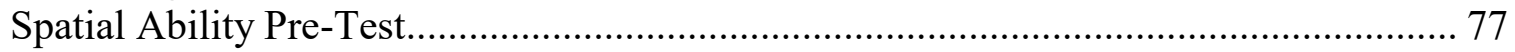

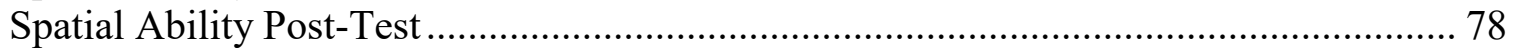

Research Questions ............................................................................................ 79

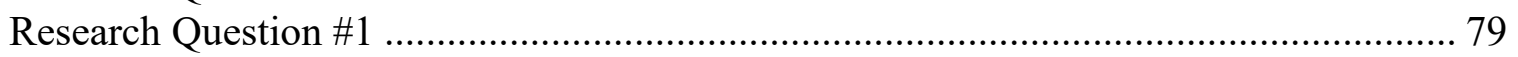

Research Question \#2 ......................................................................................... 84

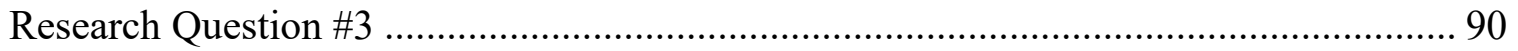

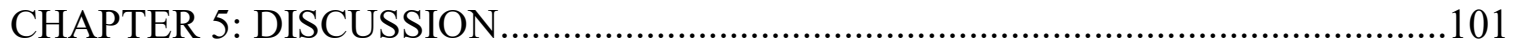

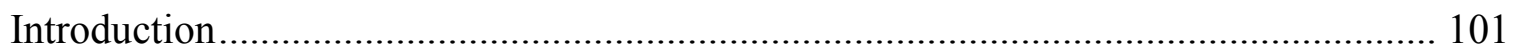

Summary of the Research Problem, Research Questions, and Findings ....................... 101

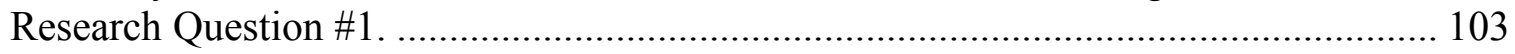

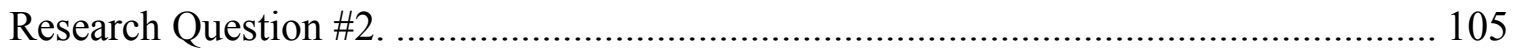

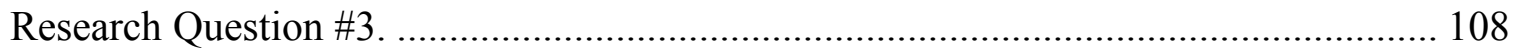

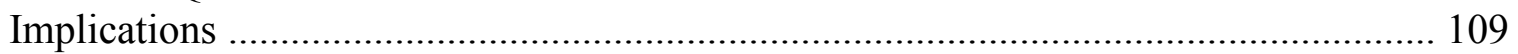

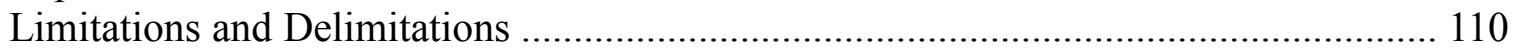

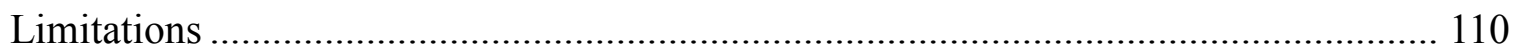

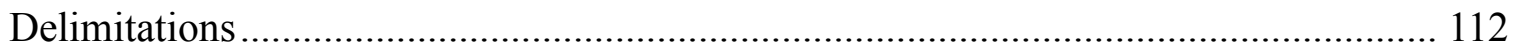

Recommendations for Future Research ............................................................... 113

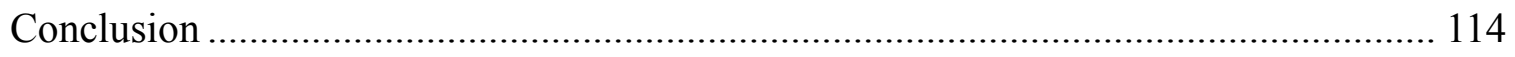

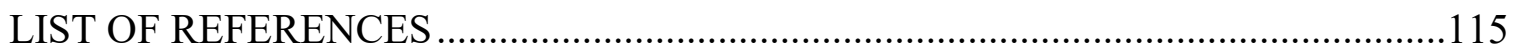

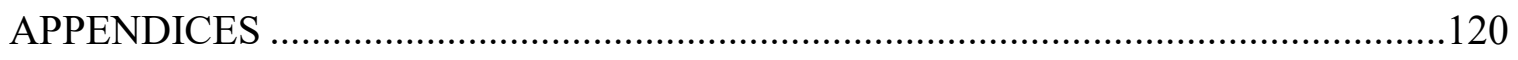

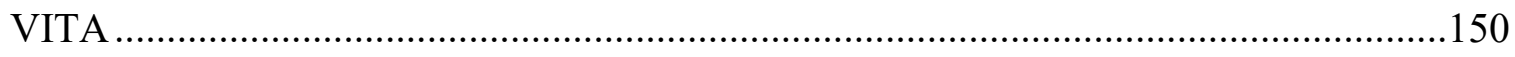




\section{LIST OF TABLES}

TABLE

PAGE

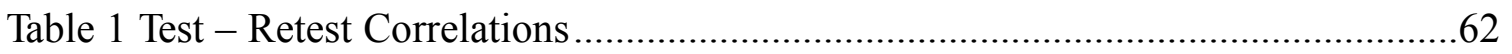

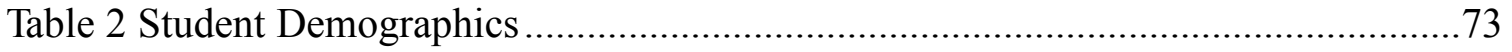

Table 3 Homogeneity of Regression Test..................................................................... 75

Table 4 Knowledge Pretest Group Data indicators................................................... 76

Table 5 Knowledge Posttest Group Data Indicators ................................................ 77

Table 6 Spatial Ability Pretest Group Data Indicators ..............................................78

Table 7 Spatial Ability Posttest Group Data Indicators ............................................. 79

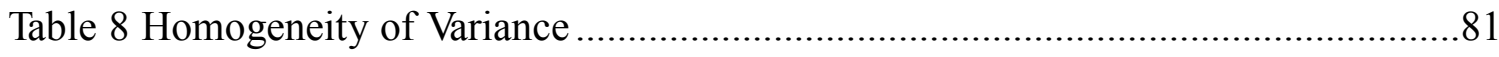

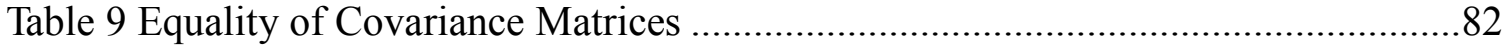

Table 10 Results of Repeated-Measures, Two-Way Mixed ANOVA for Knowledge......83

Table 11 Results for Repeated-Measures, Two-Way Mixed ANOVA for Knowledge ....84

Table 12 Equality of Variances for Spatial Ability …..............................................86

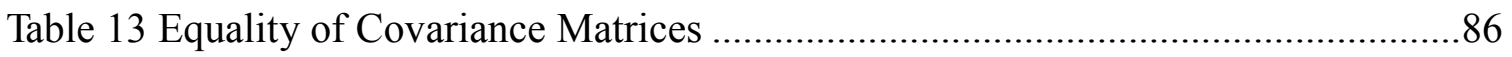

Table 14 Results of Repeated-Measures, Two-Way ANOVA for Spatial Ability ............88

Table 15 Results of Repeated-Measures, Two-Way Mixed ANOVA for Spatial Ability.88

Table 16 Results of Simple Main Effects for Treatment ............................................89

Table 17 Results of Simple Main Effects for Time ................................................90

Table 18 Normality for Knowledge (Pretest and Posttest), and Visual (Pretest and

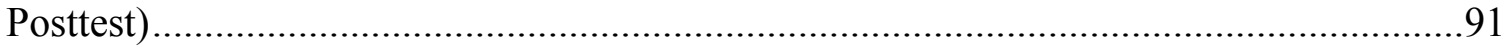

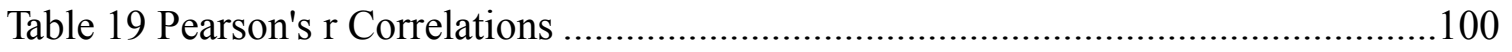




\section{LIST OF FIGURES}

FIGURE

PAGE

Figure 1. Histogram of Knowledge Pretest scores in the group Control*Low.................76

Figure 2. Histogram from Population's Knowledge Pretest .........................................92

Figure 3. Histogram for Population's Knowledge Posttest .........................................92

Figure 4. Histogram for Population's Visual Posttest ................................................93

Figure 5. Scatter/Dot Chart of Visual Pretest - Visual Posttest ......................................94

Figure 6. Scatter/Dot Chart for Visual Pretest - Knowledge Pretest ..............................94

Figure 7. Scatter/Dot Chart for Visual Pretest - Knowledge Posttest.............................95

Figure 8. Scatter/Dot Chart for Visual Posttest - Knowledge Pretest.............................96

Figure 9. Scatter/Dot Chart for Visual Posttest - Knowledge Posttest ...........................96

Figure 10. Scatter/Dot Chart for Knowledge pretest - Knowledge Posttest .....................97 


\section{CHAPTER 1: INTRODUCTION}

"Geometry and algebra are the two formal pillars of mathematics... they have both been fundamental to mathematics, but they have had an uneasy relationship" (Atiyah, 2001, p. 654). Geometry is about space and is very much related to the way we comprehend and make sense of the physical world we live in. As we interact with our surroundings through our senses, specially our vision, we develop our spatial intuition or spatial ability. It is our desire to understand and make sense of the world we see and interact with one of the reasons why geometry is such a powerful tool in mathematics; it enables us put things in a geometrical perspective thus giving us the ability to use our intuition (Atiyah, 2001, p. 658). Algebra on the other hand is concerned with manipulations in time, operations performed sequentially, one after another (Atiyah, 2001, p. 658). These two pillars, one concerned with space while the other existing in time, gives us two different points of view in the mathematics world (Atiyah, 2001, p. 658) and are instrumental in the development of mathematical understanding.

Chapter I presents the background to the problem, statement of the problem, purpose of the study, research questions, theoretical framework, significance of the study, and definition of key terms. The chapter ends with a summary and description of the remaining chapters of the dissertation.

\section{Background of the Problem}

To ensure the nation's continued economic success and national security, the National Science Board (2007) recommends: "All American citizens must have the basic 
scientific, technological, and mathematical knowledge to make informed personal choices, to be educated voters, and to thrive in the increasingly technological global marketplace" (p. V). Furthermore, it calls for coherence in the nation's science, technology, engineering, and mathematics (STEM) education system across all levels and exhorts several federal agencies, including the National Science Foundation (NSF), to support and encourage research about effective teaching strategies and the role of technology in facilitating learning (National Science Board, 2007). Science and engineering have been the foundation of our nation's innovation and technological advances, but in an increasingly global and knowledge-based economy, the National Science Board (2007) emphasizes the need for students to develop their capabilities in science and engineering to levels higher than previously required. In particular, instructions needs to balance students' acquisition of content knowledge in STEM areas with critical thinking and analytical skills and foster in them the ability to make connections among concepts and ideas and develop a capacity for life-long learning (National Science Board, 2007). In its publication Preparing the Next Generation of STEM Innovators: Identifying and Developing our Nation's Human Capital, the National Science Board (2010) called for STEM education to develop and nurture STEM "innovators," individuals with the knowledge and expertise to lead technological innovations and scientific breakthroughs. These are individuals whose capabilities "often include mathematical and spatial abilities alone or in combination with verbal aptitude, along with other factors such as creativity, leadership, self-motivation, and a diligent work ethic" (National Science Board, 2010, p. 6). 
It also acknowledged challenges within the current US STEM education system and warns of the danger of a population that "may not know enough about science, technology, or mathematics to contribute significantly to, or fully benefit from, the knowledge-based economy that is already taking shape around us" (National Science Board, 2007, p. 3). According to its latest Science and Engineering Indicators, the National Science Board (2018) estimated that 6.4 million college graduates were employed in 2015 in STEM related fields, mostly in computer and mathematical sciences (48.4\%) and engineering (26.6\%). Although STEM-related occupations have consistently grown at a faster rate than the total workforce (National Science Board, 2018), there is concern in the ability of undergraduate education in two-year institutions of higher education (IHE) to produce and retain STEM students: "Three years after enrolling in a two-year institution in the 2011-12 academic year, about 55\% of students had either completed an associate's degree (12\%) or remained enrolled in school (at the same or another institution) without having earned a degree (43\%)" (National Science Board, 2018, p. 2 | 51). Minority-serving two-year institutions are of particular importance because of the role they play educating and training minorities to pursue advanced science and engineering (S\&E) degrees: "Nearly one in five U.S. citizens or permanent residents who received an S\&E doctoral degree from 2011 to 2015 had earned some college credit from a community or two-year college" (National Science Board, 2018, p. $2 \mid 4)$.

It is equally worrisome that in minority-serving 2-year institutions, many potential homegrown STEM students may go "unrecognized and underdeveloped, and, thus, fail to reach their full potential” (National Science Board, 2010, p. 1). Minority-serving two- 
year institutions' inability to develop STEM students to their full potential is a critical issue that needs to be addressed because of the impact it may have in the supply of STEM professionals to the increasing global, technological, and knowledge-based economy of our nation. One reason for such deficiency in the identification and development of potential STEM students is an educational institution's inability to diagnose and advance students' spatial ability (National Science Board, 2010; Wai, Lubinski, \& Benbow, 2009). Another reason may be students' view of mathematics as a set of rules and procedures that need to be memorized. NCTM (2000) warned that focus on memorization of rules and procedures leads to a fragile and incomplete learning of mathematics, and instead it urged educators to combine factual knowledge, procedural proficiency, and conceptual understanding to develop well-connected, conceptually-grounded mathematical ideas that will be easier to remember and apply in different situations. "Learning with understanding is essential to enable students to use what they learn to solve the new kinds of problems they will inevitably face in the future" (National Council Of Teachers Of Mathematics, 2000a, p. 21). Moreover, learning with understanding promotes the creation of autonomous learners, critical thinkers, problem solvers, and lifelong learners, which in turn helps make subsequent learning easier (NCTM, 2000; National Science Board, 2007)

At any institution of higher education, students majoring in a STEM field (biological and biomedical sciences, computer and information sciences, engineering and engineering technologies, mathematics and statistics, and physical sciences and science technologies) usually must complete a calculus sequence as part of their required coursework. The calculus sequence students must complete varies according to their field 
of study and the applications relevant to said field. The calculus sequence normally includes differential calculus, integral calculus, and multivariate calculus.

Of the typical three courses in the calculus sequence, multivariate calculus is a course of great importance because it is one of the first courses where students learn about the geometry of space, the calculus of many variables, and vector fields. It is a course where students' spatial ability and visualization is further developed while contributing to their mathematical understanding. According to NCTM (2000), "Spatial visualization - building and manipulating mental representations of two- and threedimensional objects and perceiving an object from different perspectives-is an important aspect of geometric thinking" (p. 41). The ability to visualize and think geometrically is one of the pillars of mathematics and one of the components of learning with understanding. Therefore, enhancing students' visualization and spatial ability should contribute to the development of students' geometric thinking, which in turn contributes to their mathematical understanding and their ability to represent, interpret, and solve problems and real-world situations (National Council Of Teachers Of Mathematics, 2000a), an important asset for STEM students.

As described in the $14^{\text {th }}$ edition of "Thomas' Calculus Early Transcendentals" developed from the original work of George B. Thomas, Jr, and revised by Maurice D. Weir and Joel Hass, multivariate calculus is used in several fields such as physics, engineering, computer science, chemistry, economics, and meteorology, among others. It is employed in the modeling and study of high-dimensional systems that exhibit deterministic behavior. In physics and engineering, multivariate calculus is used in 
applications regarding electromagnetic fields, gravitational fields, and fluid flow. In computer science, it is used in simulation and graphic modeling. Multivariate calculus is also used in the application of thermodynamics to chemistry. In economics, it is used in budget constraint, utility function, production function, and cost function. In the geosciences, structural geology uses multivariate calculus to measure the orientation of planes around the surface of a fold, while tensors (such as stress and strain) are functions that relate one vector to another vector.

At the Hispanic-Serving Institution (HSI) where the study took place, the most common approach to teaching multivariate calculus is generally very algebraic because of the natural difficulty of representing three-dimensional concepts on a two-dimensional board. The visual and geometric components of the different multivariate calculus concepts therefore may be minimized and/or not explored in sufficient detail. Enhancing the geometric aspect of multivariate calculus during the lecture would require resources to circumvent the struggles of dealing with 3D mathematical objects in the traditional classroom. The advent of technology spurred the creation of tools and resources capable of reducing the complexities of the abovementioned 3D objects.

Technology has clearly revolutionized the way we see and interact with the world. It has made its way into every aspect of our lives and there are continued efforts to improve all technology around us. In mathematics education, technology provides numerous possibilities on how we teach and learn, delegating the more tedious manual tasks and calculations to computers and calculators, allowing the classroom to dedicate more time to higher-order tasks (Borchelt, 2004; White, 2003). Proper and responsible 
use of technology can support classroom instruction and improve students' understanding by providing diverse perspectives of the different mathematical ideas; moreover, students' visualization and spatial reasoning benefit from the inclusion of technology in the classroom (National Council Of Teachers Of Mathematics, 2000a). Although NCTM's Principles and Standards for School Mathematics advocates for the use of technology to enhance the teaching and learning of mathematics, it also provides a word of caution: "Technology should not be used as a replacement for basic understandings and intuitions; rather, it can and should be used to foster those understandings and intuitions" (p. 25). Following the possibilities that the inclusion of technology offers in teaching and learning, and heeding NCTM's advice, the researcher proposed an intentional, visually-enhanced approach to the teaching and learning of selected topics in Calculus III.

Several topics make up Calculus III at the HSI where the study took place. These topics include vectors and the geometry of space, derivatives and integrals of functions in more than one variable, multiple integrals, and Stoke's and Green's Theorem. The purpose is for students to develop a reasonable understanding of the different calculus concepts to be used in further mathematics and STEM courses. Calculus III is a course that is mandatory for students majoring in mathematics and engineering, and the population of students that typically enrolls in this course at the HSI is composed of mathematics and engineering majors. For the scope of the present study, the concepts that were selected as the focus of the proposed instructional strategy are as follows:

- Planes tangent to surfaces at a given point 
- Directional derivatives, including partial derivatives

- Double and triple integrals

At the HSI, the enrollment limit for a Calculus III course section is typically 35 students, most of them majoring in mathematics and engineering. Calculus III course sections are taught primarily by full-time faculty, and occasionally by adjunct faculty. Faculty have the freedom to create their own tests and teach the material in any way they like, but all faculty must teach the same set of topics known as course competencies.

Traditionally, mathematics instructors have used an algebraic approach when imparting mathematical knowledge, limiting the visualization and geometric representations of mathematical knowledge objects (Hitt, 2002). Instruction lacking visualization and geometric representations may be detrimental in multivariate calculus because they are inherently important components in the development of mathematical knowledge and understanding in multivariate calculus. Both algebra and geometry play an important and crucial role in the description and representation of mathematical objects, and their use and interplay should be highlighted in the mathematics classroom. The present study proposes a technology-enhanced, more visual approach to the teaching of selected concepts in multivariate calculus to improve students' mathematical knowledge and spatial ability. Such an approach would not only provide instruction that accommodates visual learners but should help foster and develop visualization and spatial ability for all other future STEM professionals in the classroom. Such an approach would be necessary to foster the geometric thinking that is one of the pillars of mathematics and an integral component for understanding. It is important to note the present study does 
not intend to de-emphasize the algebraic approach commonly used, but rather proposes to complement such an approach with its visual-geometric counterpart using technology in the form of a Computer Algebra System (CAS).

Some studies have presented promising findings in technology-infused classroom activities. In a study aimed to analyze the use of a CAS as an instructional aid in a differential calculus course, Tiwari (1999) found evidence of increased students' understandings and concluded that "adding graphical and numerical viewpoints to the traditional symbolic ones gives a clear insight behind the mathematical ideas being addressed" (p. 45). July's (2001) use of a CAS in a geometry classroom yielded positive and encouraging results in the development and enhancement of students' spatial ability and geometric thinking. July (2001) conducted a teaching experiment design study over a period of 10 weeks to determine the role of Geometer's Sketchpad (GSP), a dynamic geometry visualization software, on developing students' geometric thinking and spatial ability. Qualitative and quantitative data were collected where GSP was used as a tool to explore three-dimensional geometric objects in a series of teaching episodes. July found evidence that GSP improved students' geometric thinking and spatial ability, and pointed out: "That most of the students could answer post interview tasks about threedimensional objects on paper, without the help of GSP, indicates that students were able to transfer their experience with GSP into an understanding about the solid that was independent of the representation" (July, 2001, p. 223).

The present study proposes to add to the literature in the field of visualization in mathematics and its importance in students' mathematical understanding of selected 
multivariate calculus concepts. The research focused on an intentional, visually-enhanced approach to the teaching of selected concepts with the help of technology. The technology used in the study was Maple, a CAS described as a "powerful mathematics engine with an interface that makes it extremely easy to analyze, explore, visualize, and solve mathematical problems" (maplesoft.com/company/about). Addressing mathematical understanding through multiple representations facilitated by the proper use of technology is a topic of great interest. The importance of spatial skill in the learning of calculus is a topic that is under-researched (Cromley et al., 2017). Snyder (2006) suggested "it would be desirable to gain additional insight into whether a commanddriven CAS that allows for naming expressions, functions, output, and the like, can assist students in transitioning to higher mathematical thinking and improve their cognitive ability to manipulate mathematical objects" (page 224). Furthermore, "effective pedagogy that can enhance the use and power of visualization in mathematics education is perhaps the most pressing research concern at this period" (N. Presmeg, 2006, p. 233).

\section{Statement of the Problem}

At the HSI where the study took place, students completing Calculus III frequently struggle with understanding multi-dimensional objects in the traditional classroom. The teaching of Calculus III contains an inherent and natural difficulty of drawing and visualizing mathematical 3D objects in a 2D format (e.g., white board), which may lead professors to often stress the algebraic aspects of some of these concepts while paying much less attention to the visual/geometric aspects. This results in students often becoming algebraically proficient but deficient in spatial ability and geometrical thinking. Lack of spatial visualization becomes a problem for students' mathematical 
comprehension because of the absence of another perspective to complement the acquired knowledge. Any problem that requires students to think or work outside of the algebraic format in which they are accustomed will create a state of confusion and a source of incomprehension related to the change in representation needed to approach the problem from a different angle. Such deficiency affects their problem-solving and critical thinking skills in a negative way. Tall (1991) proposed that gaps in understanding will not be addressed by making the concepts simpler, but rather more complicated while infusing visualizations and visual reasoning in the presentation of such concepts: "The idea is to appeal to the visual patterning power of the metaphorical right brain, in such a way that it lays down appropriate intuitions to service the logical deductivity of the left" (Tall, 1991, p. 112). Additionally, technology can be used to enhance visualizations with user-controlled dynamic pictures which can provide insights and perceptions of the concepts explored (Tall, Smith, \& Piez, 2008). However, there is a lack of research on whether the enhancement of visualizations and geometrical understandings of the different multivariate calculus concepts through the use of technology, such as CAS, impacts students' knowledge of said concepts in a positive way.

\section{Purpose of the Study}

The purpose of the present study was to investigate the effects of a visuallyenhanced approach, facilitated by Maple, on the HSI students' performance on a multivariate calculus concepts test and a visualization test. It focused on multivariate calculus concepts (tangent planes, partial derivatives, directional derivatives, double and triple integrals) whose visual and geometric understandings are critical to the deep learning of said concepts. The population of students that typically enroll in Calculus III 
at the HSI are STEM students composed mostly of engineers and mathematics majors, and although they complete the course with a good algebraic command of these concepts, they are usually quite deficient in the visual and geometric understandings. The goal was therefore to test whether an intentional, visually-enhanced approach increased students' learning gains in their understanding of the aforementioned concepts, as well as their overall spatial ability skill.

\section{Research Questions}

The ability to visualize and geometrically represent objects is a must for any critical-thinking, problem-solver STEM professional that is going to partake in our global, knowledge-based economy. Learning with understanding contributes to the development of life-long self-learners. To explore the HSI students' spatial ability and understanding, this study examined the following questions:

1. To what extent does prerequisite knowledge, and a visually-enhanced approach to instruction facilitated by CAS affect college students' mathematical understanding of multivariate calculus concepts in an undergraduate Multivariate Calculus classroom setting at Miami Dade College?

2. To what extent does prerequisite knowledge, and a visually-enhanced approach to instruction facilitated by CAS affect college students' spatial ability in an undergraduate Multivariate Calculus classroom setting at Miami Dade College? 
3. Is there a significantly positive relationship between college students' spatial ability and mathematical understanding of multivariate calculus concepts in an undergraduate Multivariate Calculus classroom setting at Miami Dade College?

The hypotheses for this study were:

$\mathrm{H}_{\mathrm{a}}$ : The mean mathematical understanding test scores for students being taught using a visually-enhanced approach mediated by CAS in a multivariate calculus college course will be higher than those who receive a traditional, non-CAS approach in a multivariate calculus college course.

$\mathrm{H}_{\mathrm{a}}$ : The mean spatial visualization test scores for students being taught using a visually-enhanced approach mediated by CAS in a multivariate calculus college course will be higher than those who receive a traditional, non-CAS approach in a multivariate calculus college course.

$\mathrm{H}_{\mathrm{a}}$ : There will be a significantly positive relationship between spatial ability and mathematical understanding of multivariate calculus concepts.

\section{Theoretical Framework}

"There is no noesis without semiosis, no mathematical thinking without transformation of semiotic representations" (Duval, 2017, p. 22).

Drawing from Saussure's, Peirce's, and Frege's contributions to sign analysis and the foundation of semiotics, Duval offers his Theory of Registers of Semiotic Representations (TRSR) to carry out cognitive analysis of learners' mathematical 
activity. The theory is derived from a knowledge analysis scheme articulating three issues that refer to either the formation of knowledge or the cognitive functioning of thought: access to the objects themselves, systems or structures required to get the objects, and nature of the cognitive relationship between these processes and knowledge objects (Duval, 2017).

As opposed to material objects in other sciences, mathematical objects cannot be accessed directly by our senses or through instruments. Duval (2006) describes mathematical objects as knowledge objects: "the invariant of a set of phenomena or the invariant of some multiplicity of possible representations" (p. 129). Representations can be either "produced intentionally by mobilizing a semiotic system of representation" (semiotic) or "produced automatically in the mind or by an instrument" (non-semiotic) (Duval, 2017, p. 18), and mathematical objects in particular can only be accessed through semiotic representations. Duval describes a semiotic representation as showing "relations or, better, organization of relations between representational units" (Hitt, 2002, p. 321). The issue of empirical accessibility is a key difference between mathematical objects and objects in other sciences and it is not surprising to understand why: "mathematics begins when we do not limit ourselves to what is given concretely or physically any longer, but when we put it in the framework of what we can conceive as possible" (Duval, 2017, p. 25). It is the issue of empirical accessibility of a mathematical object that constitutes a source of incomprehension for learners engaged in mathematical activity (Duval, 2017); the inability of learners to differentiate when two semiotic representations evoke the same mathematical object or two different ones. 
The cognitive difficulty resulting from recognizing an object from different representations which may not have or explicitly show the same features of the object in question is easily overcome in other sciences by juxtaposing the representation and the object itself, hence learners can verify and acquire new knowledge (Duval, 2017). However, in mathematics, putting the representation side by side with the object it represents is not possible because mathematical objects are not accessible outside of their semiotic representations, thus the acquisition of knowledge for learners is slightly different in mathematics than in the other sciences.

Duval (2017) posits that symbolic knowledge can overcome the limited capacity of apprehension by providing unlimited possibilities for indirect access to mathematical objects and describes the systems essential to this access. "Signs then fill a cognitive and epistemological treatment function to produce new information or establish new knowledge" (p. 10). They can be substituted one for another independently of the mathematical objects they may evoke.

As mentioned before, mathematical objects are only accessible through their representations, and signs (semiotic productions) are used to evoke these representations. The key difference between signs and representations is that the former's relationship to the mathematical objects is referential and not causal (Duval, 2017). Signs are intentionally constructed by using semiotic systems while representations are automatically produced by physical or neuron systems, and thus there is a cognitive difference between them. (Duval, 2017). Signs produced by semiotic systems will be labeled semiotic representations, maintaining the phenomenological property of signs, 
producing as many times as needed and according to the system producing them, some aspect of the same mathematical object. Although signs and semiotic representations fulfill a common function of "standing for" or "showing", they differ in two features found in semiotic representations and not in signs: "an internal organization that varies from one kind of semiotic representation to another" and "several ways to distinguish the units of meaning and levels of organization" (Duval, 2017, p. 18).

Semiotic representations are critical for mathematical learning not only because it is the only way we have access to mathematical knowledge objects and allows us to surpass our intuition, cognitive load, and immediate memory limitations, but most importantly, because of their inherent potential for transformation into other semiotic representations, which is at the heart of mathematical work (Duval, 2017). Furthermore, the power of calculation, development of reasoning and mathematical visualization is reliant on the semiotic systems and the representation they elicit, and not the mathematical objects themselves (Duval, 2017).

Mathematical activity is driven by the use of semiotic representations and their transformation; and its development depends on "the variety of semiotic representations that can be used, and the need to produce and consider, alternately or in parallel, explicitly or implicitly two different representations of the same object" (Duval, 2017, p. 43). It is this one-to-one mapping between the meaning units of two semiotic representations whose content differs that provides the cognitive access to mathematical objects or new properties (Duval, 2017). The semiotic representations at the heart of all mathematical activity are produced by "cognitively creative semiotic systems" (p. 56), 
dubbed registers, whose existence requires the ability to produce representations of knowledge objects that are not accessible through our senses or instruments, and transform these representations into new ones (Duval, 2017). "Mathematical knowledge does not begin with the semiotic representation of 'concepts' or of mathematical objects, but with the transformations of the semiotic representations denoting mathematical objects" (Duval, 2017, p. 49). Mathematical activity necessarily involves the transformation of semiotic representations into other semiotic representations to produce new information or knowledge, and to solve problems (Duval, 2017). Thus, mathematical understanding can be studied through the different operations that can be carried out in the registers mobilized in any given mathematical activity. The most common registers associated to any mathematical activity are language, Euclidean geometric figures, algebra, and analysis (Duval, 2017).

The two cognitive conditions required to understand and carry out any mathematical activity involve the transformation of representations: treatments and conversions (Duval, 2006, 2017). Treatments are procedures in a given semiotic register that does not mobilize a second register, but rather changes a semiotic representation into a new one through an operation recognized from its inventory of accepted operations (Duval, 2017). Conversions are procedures that convert a semiotic representation into another representation of a second, mobilized register. Consequently, any mathematical activity requires, either implicitly or explicitly, the mobilization and coordination of at least two registers (Duval, 2017). Mathematical understanding, or "semiosis," can then be defined as "the synergistic activation of at least two registers in the production and transformation of semiotic representations" (Duval, 2017, p. 71). Essentially, 
mathematical understanding for learners involves the ability to change mathematical objects from one form of representation to another when warranted, aware of the characteristics and information of each representation register. The ability to perform conversions gives learners the understanding required to apply concepts outside of the contexts in which they learned them.

\section{Significance of Study}

To ensure our nation's continued economic success and national security, the NSB $(2007,2008,2010)$ calls for the improvement and coherence of STEM education vertically and horizontally in the K-20 education system, with emphasis on learning with understanding, and proper recognition and development of spatial ability along with verbal and mathematical abilities. Advances in technology have stirred up questions regarding its use in the mathematics classrooms to improve students' understanding, reasoning, and spatial abilities. Technology like Maple and other CAS appeal to educators and researches alike for its computational and visualizing capabilities, which have the potential to positively impact learning and instruction of STEM-specific courses such as multivariate calculus.

There have been some studies concerning the use of technology and visualization (Samuel, 2010; White, 2003; Habre, 2001; July 2001), and the effects of technology on mathematical understanding in calculus (Tiwari, 1999; Palmiter, 1991; Heid, 1988; Meagher, 2005; Borchelt, 2004). However, there are no studies exploring the effects of a visually-enhanced approach to teaching supported by a CAS to enhance students' mathematical understandings and spatial visualization in selected multivariate calculus 
concepts as proposed by this research. The present study is not proposing the use of a CAS as the main driver of instruction as other studies have done, but rather a visuallyenhanced approach to the traditional teaching mediated by the CAS due to the natural complexities of the concepts in the course.

The present study is important because its results could impact the way some concepts are taught in multivariate calculus. The use of CAS allows for faster and more accurate geometric visualizations than those created by instructors by hand. It is important to note that drawing inside the classroom and teaching students to draw 3D objects is important because the act of drawing the $3 \mathrm{D}$ objects requires a mental picture of the objects themselves and helps develop spatial skills and geometric representations (Newcomer, Raudebaugh, McKell, \& Kelley, 1999). For more complex mathematical 3D objects, however, manually drawing the object can be time consuming and overall a difficult task to do. Instead of spending time manually doing the geometric representations and making sure the visual is accurate enough to discuss the mathematical idea being presented, instructors will be able to spend more time in the development and relationship of the different representations; the interweaving of the algebraic and geometric aspects of the concepts.

The abilities to visualize and to move between different representations are related to learning with understanding, critical thinking, and problem-solving skills, which are highly desired for any STEM professional ready to partake in our globalized, knowledge-based economy. In a critical evaluation of research concerning visualization and working memory as it pertains to problem solving, Carden \& Cline (2015) conclude: 
"the literature reviewed suggests that visualisation is an important tool in problem solving, and that it is probably currently under-used. It is associated with reduced demands on the working memory system and can be an economical and flexible way of retaining and organising data" (p. 245).

\section{Definition of Key Terms}

Mathematical understanding refers to "the synergistic coordination of at least two registers of representation" (Duval, 2017, p. 89).

Mathematical object refers to "the invariant of a set of phenomena or the invariance of some multiplicity of possible representations" (Duval, 2006, p. 129).

Treatments refer to "transformations of representations that happen within the same register" (Duval, 2006, p. 111).

Conversions refer to transformation of representations that consist of changing a register without changing the object being denoted (Duval, 2006, p. 112).

Representation registers refer to semiotic systems that allow a transformation of representation (Duval, 2006).

Visualization refers to "processes of constructing and transforming both visual mental imagery and all of the inscriptions of a spatial nature that may be implicated in doing mathematics" (N. Presmeg, 2006, p. 206).

Visual image is a "mental scheme depicting visual or spatial information" (N. C. Presmeg, 1986). 
CAS dynamic worksheets refer to the researcher-made Maple worksheets containing multivariate calculus concepts and their dynamic visualizations.

\section{Summary}

The chapter stated the need for our nation to have, now more than ever, a stream of STEM professionals with critical thinking and problem-solving skills; dedicated lifelong learners not only capable of meeting the demands, but able to thrive and contribute to our increasingly global, knowledge-based economy. This chapter also introduced the research questions explored in this study, and the theoretical framework used to approach the problem described.

Chapter 2 presents a review of the literature relevant to this research project in the field of mathematics education related to the teaching of calculus for understanding, the role of technology in the teaching and learning of calculus, and research about visualization and the robust influence it has in individuals pursuing s STEM career.

Chapter 3 presents a description of the research design and methods. It includes the research questions and the statistical tests performed to answer the questions. It describes the student population of the participating HSI and the sample that partook in the study. The chapter also describes the instructional strategy and instruments used in the study.

Chapter 4 presents the results of the statistical tests used to test the alternative hypotheses and any descriptive statistics performed to satisfy the assumptions of the statistical tests. 
Chapter 5 presents a summary of the research questions and the findings. It also presents the implications of the results, reports the limitations and delimitations of the study, and provides recommendations for future research. 


\section{CHAPTER 2: REVIEW OF LITERATURE}

Introduction

After summarizing years of research on visualization in the teaching and learning of mathematics and recent trends, Presmeg (2006) proposed a list of "Big Research Questions" which she believed to be of major significance in the field. Two of those questions are closely related to the goals of the present study:

- How can teachers help learners to make connections between visual and symbolic inscriptions of the same mathematical notions?

- How do visual aspects of computer technology change the dynamics of the learning of mathematics?

Helping students make the connection between the visual and symbolic representations of the same mathematical concepts is in line with Duval's (2017) assertation that semiosis, or mathematical understanding, is associated to the synergy, or connection, between at least two registers of semiotic representation, such as the geometric and algebraic registers. To make such visualizations and connections clearer, advanced software such as CAS may be used to infuse the teaching and learning of mathematics in the classroom with dynamic figures that may be otherwise prove too difficult to produce inside the classroom. Visualization and mathematical understanding are some of the pillars that aid in the creation of the future STEM professionals that will thrive and innovate tomorrow and contribute to the continued development of our nation's economy. 


\section{Calculus and Mathematical Understanding}

Learning with understanding has always been an issue in the teaching and learning of mathematics, and recent psychological and educational research has provided strong support for understanding as an important component of mathematical proficiency (National Council Of Teachers Of Mathematics, 2000a). Good mathematical understanding goes beyond developing skills or being able to carry out mathematical procedures; it speaks of a learner's ability to apply his/her knowledge in situations and circumstances outside of those learned in the classroom. Good mathematical understanding is related to problem solving, a critical skill for STEM students who wish to become STEM professionals.

The teaching of calculus came under fire in the 1980s for several reasons: concerns over students perceived lack of understanding of the subject, high failure rates particularly for women and minority students, and technological advances (Hallet, 2000). More importantly, students were unable to recognize mathematical ideas that were presented in different ways:

For example, the minimization of average cost is done symbolically in mathematics, if at all, whereas it is usually done graphically in economics. Similarly, line integrals and the divergence of a vector field are defined symbolically in most mathematics courses the line integral using a parameterization and the divergence using partial derivatives. In physics and electrical engineering, however, students are expected to know from a diagram whether a line integral or 
divergence is positive or negative. This requires a level of visualization seldom expected in calculus courses in the middle 80s (Hallet, 2000, p. 53).

Many mathematical objects, including those in a multivariate calculus course, can be represented in different forms including algebraically and geometrically. Without tools or resources to support instruction, natural complexities associated with the mathematical objects explored tend to steer instruction towards an algebraic approach, de-emphasizing much of the geometrical understanding of said concepts as quoted above. Some studies (Dreyfus, 1991; Goldenberg 1995) reported that while instructors recognized the importance of visual thinking, actual classroom implementation comprised mostly of symbolic expressions and algebraic manipulation (Habre, 2001). In multivariate calculus, the visual representation of mathematical objects becomes more complex for students as they must transition from objects in the plane to objects in the space. Some studies have approached mathematical understanding in multivariate calculus by using frameworks analyzing multiple representations such as the Onto-Semiotic Approach (Montiel \& Wilhelmi, 2009), APOS Theory (Martínez-Planell, Gaisman, \& McGee, 2015; MartínezPlanell, Trigueros Gaismán, \& McGee, 2017), and Duval's TRSR (McGee \& MartinezPlanell, 2014; McGee \& Moore-Russo, 2015).

McGee \& Martinez-Planell (2014) and McGee \& Moore-Ruso (2015) conducted similar qualitative studies at the University of Puerto Rico Mayaguez investigating students' understanding of some multivariate calculus concepts after incorporating materials created under Duval's TRSR framework to explore the concepts in terms of treatments and conversions between the registers associated to these concepts. McGee \& Martinez-Planell (2014) used researcher-made worksheets with static figures to 
complement the textbook with some omitted representations while McGee \& MooreRuso (2015) used 3D manipulatives to make the visualizations of tangent planes accessible to students. Data were collected in the form of classroom observations (experimental group only), semi-structured interviews (experimental group only), common exam questions (both experimental and control groups), and additional exam questions (experimental group only). Both studies show evidence of the experimental group's ability to perform the treatments and conversions associated with the selected concepts, and better performance than the control group in the common exam questions. These findings support instruction that explicitly incorporates the synergy of the different registers of representation and the treatments and conversions associated to mathematical concepts to enhance students' learning and understanding. However, these studies did not use CAS to make the geometric representations intentional and limited themselves to one specific topic in the multivariate calculus course. The advantage of CAS is the rendering visual power and dynamic feature of the visualizations. For the study, the visual representations associated to the selected multivariate calculus concepts were enhanced by CAS dynamic worksheets to facilitate the synergy between the algebraic and the geometric representations during the lecture. The CAS dynamic worksheets were created in conjunction with the instructors to guarantee ease of use and integration with their traditional lecture routine.

An interesting study was conducted by Bagley (2014) as part of his dissertation titled "Improving Student Success in Calculus: A Comparison of Four College Calculus Classes," in which the author examined four different approaches to the teaching of differential calculus in terms of students' conceptual and procedural achievement, 
persistence, and attitudes and beliefs about mathematics. The study took place at a large public university in the southwestern United States and the four participating classes consisted of a traditional lecture-based instruction, lecture with discussion, lecture with discussion and technology, and the inverted approach. The traditional lecture approach classroom had 180 students and met three times a week for 50 minutes and had a 50 minute per week recitation component. The lecture with discussion class had 60 students and contained more student interaction with their peers and instructor. It met 105 minutes twice a week with no recitation component. The lecture with discussion and technology class had 120 students and met three times a week for 50 minutes each and a 50-minute recitation component. It was similar to the lecture with discussion class, but Geometer's Sketchpad applets were included in the lectures to promote students' intuition of the concepts explored. Finally, the inverted class had 100 students and met two times a week for 105 minutes each and no recitation component. Content was delivered outside the class via Khan Academy videos and class time was used for small group work. Teaching Assistants (TAs), and not the instructor, were present during class time to facilitate students' group work.

Results from Bagley (2014)'s study showed students in the inverted classroom scored significantly lower than some of their peers on some items of the measure of beliefs and attitudes about mathematics, while students in the lecture with discussion and technology were significantly more likely to memorize instead of make sense than their traditional lecture peers. Furthermore, students in the traditional lecture demonstrated less increase in interest in mathematics than their peers in the lecture and discussion classroom. Students in the traditional lecture and lecture with discussion and technology 
performed better on the common final exam than their peers, with students in the traditional lecture outperforming all their peers in procedural items while students in the lecture with discussion and technology outperforming their peers on conceptual items. The results show some merit for the traditional lecture and the potential for technology to augment students' understandings.

Technological advances such as CAS have opened the door to new ideas and conceptions about calculus instruction. The use of technology in the classroom seemed like a panacea to students' apparent lack of understanding by helping facilitate lengthy computational tasks and better incorporating the visual and geometric aspects of mathematics in the classroom. As a consequence of the types of knowledge in multivariate calculus (vectors and geometry of the space, the calculus of functions of several variables, and different three-dimensional coordinate systems), studies exploring visualization in the learning of calculus require the incorporation of some sort of visualization technology, typically a CAS.

Role of Technology in the Teaching and Learning of Calculus

The advent of calculators and computers in the second half of the $20^{\text {th }}$ century transformed the teaching and learning of mathematics but their use was not widespread because of their cost and limited capabilities (Lavicza, 2007). As technology continues to improve, its availability in the classroom for learning purposes increases the possibility to engage students in activities that may not have been previously possible as a result of their complexity or cognitive demands (Snyder, 2006). 
Analysis of empirical research regarding the inclusion of technology (calculators, CAS) in the classroom shows mixed results (Tall et al., 2008). In their review of doctoral theses investigating the use of technology in the calculus classroom, Tall, Smith \& Piez list studies showing that: technology used incorrectly makes no significant difference (Barton, 1996; Fredenberg, 1994; Melin-Conejeros, 1992), partial evidence for technology producing changes (Castillo, 1998; Parks, 1994), evidence that technologyintegration produces measurable gains (Schrock, 1990; Cooley, 1996; Porzio, 1995; Hare, 1997; Connors, 1995; Estes, 1990; Fitzsimmons, 1995; Ramey, 1997; Rich, 1996; Ellison, 1994), and some partial counter-evidence to technology-integration producing measurable gains (Roddick, 1998; Soto-Johnson, 1998; Meel, 1996; Crocker 1993). Then Tall et. al. summary of the abovementioned dissertations presented salient themes useful when considering integrating technology in the calculus classroom. Technology used incorrectly or with very little structure behind its use in the classroom usually produces no measurable gains in student learning; however, a well-designed integration can lead to positive gains in conceptual understanding, regardless of brand or type of technology (Tall et al., 2008). Although it is more important how technology is used as opposed to which technology is used, there is no doubt that CAS have more capabilities than calculators and would be therefore prime candidates for integration in the calculus classroom.

These mixed findings are supported by other research studies (Bagley, 2014; Borchelt, 2004; Heid, 1988; Meagher, 2005; Mendezabal \& Tindowen, 2018; Palmiter, 1991). Heid's (1988) subjects sample consisted of 39 students enrolled in two sections of a first semester applied calculus course (experimental sections) at a large public 
university; most students were majoring in business, architecture, and life science. The experimental class used the computer for 12 weeks to explore several calculus concepts, followed by three weeks of skill acquisition. Comparison information was gathered from a large lecture calculus section. Heid collected data from audio-tapes, student assignments including exams, field notes, and questionnaires and found that students in the experimental classes performed almost as well in the final exam as students in the comparative class, but they showed greater understanding of the calculus concepts.

Mendezabal \& Tindowen (2018) conducted a quasi-experimental study in Differential Calculus examining the effects of Microsoft Mathematics on students' attitudes, conceptual understanding, and procedural skills. The participants consisted of two groups of 30 Electrical Engineering students, one control and one experimental. The control group as taught in a traditional, lectured-based approach, while the experimental group was taught using "technology-based activity sheets" (p. 387). These activity sheets were created with Microsoft Mathematics, which is described by the authors as a fullfeatured scientific calculator with extensive graphing capabilities. The activity sheets were designed with a student-centered methodology in mind coordinating different forms of representations (graphical, numerical, and analytical). A pretest and posttest on conceptual understanding and procedural skills were given to the two groups, as well as the Mathematics and technology Attitude Scale (MTAS). The findings of the study suggest students in the experimental group learned just as much as their peers in the control group, as measured by the conceptual understanding and procedural skills instrument. 
Palmiter's (1991) sample consisted of 78 students (39 experimental group, 39 control group) enrolled at a large university. However, in contrast with Heid's (1988) research, students in the study were mostly engineering majors and the course in question was the second course in the calculus sequence. Like Heid's study, students in the treatment class actively used the CAS, becoming a main component of their learning. Palmiter found that students in the treatment class did significantly better than the control group on conceptual and computational exams. Furthermore, on subsequent calculus courses, students in the treatment class did as well or better than students in the control group class. It is important to point out that the computational exam given to students in the treatment class allowed for them to use a CAS to perform the computational tasks. Although no partial credit was given for syntax errors while using the CAS, the test may be interpreted as being more about the proper syntax use of a CAS to solve computational exercises and less about paper-and-pencil skills.

Borchelt (2004) conducted an ethnographic case study to investigate the effects of a computer tool (MathCAD) on students' cognitive demand in an undergraduate calculus course. The study was conducted at a four-year state university in the southeastern United States with volunteer students enrolled in a first-semester calculus course. All students had access to their own computer in the classroom and were required to install MathCAD as part of their course. Participants were purposely placed in cooperative groups of four and data were gathered through student surveys, interviews, audio and video recordings. Of all participating students, in-depth analysis was conducted only in one of the groups. Borchelt found that CAS's capability to perform numeric and symbolic calculations allowed students to focus less on the algebraic manipulations and more on the 
interpretations of the results; furthermore, the CAS allowed students to combine algebraic, graphical representations, and written responses in the same worksheet. "In general, MathCAD provided support for developing conceptual fluency, aided in mathematical exploration, and allowed for the analyzing of different mathematical representations" (Borchelt, 2004, p. 108). However, he noticed most of the times students were trying to solve the problems without making full use of the available technology and proposed special care to be taken when trying to implement the technology efficiently.

Meagher (2005) conducted a qualitative study designed to research the impact a CAS can have on student learning on a day-to-day basis and across the entire length of a calculus course. The study took place in a large Midwestern university where students have the option of taking a traditional first-semester calculus course or a computer-based calculus course taught with the aid of Mathematica (CAS) with a CD interactive textbook which required self-directed learning on the students' part. Students worked in groups of three and had access to a lecturer and teaching assistant in the computer lab that responded to students' questions rather than lecture the content. Meagher conducted a case study of three students in the computer lab as individuals and as a group. Data consisted of audiotapes and video-capture of students' computer screens of group discussions and learning episodes, along with interviews, survey, and analysis of students' responses. Data analysis points to Mathematica overpowering the calculus learning experience of the students, making them focus more on the CAS and less on the calculus itself. Meagher's study took place in classes where a more student-centered approach to learning was used, with technology playing a stronger, central role in the learning process. Findings from Meagher's study are less promising with technology 
seemingly becoming a distraction while students attempt to make sense of the calculus concepts.

Both Heid's (1988) and Palmiter's (1991) studies took place around the calculus revolution where technology is seen as a tool capable of spurring new ways of teaching mathematical content. Both studies use available technology at the time to replace paperand-pencil computations and dedicate more time to understanding and interpretation. Borchelt's (2004) and Meagher's (2005) studies come later using newer, more powerful technology as it pertains to multiple representations and understanding. The more recent study by Mendezabal \& Tindowen (2018) shows that the inclusion of technology allows for more student interaction and exploration, although it did not show statistically significant differences in learning between the experimental and control groups. The results clearly show that the complexities associated with the integration of more powerful technologies and its use by teachers and learners without proper training can hinder the potential benefits of said technology, results consistent with those summarized by Tall et. el. (2008).

Computer Algebra Systems have expanded the way computers can be used in the classroom and opened new possibilities in teaching and learning (Marshall, Buteau, Jarvis, \& Lavicza, 2012; Snyder, 2006). They can be defined as technology that helps us surpass our mind's limitations in thinking, learning, and problem-solving activities.

Computer Algebra Systems may play a role in the mathematics curriculum that can be categorized as amplifiers or reorganizers (Pea, 1987; Snyder, 2006). When used as amplifiers, CAS do not fundamentally change the curriculum, but rather they enhance the 
teaching and learning by simplifying some of the tedious tasks done by hand that are usually part of the curriculum and leaving higher-order thinking to humans (Snyder, 2006; White, 2003). When used as reorganizers, CAS change the curriculum in terms of the nature and priority of topics, the way these topics are taught and learned, and even the inclusion of activities that might not have been possible or feasible in the traditional classroom (Snyder, 2006). Computer Algebra Systems such as Maple and Mathematica, among others, have the likelihood to become tools not only for learning, allowing for mathematical exploration, integration of different representations and development of conceptual fluency (Pea, 1987), but also part of students' professional careers in STEM fields. When integrating a CAS into the learning environment of the classroom, one must consider the many ways a teacher and his/her students can interact with the technology (Habre, 2013; Tall et al., 2008; Thomas, M. \& Hong, 2004). Therefore, careful consideration must be given to questions regarding how to and when to use the CAS, and the goals to be accomplished.

Although there are mixed results when it comes to the inclusion of technology in the classroom, its use in the teaching and learning of mathematics will continue to grow as technology improves. Furthermore, students are getting increasingly more comfortable with technology and its use inside and outside of the classroom. However, we need to keep in mind that the choice of including technology in the classroom should not be made as a fad, but rather special attention should be paid to the design and pedagogical consequences of such choice (de la Villa, García, García, \& Rodríguez, 2017) 
The CAS dynamic worksheets were used as an amplifier that allowed the exploration of several multivariate calculus concepts through its visualization and computational features, supporting integration of different representations and contributing to students' mathematical understanding. The CAS dynamic worksheets were used as an enhancing supplement to the traditional, lecture-based instruction. Maple is a software package that is widely used in university mathematics classrooms and it is explicitly fashioned to carry out mathematical operations (Lavicza, 2007).

To maximize the use of lecture time in the classroom, visualizations relevant to the selected concepts were developed beforehand by the researcher in conjunction with the professors. The visualizations in the CAS dynamic worksheets were saved on OneDrive where the faculty from the experimental group had access. The CAS dynamic worksheets would typically be loaded on the computer using Maple Player before the class would officially start, and they were video-muted in the projector until the professor would need them as part of the lecture.

\section{Maple}

Maple was used as the technology of choice for the present study. Maple was initially designed to help researchers perform quick symbolic manipulations much like a calculator can perform quick arithmetic operations. Because of its popularity and demand, improvements were made in its user-interface and eventually Maple found its way into the mathematics classroom. "Maple documents seamlessly combine numeric and symbolic calculations, explorations, mathematical notation, documentation, buttons and sliders, graphics, and animations that can be shared and reused" (Zotos, 2007, p. 1247). It is used today by scientists, mathematicians, engineers, and by several colleges 
and universities throughout North America, Europe, and Australia for educational purposes (Snyder, 2006).

Schrock’s (1990) study (as summarize in Tall et al., 2008) compared students in a conceptually focused, Maple-integrated, differential calculus course with students in a traditional calculus course. Schrock found that students in the experimental class did better on conceptual understanding, and equally well in hand calculations. The results from Schrock's study provide incentive to integrate Maple in a multivariate calculus.

Snyder (2006) conducted a collective case study to better understand student's use of Maple in a multivariate calculus course at the University of Detroit Mercy. The students that participated in the study were chosen purposely from the data gathered from two surveys measuring computer confidence and mathematical confidence. Data gathered by Snyder included structured interviews, observations, video-tape computer work, and weekly student logs. Snyder results suggests the use of Maple as the main tool for student's learning and conceptual understanding of mathematics suffers from the added complexity of the Maple command language.

Snyder's findings, along with other aforementioned studies, informed the present study by using Maple software not as the main component of the classroom instruction, but rather a supplemental resource for instructors to explore the visual and geometric aspects of selected concepts and integrate different representations to enhance student's learning and understanding of the mathematical concepts. Since students were not responsible for the use of the software in the classroom, the added complexity of Maple software syntax did not interfere with their learning. The researcher, along with the 
instructors, were responsible for the integration of CAS into the lesson plans as a visual enhancement to the traditional lecture method.

$$
\text { Spatial Ability and Visualization }
$$

\section{Spatial Ability}

Geometry is about space and is very much related to the way we comprehend and make sense of the physical world we live in. As we interact with our surroundings through our senses, we develop our spatial intuition or spatial ability. There is evidence that spatial ability has a robust influence in STEM domains and constitutes an asset for individuals who wish to pursue a STEM career (Wai et al., 2009).

Various studies centered around spatial ability have summarized authors' major contributions to the salient spatial factors that represent spatial ability (Yoon, 2011; July, 2001). After an extensive review of factor analytic studies, McGee (1979) concluded there was ample evidence that points to two broad spatial factors: spatial visualization and spatial orientation (July, 2001; Yoon, 2011). Spatial visualization alluding to:

"The ability to mentally manipulate, rotate, twist, or invert pictorially presented visual stimuli. ... involve a process of recognition, retention, and recall of a configuration in which there is movement among the internal parts of the configuration, or of an object manipulated in three-dimensional space, or the folding or unfolding of flat patterns" (Per McGee (1979) as quoted by Yoon (2011), p. 15; July (2001), p. 23).

McGee (1979) summarized spatial orientation as "ability that involves the comprehension of the arrangement of elements within a visual stimulus pattern, the aptitude for 
remaining unconfused by the changing orientation in which a configuration may be presented" (As quoted by Yoon (2011), p. 15; July (2001), p. 23).

Four years later, reviewing and summarizing his own works, Bishop (1983) puts forward two factors for spatial abilities: interpreting figural information (IFI) and visual processing (VP); definitions which according to Bishop refine and extend those posed by McGee and are more attuned to mathematics education (July, 2001). According to Bishop (1983) as quoted by July (2001):

The ability for interpreting figural information (IFI). This ability involves understanding the visual representations and spatial vocabulary used in geometric work, graphs, charts, and diagrams of all types. Mathematics abounds with such forms and IFI concerns the reading, understanding, and interpreting of such information. It is an ability of content and of context, and relates particularly to the form of the stimulus material.

The ability for visual processing (VP). This ability involves visualization and the translation of abstract relationships and nonfigural information into visual terms. It also includes the manipulation and transformation of visual representations and visual imagery. It is an ability of process, and does not relate to the form of stimulus material presented (p. 185).

Linn and Petersen (1985) on the other hand described three factors associated with spatial ability: spatial perception, mental rotation, and spatial visualization; a slight difference from the works of McGee (1979) and Bishop (1983), considering mental rotation a separate factor from spatial visualization (Yoon, 2011). Carroll (1993) used 
factor analysis with huge datasets and concluded five first-order factors for spatial ability, two of them similar to previously defined factors: spatial visualization and spatial relations (Yoon, 2011).

All the studies above identified spatial visualization as an important factor of spatial abilities, although Bishop (1983) labeled it visual processing (VP). Bishop's VP definition is more attune to the abilities this study sought to improve through CASenhancement of instruction because it describes not only mental manipulation, but transformation and translation of visual representations and visual imagery. However, spatial visualization is a term widely used in the literature. Therefore, for the present study, the term spatial visualization was used to refer to Bishop's VP.

Two main approaches to fostering and developing students' spatial visualization may be taken in the teaching and learning of mathematics. One approach may use technology and its visual-rendering power to produce visualizations which can then be interpreted by students. Another approach is hands-on sketching and graphing of the visualizations related to the concepts of study. Leopold, Gorska, and Sorby (2001) conducted a study to compare spatial ability of engineering students entering their three universities by using the Mental Rotations Test, the Mental Cutting Test, and the Differential Aptitude Test: Space Relations. The students were enrolled in an introductory descriptive geometry course. Two of the universities primarily used computer-aid design to solve spatial tasks related to descriptive geometry concepts while sketching was mostly used at the third university. Their findings suggested that students enrolled in the descriptive geometry course that stressed hand-on sketching and drawing 
improve their spatial skills more than the courses that used computer-aid approach. The present study takes into account the benefits of hand-on drawing and sketching for the development of students' spatial skills and includes the use of technology as an enhancement to instruction to facilitate visualization of simple and more complex 3D mathematical objects.

Visualization

Drawing from the works of Zimmerman \& Cunningham (1991), and Hershkowitzs et al. (1989), Arcavi (1999) proposed that:

"Visualization is the ability, the process and the product of creation, interpretation, use of and reflection upon pictures, images, diagrams, in our minds, on paper or with technological tools, with the purpose of depicting and communicating information, thinking about and developing previously unknown ideas and advancing understandings." (p. 270).

Visualization is strongly related to spatial ability and it plays a key role in mathematics education and the cognition of mathematical objects through multiple representations. To visualize in mathematics education is to create or make connections between a mathematical object and the internal or mental image representation of the mathematical object, which can be made visible through computer software or paper-andpencil (Sheikh, 2015). Furthermore, visualizations can facilitate or foster analytical thinking and lend critical aid to problem-solving (Carden \& Cline, 2015; Sheikh, 2015; Zazkis, 2013). 
Following on the steps of research interest in spatial abilities and the calculus revolution that was taking place in the late 1980 's, research on visualization and its importance in mathematics education started to rise in the early 1990's. Behaviorism and its influence in education was challenged by constructivism, which opened the doors for more qualitative studies and a renewed interest in topics regarding visual thinking in the teaching and learning of mathematics (N. Presmeg, 2006). At the $15^{\text {th }}$ Annual Conference of the International Group for the Psychology of Mathematics Education (PME-15) in 1991, Imagery and Visualization was considered for the first time as a category by itself, drawing 10 research reports, three poster sections, and two plenary talks (N. Presmeg, 2006); a significant difference compared to previous years. In 1998, at the North American Chapter of PME, the Working Group on Representations and Mathematical Visualization is formally constituted, with a focus on representations and visualization and their role in students' learning of mathematics (Hitt, 2002, p. xvii).

"An important objective of our working group on Representations and Mathematics Visualization is to promote an open discussion of the relevant theoretical orientations endorsed by different authors, and their influence in empirical research that intend to improve our understanding of the learning of mathematics. Particularly, there is interest in discussing how these research results can be interpreted and finally applied into classroom settings.” (Hitt, 2002, p. 2).

The $21^{\text {st }}$ century has seen a continued interest in visualization and student learning in regards to curriculum development and particular content areas, gender differences in mathematics visualization, students' reluctance to visualize, semiotics and representation, 
and more importantly, the influence of CAS and dynamic computer environments $(\mathrm{N}$. Presmeg, 2006).

Some studies have investigated the use of technology in the classroom as it pertains to visualization (July, 2001; Karakus \& Aydin, 2017; Samuel, 2010; White, 2003). White (2003) conducted a cyclical research design over the course of five terms at the University of Oklahoma from 1999 to 2002 to explore some effects of CAS use on students' ability to visualize in multivariate calculus. He used questionnaires and interviews to gather data focusing on specific patterns that arose from data gathered in previous terms. While White found no significant differences between CAS (Mathematica) and non-CAS student's visualization ability, student's exposure to Mathematica in the treatment classes was not structured and relatively low. White's study included some lab sessions where students were provided some limited instruction in the use of the CAS and a sheet with tips and examples. White's study suggests care be taken when implementing the use of technology in the classroom, especially if the technology requires a learning curve to fully exploit its capabilities in the teaching and learning of mathematics. An improvement to White's study would include clearly defining the way technology would be used in the classroom in terms of structure and frequency.

July (2001) conducted a teaching experiment in a $10^{\text {th }}$-grade geometry class over a 10-week period to uncover how students constructed knowledge and developed visualization and spatial skills in a classroom environment where technology was used as the main instructional tool. Data gathered included videotape of class sessions, field notes, student work, and student interviews. July (2001) found evidence of technology's 
(GSP) influence in students' progress of their geometric thinking and in creating a supportive environment for students' development of visualization and spatial skills. Although the results are promising, the participants of this study had been together as a group for more than three years and had ample experience in using GSP, conditions that are not typical in the mathematics classroom at the HSI.

Samuel (2010) used a case study to investigate student learning for 28 students in a first-semester calculus course emphasizing visualization using a "mathlet," or java applet for mathematics instruction, at an urban community college. Students meet with an instructor three times a week for 14 weeks, nine out of which were lab sessions where they worked on pre-made lab activities in a computer. Samuel used surveys to measure student's spatial ability, representation preference, and attitudes on mathematics and technology, as well as test scores, interviews, and recordings of lectures to measure content knowledge. Samuel found that students "demonstrated robust conceptions of the derivative" and "overwhelming improvement in attitudes for a small group of students with high spatial ability" (pp. 182-183). Noting the positive results observed, Samuel proposes an experimental study to be conducted to examine students' understanding using a more visual approach to the teaching of some calculus concepts, particularly, derivatives and local linearity.

Karakus and Aydin (2017) conducted a study to determine the effects of using a CAS in students' spatial visualization skills in a multivariate calculus course and whether spatial visualization was a predictor for student academic success in the course. A onegroup pretest-posttest design was used to assess gains in spatial visualization as measured 
by Guay's (1976) PSVT: R. Students were trained how to use basic commands in Maple during the first week followed by instruction in a computer-lab setting with guiding worksheets. The findings suggest the CAS-based instruction had a positive impact in students' development of spatial visualization. Moreover, the study found that students' spatial visualization skills can be a predictor for success in the course. One limitation of the study is the lack of a control group to assess whether the gains would be significantly higher for the group using CAS-grounded instruction versus a group not using CASgrounded instruction.

The result of these studies and their limitations provided ideas for direction and further research. Samuel's (2010) and July's (2001) qualitative studies providing some evidence to the usefulness of technology for visualization and conceptual fluency of students, along with White's (2003) lack of structure and frequency of technology use and Karakus and Aydin (2017) lack of a control group indicated the need for a more rigorous, experimental design regarding the use of technology in the classroom to improve students' visualization and mathematical understanding. Furthermore, research on the importance of spatial skills and their relation to students' learning of multivariate calculus concepts is scarce (Cromley et al., 2017).

Observing the opportunities that technology offers while acknowledging some of its drawbacks as discussed above, the present study made use of the technology as a visual enhancement tool for the faculty in their delivery of the multivariate calculus content. Two factors of importance are pointed out. First, the students did not have to face the added complexity the CAS syntax brings, rather the researcher and the 
instructors were responsible for the creations of dynamic figures relevant to the concepts to supplement the instruction. Second, since the CAS was available for the instructor to teach but not for the students to use, students had to sketch and graph by hand the visualizations associated with the different concepts which may be associated to higher learning gains in spatial visualization (Leopold, Gorska, \& Sorby, 2001).

Visualization and Mathematical Understanding in Calculus

Differential Calculus

In a recent study, Cromley et al. (2017) investigated the relation of spatial skills to calculus proficiency using 77 calculus and pre-calculus students from two suburban high schools and 11 undergraduate students from a large urban university. In terms of spatial skills, students were measured in a test of rigid transformations in 3D (Mental Rotation Test), a test of non-rigid transformations in 3D (Paper Folding test), and a test of guided attention in 2D (Hidden Figures Test). Students were also given an assessment to measure their ability to coordinate multiple representations (Coordinating Multiple Representations Test), AP Calculus exam items, and a researcher-made calculus concepts test (Calculus Conceptual Knowledge) composed of multiple-choice items with no calculation, only questions to measure knowledge of relationships among concepts. After conducting simple linear regressions, results from the study showed that the Mental Rotation Test (MRT) scores and the Coordinating Multiple Representations (CMR) Test scores were strong predictors of the AP Calculus exam items scores, the MRT scores were significantly correlated with CMR scores, and the CMR was a strong predictor of the Calculus Conceptual Knowledge (CCK) scores. Cromley et al. (2017) concluded that "spatial skills training might help some students succeed better in calculus" (p. 63). 
However, the study was a correlational study where no treatment took place. There were no intentional efforts to affect spatial ability and mathematical understanding, but rather just describe the relationship between spatial skills and calculus proficiency in the group of participants. Furthermore, the measures of calculus proficiency used in the study, both AP Calculus exam items and the researcher-made CCK were based on differential calculus and not multivariable calculus.

Zazkis (2013) conducted a qualitative study to learn about the effect of a Geometer's Sketchpad applet used to enhance the teaching and address students' difficulties in relating the graph of a function and the graph of its derivative. The slopewidget applet was used to visualize the tangent line of the graph of a function at a point and the value of the derivative of the function at that point. Three students were videorecorded during work group and interviewed without to ascertain their learning. The students completed a series of problems without the help of the Geometer's Sketchpad applets. Zazkis (2013) proposes the applet fostered and enhanced the participants' thinking when solving the given problems in terms of using strategies that incorporated both the analytical and graphical reasoning.

\section{Multivariate Calculus}

Not many studies have examined the use of technology to enhance visualization and its relation to understanding in multivariate calculus. In one of the earlier ones, Habre (2001) conducted an observational study in a multivariate calculus course section of 26 students where the instructor emphasized the visual aspects of the course. The instructor met with the students in a traditional classroom two times a week for 50-minutes each 
and once a week in a computer-lab setting. Students were assigned weekly problems, applications, and visualization assignments often requiring the use of graphic programs. The data collected included observations, copies of students' assignments and exams, and questionnaires. Some students reported appreciation for the technology being useful to illustrate the geometric aspect of some of the multivariate calculus concepts and helping them realize the relationship between algebra and geometry, while others still preferred the analytical approach (Habre, 2001).

More recently, in a PhD dissertation, Sheikh (2015) investigated the role of visualization in the mathematical understanding and problem-solving skills of a multivariate calculus and dynamic systems course. Treatment in the experimental group consisted of activities to facilitate visualization of $3 \mathrm{D}$ objects that took place in a computer-lab setting additional to the traditional lectures, while the control group received the traditional lecture as well as some tutorial instruction. The activities facilitating visualization utilized MATLAB and consisted mostly of recognizing surface features and properties of 3D objects, and generating, rotating, and sketching 3D objects and their projections. The same instructor taught both the experimental and control group sections, and all class notes, assignments, and other relevant course materials were virtually the same for both groups. Both groups had access to CalcPlot3D and Mathematics Visualization Toolbox on the internet, and data collected on both groups included three tests, interviews, assignments, and six laboratory worksheets.

Shiekh's finding showed no statistically significant differences in the scores of Test 1 and Test 2 between the experimental and control group. However, the study found 
statistically significant differences in the performance of Test 3 between both groups, providing evidence of the complementing role visualizations play with analytical thinking to enhance understanding in multivariate calculus. The interview data showed students' learning experience in the lab was positive overall, and there were suggestions for more sessions and more time in the future. There were also some negative comments including the cognitive load of students having to learn the math and the software at the same time. Sheikh's research study provides support to the visual-enhancement of traditional lectures to improve students' understanding of the topic discussed in multivariate calculus.

Moreover, care must be taken when infusing the technology in the classroom as to no create a cognitive overload on the students' learning.

\section{Gaps in the Research}

Review of some of the literature on the teaching and learning of calculus and the role of technology showed the potential for technology-integration in the calculus classroom. Although the results are mixed when it comes to technology in the classroom, there is a salient theme to inform educators and researchers when considering the inclusion of technology for teaching and learning: some technologies might be better than others, but it is more important to consider how to and when to include technology in the teaching and learning of mathematical concepts (Borchelt, 2004; Habre, 2013; Meagher, 2005; Tall et al., 2008; Thomas, M. \& Hong, 2004). The literature on spatial ability and visualization shows a growing interest in paying attention to and purposely developing these abilities for STEM students, which coupled with good understanding should lead to better critical thinking and problem-solving skills (Sheikh, 2015). 
Research on students' understanding in a first-semester calculus course is abundant, and although some studies in multivariate calculus have investigated students' understanding of directional derivative, partial derivative of two-variable functions, tangent planes (Martínez-Planell et al., 2017), different coordinate systems and double and triple integrals (Montiel \& Wilhelmi, 2009), they are fewer and qualitative in nature. There are many studies exploring the intentional use of visualizations in the classroom to improve students' understanding of calculus (July, 2001; Samuel, 2010; White, 2003), however they addressed differential calculus concepts and not multivariate calculus.

Sheikh (2015)'s PhD dissertation is one of the very few studies done investigating the use of intentional visualization on students' understanding using technology. Acknowledging this, Sheikh (2015) suggests: "Given the increasing availability and use of technology, more research is needed on technology-enhanced techniques that aid with visualization and representations, and the conditions under which they are effective" (p. 174). There is a need for research exploring spatial ability and visualizations in multivariate calculus enhanced by technology and its relation to students' understanding of the different multivariate calculus concepts. This research is important considering how important mathematical understanding and spatial ability are to the development of "STEM innovators" (National Science Board, 2010).

Summary

This literature review aimed to present research relevant to spatial ability and mathematical understanding of undergraduate college students enrolled in a multivariate calculus course. It explored some of the research that has been done in calculus to 
improve students' conceptual learning and mathematical understanding, with or without the use of technology. The literature review also explored some of the research fostering and developing students' spatial ability and visualization in mathematics courses facilitated with the use of technology. Finally, it looked at research exploring visualization and mathematical understanding in multivariate calculus courses enhanced by technology. The next chapter will describe the research methodology and design that was used to answer the research questions for the present study. 


\section{CHAPTER 3: METHODOLOGY}

\section{Research Methodology and Design}

In this chapter the methodology and research design for this study will be presented. The chapter will include the population, sample, sampling design, instrumentation, and instructional strategy. Attention will be given to the development of the instruments to assess pre-requisite knowledge and mathematical understanding. The purpose of the present study was to determine whether a more visual approach to the teaching of several concepts in multivariate calculus improves students' mathematical understanding and spatial ability. The participating students were enrolled in a multivariate calculus course section at a large HSI in the South.

The present study followed a quantitative methodology. Quantitative research is originally rooted in positivism, a philosophical view that proposes the social world is governed by general principles and laws much like the physical world, and through objective data gathering and hypothesis testing, researchers can arrive at systematic, generalizable, and replicable findings (Ary, Jacobs \& Sorensen, 2010). It employs a deductive approach to study relationships using large samples and preselected instruments, and employs statistical analysis of numerical data (Ary, Jacobs \& Sorensen, 2010).

The study explored an instructional strategy in an undergraduate classroom setting at a two-year HSI in the Southeastern United States. Research in educational settings like the one the present study conducted usually lack randomization of subjects. Because whole intact classes were used and therefore randomization of subjects was impossible, 
the overall research design for the present quantitative study was a quasi-experimental design.

Quasi-experimental designs are similar to randomized experimental designs in that descriptive causal hypothesis about controlled causes are tested but differ in the ability to randomly assign subjects (Ary et al., 2010; Shadish et al., 2002). Structural details in quasi-experimental designs include the frequent presence of control groups and pretests measures, and although full control is not possible, they are still considered worthwhile because they allow for reasonable conclusions to be reached (Ary et al., 2010; Shadish et al., 2002). Among the quasi-experimental designs, the design that fits best for this study is the Nonrandomized Control Group, Pretest-Posttest Design. In the Pretest-Posttest design, groups are given the pretest before treatment, and then after treatment is completed (Ary, Jacobs, Sorensen, Walker, \& Razavieh, 2010; Shadish, Cook, \& Campbell, 2002). For the present study, the experimental and control groups were chosen by the researcher in conjunction with the participating faculty. All participating course sections received a pretest on mathematical understanding and spatial ability constructs in the beginning of the semester. Treatment was then implemented in the experimental group, followed by a posttest on both mathematical understanding and spatial ability constructs at the end of the semester, administered to both groups.

The research questions for the study were as follows:

1. To what extent does prerequisite knowledge, and a visually-enhanced approach to instruction facilitated by CAS affect college students' mathematical understanding of multivariate calculus concepts in an 
undergraduate Multivariate Calculus classroom setting at Miami Dade College?

2. To what extent does prerequisite knowledge, and a visually-enhanced approach to instruction facilitated by CAS affect college students' spatial ability in an undergraduate Multivariate Calculus classroom setting at Miami Dade College?

3. Is there a relationship between college students' spatial ability and mathematical understanding of selected multivariate calculus concepts in an undergraduate Multivariate Calculus classroom setting at Miami Dade College?

The hypotheses for this study were:

1. $\mathrm{H}_{\mathrm{a}}$ : The mean mathematical understanding test scores for students being taught using a visually-enhanced approach mediated by CAS in a multivariate calculus college course will be higher than those who receive a traditional, non-CAS approach in a multivariate calculus college course.

2. $\mathrm{H}_{\mathrm{a}}$ : The mean spatial visualization test scores for students being taught using a visually-enhanced approach mediated by CAS in a multivariate calculus college course will be higher than those who receive a traditional, non-CAS approach in a multivariate calculus college course.

3. $\mathrm{H}_{\mathrm{a}}$ : There will be a significantly positive relationship between spatial ability and mathematical understanding of multivariate calculus concepts. 
To address the first question, a Mixed-Effect, Repeated Measures, One-Way Analysis of Covariance (ANCOVA) design was to be used. As a result of the lack of randomization and the fact the study contains one independent variable and one dependent variable, a One-Way ANCOVA was to be used to ameliorate the effect of extraneous variables that affect the dependent variable and provide more power to the test of group differences on mathematical understanding. The covariate envisioned was prerequisite knowledge. However, after testing and failing some of the assumptions for the One-Way ANCOVA, the researcher changed the covariate variable into a second independent variable to consider because its interaction with the first independent variable. Therefore, the statistical run to answer the first question was changed to a Repeated Measures, Two-Way Mixed Analysis of Variance (ANOVA). The pretestposttest design was employed to measure students' mathematical understanding on both the control and the experimental groups, thus between-groups and within groups (time) factors were measured as well as between-within interactions, explaining the repeated measures, mixed-effects design.

The same design was employed to address the second question. Although prerequisite knowledge was not envisioned as a covariate for spatial ability, because of its change from covariate to independent variable made the researcher include pre-requisite knowledge in the test conducted. Therefore, Repeated Measures, Two-Way Mixed ANOVA was used as well. To address the third question, a Pearson product moment correlation was carried out. The Pearson coefficient is an appropriate measure of the relationship between two variables of interest that are normally distributed and measured 
on an interval or ration scale (Ary et al. 2010), and thus, was suitable for the present study.

\section{Population and Sampling}

The population for the current study were undergraduate students enrolled in a multivariable calculus course section at a large HSI in the Southeast Region. Participants were recruited from Miami Dade College (MDC), who has the largest undergraduate enrollment of any college or university in the country, with 92,085 students enrolled in credit courses at MDC (2014-2015), and most of them Hispanic (71\%) and Black NonHispanic (17\%) (mdc.edu/about/facts.aspx). Calculus III (Multivariate Calculus) at MDC is a course typically aimed at STEM students, and its population mirrors that of the school in general.

For this study, Calculus III sections at MDC Eduardo J. Padron (formerly InterAmerican), Wolfson, and Kendall campuses were selected because of faculty willing to participate in the study and integrate Maple in their lectures to provide a more visual approach to the teaching of the concepts discussed earlier. The faculty who volunteered to participate in the experimental sections were familiar with Maple software and how it was going be used for the present study. Furthermore, CAS dynamic worksheets consisting of dynamic features were developed by the researcher in conjunction with the faculty in the experimental groups to seamlessly integrate the use of Maple in the lesson plans of the proposed concepts.

The study took place during spring 2019 at the campuses mentioned above. Eduardo J. Padron Campus offered two multivariate calculus course sections, one in the 
morning and one in the evening. Each section was capped at 35 seats, but student enrollment only reached 17 students for each course section. Wolfson Campus was offering only one multivariate calculus course section during the midday which filled with 38 students. Kendall Campus offered two sections of multivariate calculus, one section during the midday and the other in the evening. Both sections had enrollment of 23 students each.

Sample

The sample size for the current study was calculated with G-power 3.1.9.2 software (Faul, Erdfelder, Lang, \& Buchner, 2007). The statistical test selected was an Ftest ANCOVA: fixed effects, main effects and interactions. The test requires six input parameters to determine total sample size a-priori: effect size f, $\alpha$ error probability, power ( 1 - $\beta$ error probability), numerator df, number of groups, and number of covariates.

Effect size is "a measure of the magnitude of a relationship, specific instances of which include the standardized mean difference statistic, the odds-ratio, the correlation coefficient, the rate difference, and the rate ratio" (Shadish et al., 2002, p. 507). It indicates the strength of the relationship between the independent variable and the dependent variable, and it is considered an important statistic for evaluating quantitative studies (Ary et al., 2010). Effect size is categorized as small (0.10), medium (0.25), and large (0.40) in the G-power software for the ANCOVA statistical test, and for this study the effect size chosen was 0.25 .

The significance level $\alpha$ refers to the probability of rejecting the null hypothesis when the null hypothesis is true, and in the behavioral sciences the most commonly used 
significance level is $\alpha=0.05$ (Ary et al., 2010). Rejecting the null hypothesis when the null hypothesis is true may lead to changes and expenditure in terms of time and money that is not warranted. For that reason, the significance level for the present study was chosen to be $\alpha=0.05$. Power refers to "the ability to reject a null hypothesis when it is false" (p. 169); it is calculated as $1-\beta$, where $\beta$ stands for the probability of failing to reject the null hypothesis when the null hypothesis is false (Ary et al., 2010). For the current study, failing to reject the null hypothesis would lead to no changes in the traditional instruction of Calculus III, and although not a desirable outcome, it was considered less severe than proposing changes that are not warranted. For this reason, the power for this study was chosen to be $0.70(\beta=0.30)$.

For the remaining parameters, the numerator $\mathrm{df}=1$, the number of groups $=2$ (treatment and control), and the number of covariates $=1$ (pre-requisite knowledge). The total sample size based calculated a-priori using the parameters explained above resulted in 101; this included the number of students in both the treatment and control classes.

The final sample size for this study was 65 , well below the calculated a-priori sample size of 101 for the parameters described above. The reasons for such a small sample size are largely associated with time constrains, and the fact that multivariate calculus course sections are few and do not typically have high enrollment at the HSI where the study took place. An inadequate sample size has a negative effect on the statistical power of the study and the researcher is aware of the limitation imposed by the small sample size. 


\section{Sampling Design}

To obtain the sample of students to participate in the study, the researcher contacted several instructors at MDC in fall 2018 who were scheduled to teach multivariate calculus in spring 2019. Five faculty agreed to participated in the study, providing a total of 118 enrolled students who could theoretically participate in the study. The researcher met with the participating instructors and it was agreed to give extra credit to the students as an incentive to participate in the study.

Out of the two faculty that participated in the experimental group, one of them was a tenured faculty (5 years of experience at HSI) with an earned M.S. in Mathematics who had been consistently teaching multivariate calculus every academic year. The second faculty did not have tenure (two years of experience at HSI) and recently started teaching the course. The second faculty had earned M.S. in Curriculum and Instruction and had complete 18 graduate math credits. Both instructors had experience with the CAS and had knowledge of the content of the CAS dynamic worksheets and their proposed use before using them in the actual classroom. Both instructors had attended a training workshop about the CAS used in the study. Furthermore, both instructors had experience using a CAS during their studies.

Out of the three faculty that participated in the control group, two were tenured faculty (15 years and 7 years of experience at HSI), while the third faculty did not have tenure yet (4 years of experience at HSI). The more experienced faculty had been consistently teaching multivariate calculus every academic year while the other two faculty did not teach the course in a consistent manner. All participating course sections 
covered the same topics (See Appendix A) and met face-to-face 200 minutes every week for 16 weeks.

Once all the IRB approvals were obtained, the researcher approached the course sections and informed and explained all the rights and responsibilities of the students as participants. Students who were under 18 years old were identified by a question in the consent form and did not form part of the data of the study although they could complete the assessments to obtain the extra-credit points as it was written in the description of the study. No other reason disqualified students from participating in the study.

\section{Ethical Considerations}

All participants were treated in accordance to the ethical guidelines of the Institutional Review Board (IRB) of Florida International University (FIU) and MDC. All potential participants were given a printed consent form (See Appendix B) and time to read it. Furthermore, its contents were described and explained, and time was devoted for possible questions. Only the students who signed the consent form acknowledging their rights and responsibilities and agreeing to participate in the study were considered as subjects for the study.

In all research involving human subjects and the collection of data with identifiers, confidentiality of the participants is very important. Because of the PretestPosttest design of the study, participants needed to be identified to link their pretest and posttest scores. The researcher achieved confidentiality of the participants by creating a special student ID for each student and securely keeping all collected assessment in a locked cabinet. The electronic file with the student data has only the researcher-created 
special id as identifier. Nonetheless, the data are password protected until the completion of the project where all confidential data will be safely disposed of through physical and electronic shredding.

\section{Instrumentation}

Mathematical understanding and prerequisite knowledge were measured using criterion-based assessments created by the researcher. The mathematical understanding assessment tested students' ability to perform transformations within a semiotic register, and conversions between registers, while the prerequisite knowledge assessment measured basic mathematical content learned in courses before multivariate calculus, namely Precalculus, Trigonometry, Calculus I, and Calculus II. When standardized tests are not available or they are not appropriate for the particular objectives of a research study, it is better to create one's own test paying attention to issues of validity and reliability of the instrument (Ary, Jacobs, \& Sorensen, 2010).

The prerequisite knowledge was measured using the Diagnostic Assessment. The assessment was created with 19 multiple-choice questions each containing the correct answer and three distractors, and one show-your-work question. The questions chosen evaluate knowledge of different topics related to Precalculus (functions, conic sections), Trigonometry (trigonometric functions), Calculus I (limits, continuity, differentiability, derivatives), and Calculus II (integrals). "Evidence based on content is mainly the result of a logical examination or analysis by content experts that shows whether the instrument adequately represents the content and objectives making up the domain" (Ary et al., 2010 , p. 227). Content validity was addressed through a panel of experts, who evaluated 
the instrument and provided feedback to the researcher to improve the instrument in terms of the questions being asked, and the clarity and conciseness of the questions. The panel of experts was made up by mathematics faculty from Miami Dade College and Florida International University, all of them with a Ph.D. in Mathematics. None of the instructors participating in the study were part of the panel of experts. Using the panel's feedback, changes were made to the instrument by the researcher and feedback was elicited again. The process of eliciting feedback and making changes accordingly was repeated until there was consensus among the experts that the instrument was good enough to measure prerequisite knowledge.

"The reliability of a measuring instrument is the degree of consistency with which it measures whatever it is measuring" (Ary et al., 2010, p. 236). Reliability of the prerequisite knowledge assessment was addressed using test-retest on a sample size of 19 MDC students who completed all prerequisite courses to Calculus III. The test-retest reliability coefficient is an indication of the consistency of a person's performance on the given test and it assumes there is no practice effect or memory effect (Ary et al., 2010). The practice effect refers to changes on the retest score based on learning that may have taken place by the subjects taking the test the first time (Ary et al., 2010). The memory effect refers to subjects answering the questions in the retest based on what they remember answering in the initial test (Ary et al., 2010). To ameliorate these effects, the retest was given two weeks after the initial test. The results were run in SPSS and a significant Pearson correlation score of 0.874 was obtained at the $\alpha=0.01$ level (see Table 1). 
Table 1 Test - Retest Correlations

Correlations

\begin{tabular}{lcc}
\hline & TEST & RETEST \\
\cline { 2 - 3 } TEST & 1 & $.874^{* *}$ \\
Pearson Correlation & & \\
Sig. (2-tailed) & 19 & $<.001$ \\
$\mathrm{~N}$ & $.874^{* *}$ & 19 \\
\hline RETEST & & 1 \\
Pearson Correlation & .000 & \\
Sig. (2-tailed) & 19 & 19 \\
$\mathrm{~N}$ &
\end{tabular}

Note. ${ }^{* *}$. Correlation is significant at the .01 level (2-tailed)

Mathematical understanding was measured using the Knowledge Assessment.

The assessment was created with 10 multiple-choice questions each containing the correct answer and four distractors, and the same process as the pre-requisite knowledge was followed to establish content validity. The instrument was revised and sent to the same panel of experts described above for feedback until consensus was reached. None of the faculty participating in the study were part of the panel of experts. The questions chosen elicited understanding of the selected concepts (planes tangent to surfaces, directional derivatives, and double/triple integrals) as defined by the theoretical framework used in this study.

Although consensus was reached to establish content validity, the researcher was not able to evaluate the assessment for reliability using test-retest design because of the 
lack of participating students. Split-half reliability was not possible because there were not enough test items measuring the same construct for split-half testing.

Spatial visualization was assessed using the Yoon's (2011) Revised Purdue Spatial Visualization Test - Rotations (subsequently known as Revised PSVT-R). Several explanations were given in a summary of research regarding the prevalence of Guay's (1976) PSVT-R in STEM areas including "strong reliability and validity evidence," "necessary complexity and difficulty of items to differentiate STEM student's degree of spatial ability," "free to use and readily available... relatively easy to score due to its multiple choice format," and "strongest measure of spatial visualization ability of mental rotation for individuals who incorporate the holistic or gestalt spatial thinking process and are the least likely to use the analytic or analogical spatial thinking process" (Yoon, 2011, pp. 36-37). However, as a result of some figural errors and lack of literature on construct validity and item level characteristics of the PSVT-R, Yoon (2011) revised and tested the new instrument (Revised PSVT-R) for construct validity, reliability, and item level characteristics. The Revised PSVT-R has 30 multiple-choice items ordered depending on the level of difficulty. Analysis showed good internal consistency reliability (Cronbach's $\alpha=.862, \mathrm{~N}=1022$ ), and factor analysis showed consistent fit indexes providing evidence of construct validity (Yoon, 2011). Yoon recommended the test be used as provided (permission and a copy of the test was obtained by the researcher (see appendix E) with no changes to the order of the questions to preserve its validity and reliability. 
A paper-and-pencil demographic survey was given to the students after their consent was obtained, and during the pretest data collection phase. The demographic survey included major, college year, honors college, sex, age, and ethnicity.

\section{Instructional Strategy}

For the current study, participants were divided into two groups:

traditional lecture-based group (control) and visually-enhanced lecture-based group (experimental). The experimental group was composed of two multivariate calculus course sections, one that met Tuesdays and Thursdays, 10:40am - 12:20pm, while the other met Mondays and Wednesdays, 8:20pm - 10:00pm. The sections were taught following Thomas' Calculus Early Transcendentals $14^{\text {th }}$ Edition. The chapters of the book associated with the course competencies are: Vectors and the Geometry of Space, Vector-Value Functions and Motion in Space, Partial Derivatives, Multiple Integrals, and Line Integrals and Vector Fields. The schedule followed by the treatment group including the collection phase of the assessments can be seen in Appendix D. All content throughout the semester was taught lecture-based in the experimental group, same as the traditional group, but any visualization typically done by hand in the control group course sections for selected topics (See Appendix C) was presented using CAS dynamic worksheets created by the researcher using the CAS of choice, Maple.

The CAS dynamic worksheets were created in conjunction with the experimental group's instructors to ensure ease of use and integration in their normal lecture routine. The examples used and relevant features in the CAS dynamic worksheets were agreed upon at least one week before the lesson to allow the investigator time to develop the 
worksheet. Although the CAS dynamic worksheets contained dynamic figures to enhance visualization of the selected mathematical objects, some static examples of the CAS dynamic worksheets can be found in appendix G. Thus, Maple was integrated in the classroom as part of the lecture for the experimental group in the form of CAS dynamic worksheets which contained dynamic figures. Some of the visualizations were presented as the concepts were introduced, while other visualizations were presented as the instructor showed examples of the concept. The use of the worksheet involved the projector, which was video-muted until the visualizations were needed. Treatment took place from Week 7 - Week 15, and a total of 12 CAS dynamic worksheets enhancing visualizations were used by each faculty of the experimental group. The topics included in each worksheet are listed below. All the visualizations presented in each one of the 12 CAS dynamic worksheets described below were dynamic in nature.

- CAS dynamic worksheet \#1: The Cartesian Coordinate System. The worksheet shows the different ways Maple shows the Cartesian Coordinate System. The idea behind this worksheet was to familiarize students with the 3D coordinate system and how it is visualized in maple.

- CAS dynamic worksheet \#2: Vector-Valued Functions. The worksheet contains three animations: two animations are related to the graph of two different vectorvalued functions, while the third animation shows the tangent vector along the curve of a vector-valued function. 
- CAS dynamic worksheet \#3: Functions of Several Variables. The worksheet contains visualizations of some basic functions of two variables and their level curves.

- CAS dynamic worksheet \#4: The sphere. The worksheet contains visualizations of a sphere. It is an example of an object that is not a function of two variables, and it was used in conjunction with CAS dynamic worksheet \#3.

- CAS dynamic worksheet \#5: Partial derivatives. The worksheet is a modified version of an existing Maple-document in Maple created in 2001 by Gregory Moore which contains a geometric view of partial derivatives.

- CAS dynamic worksheet \#6: Directional derivative and gradient. The worksheet contains step-by-step algebraic procedure for finding a directional derivative and its related visualization. It also contains the visualization of the gradient vector of a function at a point.

- CAS dynamic worksheet \#7: Tangent plane. The worksheet contains the visualization of the tangent plane of a surface at a point, and the tangent line of intersecting surfaces at a point.

- CAS dynamic worksheet \#8: Extreme values and saddle points. The worksheet contains four visualizations containing extreme values and saddle points of some surfaces.

- CAS dynamic worksheet \#9: Double integrals over rectangular regions. The worksheet contains three visualizations of double and iterated integrals of selected functions over rectangular regions. 
- CAS dynamic worksheet \#10: Double integrals over general regions. The worksheet contains three visualizations of double integrals of selected functions over general regions (non-rectangular).

- CAS dynamic worksheet \#11: Area by double integration and regions of integration of double integrals. The worksheet contains two visualizations of area by double integration, and three visualizations of regions of integration for selected double integrals.

- CAS dynamic worksheet \#12: Triple integrals in rectangular coordinate system. The worksheet contains the visualizations of two triple integrals in rectangular coordinates.

For the control group, one section met Mondays and Fridays, 12:00pm - 1:40pm, and it was also taught following Thomas' Calculus Early Transcendentals $14^{\text {th }}$ Edition with chapters listed above. The other two sections, one Tuesdays and Thursdays, 6:00pm $-7: 40 \mathrm{pm}$, and the other Mondays and Wednesdays, 2:20pm - 4:00pm, were taught following Anton's Calculus Early Transcendentals, $11^{\text {th }}$ Edition. The chapters of the book associated with the course competencies are: Three-Dimensional Space and Vectors, Vector-Valued Functions, Partial Derivatives, Multiple Integrals, and Topic in Vector Calculus. Although some of the chapters may differ slightly in the name, the content is the same for both books utilized in the study. Furthermore, the content at every campus is chosen based on the same set of college-wide competencies, therefore ensuring same content. The instructors for the control group did not use the CAS dynamic worksheets created by the researcher. Rather, the instructors for the control group used hand-drawn 
visualizations for some of the multivariate calculus concepts. Similar homework was assigned throughout the semester for both the experimental and control groups, none of them required the students to use CAS.

Fidelity of Treatment

To ensure fidelity of treatment, the researcher met with the instructors of the experimental group before a CAS dynamic worksheet was to be used, and after use. Weekly meetings with the instructors were easy to do because the office of the instructors and the researcher are on the same floor of the same building, no more than 50 feet apart. The discussions before the use of a CAS dynamic worksheet would comprise of the examples to be included in the CAS dynamic worksheet and what visualizations would fit the instructor's lesson plan. Once the CAS dynamic worksheet was created, the researcher would meet again with the instructors to show the examples of the CAS dynamic worksheet and the possible manipulations of the dynamic figures. Furthermore, the faculty from the experimental group were given access to the OneDrive folder were all the CAS dynamic worksheets were saved.

The discussion after the use of the CAS dynamic worksheet would include the instructor's feedback of the students' interest, and their perception on the helpfulness of the visualizations, and the instructor's feedback on possible improvements or extensions to the CAS dynamic worksheets. The feedback after use was mostly positive, with the faculty expressing their interest in using the worksheets in future course sections. 


\section{Data Analysis}

The data collected from the demographic survey, diagnostic assessment, knowledge pretest and posttest, and visualization pretest and posttest were input into a single Statistical Procedures for Social Sciences (SPSS) file. Exploratory analysis consisting of descriptive statistics was conducted for all variables as measured in each group in the study. The analysis included tests of normal distribution and the presence of outliers. It was hypothesized for research questions 1 and 2 that students in the treatment group would exhibit statistically significant gains in spatial ability and mathematical understanding compared to students in the control group. Additionally, it was hypothesized for research question 3 that students' spatial ability and mathematical understanding would be positively strongly correlated. All tests were carried out at a significance level of .05.

\section{Research Questions}

Before running the theorized statistical test for each research question, the researcher tested all the assumptions associated to each statistical test. If some of the assumptions for any test failed, the researcher decided on whether to run the test as is and be aware of the limitations of the results, or modify the statistical test as recommended by Cohen (2008). The assumptions for any changes or modifications to statistical tests were verified to ensure the results of the test can be trusted and interpreted. Full results and statistical tests are presented in Chapter 4. 


\section{CHAPTER 4: RESULTS}

The goal of the present research was to determine empirically whether the purposeful inclusion of CAS dynamic worksheets aimed at visualizing selected multivariate calculus concepts in experimental multivariate calculus course sections would make a significant difference in students' spatial ability and learning of said concepts versus students who participated in traditional multivariate calculus course sections at a large HSI. Furthermore, the current study investigated whether students' spatial ability and knowledge of selected multivariate calculus concepts were correlated. It was hypothesized that students in the experimental group would exhibit significant gains in the knowledge of selected concepts taught throughout the semester, as well as significant gains in spatial ability. Moreover, because of the nature of the content knowledge of this course, it was hypothesized that students' spatial ability and knowledge acquired would be strongly positively correlated.

\section{Data Collection}

Students from five different Calculus and Analytical Geometry III (MAC2313) courses were approached during class time to seek their participation in the study, totaling 118 individuals. Out of the 118 students, 101 provided their consent to participate in the current study, however, one of those students was a minor. Since the IRB consent form requested and approved was for adult students, the minor in question was not considered as a participant in the study. Out of the 100 consenting adult students, 85 completed all the pretest assessment, and only 65 out of the 85 students who had completed the pretest also completed the posttest assessment. The reasons for the attrition 
include students who withdrew from the course, students who were dropped for not attending class, and students who completed only one round of assessments. Therefore, the sample size for the present quasi-experimental study was 65 students, 26 of them being part of the experimental group, and the other 39 students belonging to the control group.

To describe and compare the student population for both the experimental and the control groups, survey data were collected for the following demographic items: major, college year, honor's college, sex, age, and ethnicity.

Students from both groups were comprised mostly of self-declared engineering and math majors ( $84.6 \%$ for the treatment group, and $74.3 \%$ for the control group). A Fisher's exact test was carried out to determine statistically significant difference of student's self-declared major as described above by treatment. A Pearson's Chi-Square Test could not be used since one of the cells (treatment*other majors) had a count of four (4) and Pearson's Chi-Square Test assumes five (5) or higher. The test revealed there is no statistically significant difference between the experimental and control groups regarding declared majors (Fisher's exact test, $p=0.373$ ).

Students from both the experimental and control groups were mostly sophomore and juniors ( $84.6 \%$ for the treatment group, and $82.1 \%$ for the control group). A Fisher's exact test was conducted, and the results indicate that there is no statistically significant difference between the two groups regarding the number of sophomore $\&$ juniors (Fisher's exact test, $p=1$ ). In terms of composition of "honor students" and "non-honor students" in both the experimental (76.9\% regular students) and control groups (94.7\% 
non-honor students), a Fisher's exact test was carried out and the results indicate no statistically significant difference between experimental and control groups in terms number of honor students at the 0.05 level (Fisher's exact test $p=0.054$ ).

Regarding the sex composition of the experimental (57.7\% male) and control (66.7\% male) groups, a Pearson's Chi-Square revealed no statistically significant differences among the two groups $\left(X^{2}(1)=0.539, p=.463\right)$. Age was dichotomized (1825 versus 26 - 33) and frequencies show both experimental (76.9\%) and control (89.7\%) groups to be composed mostly of students under 25 -years old. A Fisher's exact test was carried out and results indicated that there was no significant statistically significant difference between experimental and control groups (Fisher's exact test, $p=0.181$ ). Ethnicity was also dichotomized into Hispanic/Non-Hispanic and a Fisher's exact test revealed no statistically significant differences between both experimental $(84.6 \%)$ and control $(84.6 \%)$ in terms of Ethnicity (Fisher's exact test, $p=1$ ).

We can describe both experimental and control groups' population of participating students as mostly Hispanic, ages $18-25$, majoring in Engineering/Math, and in their second or third year of study. Table 2 shows the students demographics. 


\section{Table 2 Student Demographics}

Descriptive Statistics for the Demographic Characteristics of the Population by Class

\begin{tabular}{|c|c|c|c|c|}
\hline \multirow[b]{2}{*}{ Major } & \multicolumn{2}{|c|}{ Experimental } & \multicolumn{2}{|c|}{ Control } \\
\hline & $\mathrm{N}$ & $\%$ & $\mathrm{~N}$ & $\%$ \\
\hline Engineering \& Mathematics & 22 & 84.6 & 29 & 74.4 \\
\hline Other & 4 & 15.4 & 10 & 25.6 \\
\hline Total & 26 & 100 & 39 & 100 \\
\hline \multicolumn{5}{|l|}{ College Year } \\
\hline Freshmen & 0 & 0 & 3 & 7.7 \\
\hline Sophomore & 16 & 61.5 & 20 & 51.3 \\
\hline Junior & 6 & 23.1 & 12 & 30.8 \\
\hline Senior & 4 & 15.4 & 4 & 10.2 \\
\hline Total & 26 & 100 & 39 & 100 \\
\hline \multicolumn{5}{|l|}{ Honors College } \\
\hline Honor Students & 6 & 23.1 & 2 & 5.1 \\
\hline Non-Honor Students & 20 & 76.9 & 36 & 92.3 \\
\hline Unspecified & 0 & 0 & 1 & 2.6 \\
\hline Total & 26 & 100 & 39 & 100 \\
\hline \multicolumn{5}{|l|}{ Sex } \\
\hline Male & 15 & 57.7 & 26 & 66.7 \\
\hline Female & 11 & 42.3 & 13 & 33.3 \\
\hline Total & 26 & 100 & 39 & 100 \\
\hline \multicolumn{5}{|l|}{ Age } \\
\hline $18-25$ & 20 & 76.9 & 35 & 89.7 \\
\hline $26-33$ & 6 & 23.1 & 4 & 10.3 \\
\hline Total & 26 & 100 & 39 & 100 \\
\hline \multicolumn{5}{|l|}{ Ethnicity } \\
\hline Hispanic & 22 & 84.6 & 33 & 84.6 \\
\hline Non-Hispanic & 4 & 15.4 & 6 & 15.4 \\
\hline Total & 26 & 100 & 39 & 100 \\
\hline
\end{tabular}




\section{Measured Variables}

Diagnostic Assessment

The Diagnostic Assessment was comprised of 20 questions from the previous mathematics courses, mostly differential and integral calculus: 19 multiple-choice questions and one show-work question. Both the treatment and control groups were given the Diagnostic Assessment to measure their pre-requisite knowledge for multivariate calculus. The Diagnostic Assessment score was originally meant to be used as a covariate for a Repeated-Measures One-Way ANCOVA statistical test to answer RQ \#1.

When testing the assumptions for the statistical test, independence, normal distribution, homogeneity of variance, and linear relationship between covariate and dependent variable were all satisfied. The boxplot of the Diagnostic Assessment scores for the control group showed an outlier above the top whisker (Appendix F). There are some alternatives when dealing with outliers, including trimming and data transformation (Cohen, 2008), but for the current study all outliers were kept as is because they represent the diversity of skills and knowledge that the population brings to the multivariate calculus course. Furthermore, the homogeneity of regression assumption was violated because its significant interaction with the independent variable (See Table 3).

The violation of the homogeneity of regression assumption is an indication that ANCOVA should not be performed (Cohen, 2008). The pre-requisite knowledge variable, Diagnostic, was therefore changed to an independent variable with two levels. On the basis of their score, each student was categorized either as "Low" (score $<50$ ) or "High" ( score $>=50)$. 
Table 3 Homogeneity of Regression Test

Test of Between-Subjects Effects

\begin{tabular}{lcccccc}
\hline \multicolumn{1}{c}{ Source } & $\begin{array}{l}\text { Type III } \\
\text { Sum of } \\
\text { Squares }\end{array}$ & df & $\begin{array}{c}\text { Mean } \\
\text { Square }\end{array}$ & F & Sig. & $\begin{array}{c}\text { Partial } \\
\text { Eta } \\
\text { Squared }\end{array}$ \\
\hline Intercept & 8052.564 & 1 & 8052.564 & 34.197 & $<.001$ & .355 \\
Treatment*Diagnostic & 6351.364 & 2 & 3175.682 & 13.486 & $<.001 *$ & .303 \\
Error & 14599.405 & 62 & 235.474 & & & \\
\hline
\end{tabular}

Note. ${ }^{*} \mathrm{p}<.05$

The instrument was scored using the correctness of the student's answer to each question and had a minimum possible score of zero, and a maximum possible score of 100. Out of the 39 students in the control group, 20 scored low and 19 scored high in the diagnostic assessment. In the treatment group, 13 scored low and 13 scored high in the diagnostic assessment (See Appendix F, page 131).

Knowledge Pre-Test

Students' mathematical understanding of specific multivariate calculus concepts was measured using a 10-question, multiple choice instrument that was administered to both the experimental and control groups before treatment took place. The results show that all four groups have Kurtosis and Skewness between -1 and 1, which are usually good indicators for normal distribution. Although Shapiro-Wilk $<0.05$ for the control*low group, the histogram shows fairly normally distributed data for the dependent variable (See fig. 1). The other three groups are considered normally distributed by all measures. (See Table 4). 
Histogram

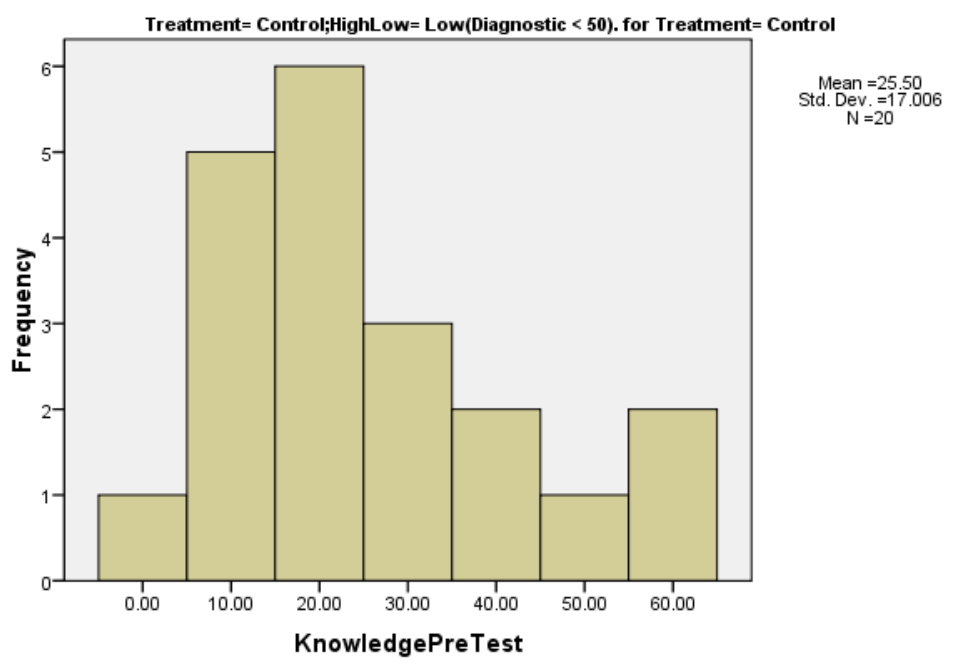

Figure 1. Histogram of Knowledge Pretest scores in the group Control *Low

Table 4 Knowledge Pretest Group Data indicators

Mean, Standard Deviation, Kurtosis, Skewness, and Shapiro-Wilk Test by Group

\begin{tabular}{lccccc}
\hline \multicolumn{1}{c}{ Groups } & M & SD & Kurtosis & Skewness & Shapiro-Wilk \\
\hline Control*Low & 25.5 & 17.0 & -.084 & .797 & $.046^{*}$ \\
Control*High & 30.5 & 17.8 & -1.035 & .243 & .102 \\
Experimental*Low & 29.2 & 13.8 & -.702 & .384 & .060 \\
Experimental*High & 34.6 & 7.8 & .196 & .150 & .062 \\
\hline
\end{tabular}

Note. $* \mathrm{p}<.05$

Knowledge Post-Test

Students' mathematical understanding of specific multivariate calculus concepts was also measured at the end of the semester, after treatment, using the same knowledge instrument that was administered to both the experimental and control groups before 
treatment. The results show that all four groups have Skewness between -1 and 1 , and two (Control*Low, Exper*High) of them have Kurtosis between -1 and 1, and the other two are slightly outside this range. However, the histograms show all four groups roughly normally distributed, with the Control*High group deviating more from normal distribution, but the Shapiro-Wilk test for all four of them indicate the data are normally distributed for all groups (See Table 5). Full descriptive statistics results, and tables, can be seen in Appendix H.

Table 5 Knowledge Posttest Group Data Indicators Mean, Standard Deviation, Kurtosis, Skewness, and Shapiro-Wilk Test by Group

\begin{tabular}{lccccc}
\hline \multicolumn{1}{c}{ Groups } & M & SD & Kurtosis & Skewness & Shapiro-Wilk \\
\hline Control*Low & 34.5 & 15.4 & -.985 & .104 & .209 \\
Control*High & 51.6 & 19.8 & -1.347 & .100 & .073 \\
Experimental*Low & 52.3 & 14.8 & 1.329 & .284 & .470 \\
Experimental*High & 57.7 & 13.0 & -.954 & .035 & .229 \\
\hline
\end{tabular}

Spatial Ability Pre-Test

Yoon (2011)'s Revised PSVT:R was used to measure students' spatial ability before treatment. The Revised PSVT:R contains 30 multiple-choice questions and it was scored using the correctness for each question. The instrument has a possible minimum score of zero and a possible maximum score of 30 . The results show that all four groups have Kurtosis and Skewness between -1 and 1, and all but one (Control*High) have nonstatistically significant Shapiro-Wilk p-values (See Table 6). In looking closely to Control*High data, the histogram deviates from a normal distribution having some heavy 
distribution to the right, however, "the F test for ANOVA is not very sensitive from departures from normal distribution" (Cohen, 2008). Full descriptive statistics results, and tables, can be seen in Appendix I.

\section{Table 6 Spatial Ability Pretest Group Data Indicators}

Mean, Standard Deviation, Kurtosis, Skewness, and Shapiro-Wilk Test by Group

\begin{tabular}{lccccc}
\hline \multicolumn{1}{c}{ Groups } & M & SD & Kurtosis & Skewness & Shapiro-Wilk \\
\hline Control*Low & 16.9 & 5.7 & -.141 & -.724 & .119 \\
Control*High & 22.3 & 6.0 & -.731 & -.753 & .024 \\
Experimental*Low & 16.8 & 6.1 & -.636 & .301 & .851 \\
Experimental*High & 20.5 & 3.1 & -.073 & .653 & .450 \\
\hline Note. ${ }^{*} \mathrm{p}<.05$ & & & & &
\end{tabular}

Spatial Ability Post-Test

Yoon (2011)'s Revised PSVT:R was also used to measure students' spatial ability after treatment. The results show that all groups have Kurtosis and Skewness between -1 and 1 except for Control*High, and again all but one (Control*High) have nonstatistically significant Shapiro-Wilk p-values (See Table 7). Furthermore, in looking closely to Control*High data, the histogram deviates from a normal distribution having some heavy distribution to the right, however, the F test for ANOVA is robust to deviations from normal distribution (Cohen, 2008). Full descriptive statistics results, and tables, can be seen in Appendix J. 
Table 7 Spatial Ability Posttest Group Data Indicators

Mean, Standard Deviation, Kurtosis, Skewness, and Shapiro-Wilk Test by Group

\begin{tabular}{lccccc}
\hline \multicolumn{1}{c}{ Groups } & M & SD & Kurtosis & Skewness & Shapiro-Wilk \\
\hline Control*Low & 15.9 & 6.5 & -.778 & .092 & .491 \\
Control*High & 20.6 & 7.5 & 1.302 & -1.518 & $.001^{*}$ \\
Experimental*Low & 19.6 & 5.8 & -.552 & -.350 & .523 \\
Experimental*High & 22.2 & 4.1 & .825 & -.707 & .610 \\
Note. ${ }^{*} \mathrm{p}<.05$ & & & & &
\end{tabular}

Research Questions

Research Question \#1

- To what extent does existing knowledge and a more visually-enhanced approach to instruction facilitated by CAS affect college students' mathematical understanding of multivariate calculus concepts in an undergraduate Multivariate Calculus classroom setting at Miami Dade College?

Originally, the question posed was: To what extent does a visually-enhanced approach to instruction facilitated by CAS affect college students' mathematical understanding of multivariate calculus concepts in an undergraduate Multivariate Calculus classroom setting at Miami Dade College after controlling for prerequisite knowledge? A Repeated-Measures, One-Way ANCOVA was going to be used, measuring the difference between the Knowledge Pre-Test Assessment and Knowledge Post-Test Assessment scores, and using the Diagnostic Assessment score as covariate. The results from the Repeated-Measures, One-Way ANCOVA indicated treatment was statistically significant $(F=7.141, p=0.01)$. However, because a violation of 
homogeneity of regression and a significant interaction between the independent and the covariate variables, the recommendation is to consider running a randomized-blocks design instead of the ANCOVA (Cohen, 2008). "The covariate is turned into a second factor in the ANOVA by dividing it into categories" (Cohen, 2008, p. 657). Therefore, a new categorical variable was created to differentiate students in terms of their Diagnostic Assessment score (High: score $>=50$, Low: score $<50$ ), and the covariate variable (diagnostic) was changed to an independent variable. The question was then addressed with a Repeated Measures, Two-Way Mixed ANOVA, and several assumptions associated with the statistical test were checked (Cohen, 2008).

\section{Assumption \#1 Independent Random Sampling}

Random sampling was not achieved since the study is working with intact groups of students who self-registered into the different course sections and thus the reason why the study was classified as quasi-experimental in Chapter 3. However, the assumption of independence of groups is satisfied since no student was enrolled in more than one of the course sections, and no student appeared in more than one group (Control*Low, Control*High, Experimental*Low, Experimental*High).

\section{Assumption \#2 Normal Distributions}

The dependent variable, understanding of specific multivariate calculus concepts, is being measured by the Knowledge Assessment which contains ten multiple-choice questions, with a possible minimum score of zero and possible maximum score of 100 . The dependent variable is continuous and satisfies the interval/ratio scale property that is needed to perform parametric tests. In the 'Knowledge Post-Test' section, the dependent 
variable had normal distribution among all four groups as shown by their respective Shapiro-Wilk test p-values.

Assumption \#3 Homogeneity of Variance

Levene's Test of Equality of Error Variances for the Knowledge Post-Test is not significant $(\mathrm{p}>0.05)$, indicating the error variance of the dependent variable is considered equal across all groups. Levene's Test of Equality of Error Variances for the Knowledge Pre-Test is significant $(p=0.022)$, indicating there are some differences in the error variance of the dependent variable across all groups (see Table 8).

\section{Table 8 Homogeneity of Variance}

Levene's Test of Equality of Error Variances

\begin{tabular}{lcccc}
\hline & $\mathrm{F}$ & $\mathrm{df1}$ & $\mathrm{df2}$ & Sig. \\
\hline Knowledge Pretest & 3.439 & 3 & 61 & $.022^{*}$ \\
Knowledge Posttest & 2.571 & 3 & 61 & .062 \\
\hline
\end{tabular}

Note. ${ }^{*} \mathrm{p}<.05$

Assumption \#4. Homogeneity of Covariance Across Groups

Box's Test of Equality of Covariance matrices test whether the observed covariance matrices are equal across all groups. Based on the results from Table 9 , it is concluded this assumption is met. 


\section{Table 9 Equality of Covariance Matrices}

Box's Test of Equality of Covariance Matrices

\begin{tabular}{ccccc}
\hline Box's M & F & df1 & df2 & Sig. \\
\hline 12.127 & 1.263 & 9 & 24092.473 & .251 \\
\hline
\end{tabular}

Assumption \#5 Test for Sphericity

Sphericity is "the same as requiring that the variance of the difference scores will be the same no matter which pair of treatment levels you look at" (Cohen, 2008, p. 506). Since the repeated measure contained only two levels the sphericity assumption was met, because there is only one pair and therefore there is no comparison of the variance of the difference scores for different pairs.

\section{Repeated Measures, Two-Way Mixed ANOVA}

The statistical test was run in SPSS under the General Linear Model: Repeated Measures. Time was defined as the Within-Subjects factor with two levels: Knowledge Pre-Test and Knowledge Post-Test, and two Between-Subjects factors: Treatment and HighLow (diagnostic level). Table 10 contains the results of the test, which show the main effect of treatment on knowledge was significant such that students in the experimental group obtained higher scores in the knowledge assessment than those in the control group $(F=7.415, p=0.008)$. The results also show that the main effect of diagnostic level on knowledge was significant such that students at the high level of the diagnostic obtained higher scores in the knowledge assessment than those at the low level 
of the diagnostic $(F=7.954, p=0.006)$. However, the test shows no significant interaction between treatment and diagnostic level $(F=0.946, p=0.335)$.

Table 10 Results of Repeated-Measures, Two-Way Mixed ANOVA for Knowledge Tests of Between-Subjects Effect

\begin{tabular}{lcccccc}
\hline \multicolumn{1}{c}{ Source } & $\begin{array}{c}\text { Sum of } \\
\text { Squares }\end{array}$ & df & $\begin{array}{c}\text { Mean } \\
\text { Square }\end{array}$ & F & Sig. & $\begin{array}{c}\text { Partial } \\
\text { Eta } \\
\text { Squared }\end{array}$ \\
\hline Intercept & 194608.118 & 1 & 194608.118 & 734.693 & $<.001$ & .923 \\
Treatment & 1964.077 & 1 & 1964.077 & 7.415 & $.008^{*}$ & .108 \\
Diagnostic & 2106.874 & 1 & 2106.874 & 7.954 & $.006^{*}$ & .115 \\
Treatment*Diagnostic & 250.520 & 1 & 250.520 & .946 & .335 & .015 \\
Error & 16157.895 & 61 & 264.884 & & & \\
\hline Note $* \mathrm{p}<.05$ & & & & & & \\
\hline
\end{tabular}

Table 11 displays the within-subjects tests, which show the main effect of time on knowledge was significant such that students obtained higher scores in the Knowledge Posttest versus the Knowledge Pretest $(F=48.442, p<0.001)$. However, the test shows no significant interaction between time and treatment $(F=2.163, p=.147)$, no significant interaction between time and diagnostic level $(F=1.212, p=.275)$, and no significant interaction between time and treatment and diagnostic level $(F=1.212, p=.275)$. 
Table 11 Results for Repeated-Measures, Two-Way Mixed ANOVA for Knowledge Tests of Within-Subjects Contrasts

\begin{tabular}{lcccccc}
\hline \multicolumn{1}{c}{ Source } & $\begin{array}{c}\text { Sum of } \\
\text { Squares }\end{array}$ & df & $\begin{array}{c}\text { Mean } \\
\text { Square }\end{array}$ & F & Sig. & $\begin{array}{c}\text { Partial } \\
\text { Eta } \\
\text { Square } \\
\text { d }\end{array}$ \\
\hline Time & 11321.50 & 1 & 11321.50 & 48.44 & $<.001$ & .443 \\
& 4 & & 4 & 2 & $*$ & \\
Time*Treatment & 505.403 & 1 & 505.403 & 2.163 & .147 & .034 \\
Time*Diagnostic & 283.194 & 1 & 283.194 & 1.212 & .275 & .019 \\
Time*Treatment*Diagnosti & 283.194 & 1 & 283.194 & 1.212 & .275 & .019 \\
c & & & & & & \\
Error (Time) & 14256.39 & 6 & 233.711 & & & \\
& 7 & 1 & & & & \\
\hline
\end{tabular}

Note. ${ }^{*} \mathrm{p}<.05$

Research Question \#2

- To what extent does prerequisite knowledge and a more visually-enhanced approach to instruction facilitated by CAS affect college students' spatial ability in an undergraduate Multivariate Calculus classroom setting at Miami Dade College?

Initially, the question posed was: To what extent does a visually-enhanced approach to instruction facilitated by CAS affect college students' spatial ability in an undergraduate Multivariate Calculus classroom setting at Miami Dade College? The question was going to be addressed with a Mixed-Effect, Repeated-Measures, One-Way 
ANOVA, however, because of violations to the homogeneity of variance and homogeneity of covariance assumptions, the statistical test was changed to a Repeated Measures, Two-Way Mixed ANOVA, with one within-subjects factor (Time: Visual PreTest, Visual Post-Test) and two independent factors (Treatment: Experimental, Control; Diagnostic: High level, Low level). Several assumptions needed to be checked before using the statistical test (Cohen, 2008).

\section{Assumption \#1 Independent Random Sampling}

Random sampling was not achieved since the study is working with intact groups of students who self-registered into the different course sections and thus the reason why the current study was denominated quasi-experimental in Chapter 3. However, there is independence of groups since no students was enrolled in more than one of the course sections, and no student appeared in more than one group (Control*Low, Control*High, Exper*Low, Exper*High).

\section{Assumption \#2 Normal Distributions}

The dependent variable, spatial ability, was measured by the Yoon's PSVT:R instrument which contains 30 multiple-choice questions, and a maximum score of 30 pts. Spatial ability is continuous and satisfies the interval/ratio scale property that is needed to perform parametric tests. In the 'Visual Post-Test' section, the dependent variable had normal distribution among all groups, except for one. However, the F test tends to be robust for normal distribution if most groups are normally distributed and they do not differ by much from each other, which was corroborated by the histograms of each respective group. 
Assumption \#3 Homogeneity of Variance

Levene's Test of Equality of Error Variances tests the null hypothesis that the error variance of the dependent variable is equal across groups. Levene's test for the Visual Post-Test is not significant $(\mathrm{F}=2.177, \mathrm{p}=0.286)$, indicating the error variance of the dependent variable is considered equal across all groups. Levene's test for the Visual PreTest is also not significant $(\mathrm{F}=1.291, \mathrm{p}=0.100)$, indicating there are no differences in the error variance of the dependent variable across all groups (See Table 12).

Table 12 Equality of Variances for Spatial Ability

Levene's Test of Equality of Error Variances

\begin{tabular}{lcccc}
\hline & F & df1 & df2 & Sig. \\
\hline Visual Pretest & 2.177 & 3 & 61 & .100 \\
Visual Posttest & 1.291 & 3 & 61 & .286 \\
\hline
\end{tabular}

Assumption \#4. Homogeneity of Covariance Across Groups

Table 13 Equality of Covariance Matrices

Box's Test of Equality of Covariance Matrices

\begin{tabular}{ccccc}
\hline Box's M & F & df1 & df2 & Sig. \\
\hline 15.989 & 1.665 & 9 & 24092.473 & .091 \\
\hline
\end{tabular}

Assumption \#5 Test for Sphericity 
Box's Test of Equality of Covariance matrices test whether the observed covariance matrices are equal across all groups. Based on the results from Table 13 shown above, we can conclude this assumption is met.

As explained for the test for sphericity for research question \#1, the sphericity assumption is met since the repeated measured contain only two levels.

Repeated-Measures, Two-Way Mixed ANOVA

The statistical test for spatial ability was run in SPSS under the General Linear Model: Repeated Measures. Time was defined as the Within-Subjects factor with two levels: Visual Pre-Test and Visual Post-Test, and two Between-Subjects factors:

Treatment (Control and Experimental) and Diagnostic (Low Level and High Level). Table 14 Results of Repeated-Measures, Two-Way ANOVA for Spatial Ability Tests of Between-Subjects Effect

\begin{tabular}{lcccccc}
\hline \multicolumn{1}{c}{ Source } & $\begin{array}{c}\text { Sum of } \\
\text { Squares }\end{array}$ & df & $\begin{array}{c}\text { Mean } \\
\text { Square }\end{array}$ & F & Sig. & $\begin{array}{c}\text { Partial } \\
\text { Eta } \\
\text { Squared }\end{array}$ \\
\hline Intercept & 46700.119 & 1 & 46700.119 & 786.630 & .000 & .928 \\
Treatment & 22.266 & 1 & 22.266 & .374 & .543 & .006 \\
Diagnostic & 531.073 & 1 & 531.073 & 8.911 & $.004 *$ & .127 \\
Treatment*Diagnostic & 29.495 & 1 & 29.495 & .495 & .484 & .008 \\
Error & 3635.272 & 61 & 59.595 & & & \\
\hline
\end{tabular}

Note. ${ }^{*} \mathrm{p}<.05$

The test results (See Table 14 above) show the main effect of Diagnostic on Spatial Ability was significant such that students in the high level of the diagnostic assessment scored better in the visualization assessment than those in the low level $(F=8.911, p=$ 
0.004). However, the test shows the main effect of Treatment on Spatial Ability was not significant $(F=0.374, p=0.543)$. Furthermore, the interaction of Treatment and Diagnostic was not significant either $(F=0.495, p=0.484)$.

\section{Table 15 Results of Repeated-Measures, Two-Way Mixed ANOVA for Spatial Ability}

Tests of Within-Subjects Contrasts

\begin{tabular}{lcccccc}
\hline \multicolumn{1}{c}{ Source } & $\begin{array}{c}\text { Sum of } \\
\text { Squares }\end{array}$ & df & $\begin{array}{c}\text { Mean } \\
\text { Square }\end{array}$ & F & Sig. & $\begin{array}{c}\text { Partial } \\
\text { Eta } \\
\text { Squared }\end{array}$ \\
\hline Time & 6.899 & 1 & 6.899 & .738 & .394 & .012 \\
Time*Treatment & 105.305 & 1 & 105.305 & 11.259 & $.001 *$ & .156 \\
Time*Diagnostic & 5.708 & 1 & 5.708 & .610 & .438 & .010 \\
Time*Treatment*Diagnostic & .382 & 1 & .382 & .041 & .840 & .001 \\
Error (Time) & 70.528 & 61 & 9.353 & & & \\
\hline
\end{tabular}

Note. ${ }^{*} \mathrm{p}<.05$

The test results (See Table 15 above) for the within-subjects factors indicate that the main effect of Time on Spatial Ability was not significant $(F=.738, p=.394)$. The test also showed that the interaction effect of Time and Treatment was significant $(F=$ $11.259, p=0.001)$, indicating that students in the experimental group, the Visual Posttest scores were higher than the Visual Pretest scores. For the students in the control group, there were no differences between the Visual Posttest and Visual Pretest scores. Moreover, the test showed that the interaction between Time and Diagnostic was not significant $(F=.610, p=.438)$, nor the interaction between Time, Treatment, and Diagnostic $(F=.041, p=0.840)$. 
Simple Main Effects Analysis

As a result of the interaction between time and treatment, test for simple main effects were run to determine effect of time when treatment is hold fixed at a level, and to determine the effect of treatment when time is hold fixed at a level. The results of the pairwise comparison from the simple main effects can be seen in Table 16 and Table 17.

The results from Table 16 show no statistically significant difference in spatial ability between the experimental and the control group at the pretest (Time 1). It also shows no statistically significant difference in spatial ability between the experimental and control group at the posttest (Time 2).

Table 16 Results of Simple Main Effects for Treatment

Pairwise Comparisons

\begin{tabular}{|c|c|c|c|c|c|c|c|}
\hline \multirow[b]{2}{*}{ Time } & \multirow[b]{2}{*}{ (I)Treatment } & \multirow[b]{2}{*}{ (J)Treatment } & \multirow{2}{*}{$\begin{array}{c}\text { Main } \\
\text { Difference } \\
(\mathrm{I}-\mathrm{J})\end{array}$} & \multicolumn{4}{|c|}{$\begin{array}{l}\text { 95\% Confidence } \\
\text { Interval }\end{array}$} \\
\hline & & & & $\begin{array}{l}\text { Std. } \\
\text { Error }\end{array}$ & Sig. & $\begin{array}{l}\text { Lower } \\
\text { Bound }\end{array}$ & $\begin{array}{l}\text { Upper } \\
\text { Bound }\end{array}$ \\
\hline \multirow[t]{2}{*}{1} & Control & Experimental & .993 & 1.379 & .474 & -1.765 & 3.750 \\
\hline & Experimental & Control & -.993 & 1.379 & .474 & -3.750 & 1.765 \\
\hline \multirow[t]{2}{*}{2} & Control & Experimental & -2.682 & 1.587 & .096 & -5.856 & .491 \\
\hline & Experimental & Control & 2.682 & 1.587 & .096 & -.491 & 5.856 \\
\hline
\end{tabular}

The results from Table 17 show no statistically significant difference in spatial ability between the pretest (Time 1) and the posttest (Time 2) for the control group. 
However, it shows statistically significant difference between the pretest (Time 1) and the posttest (Time 2) for the experimental group.

\section{Table 17 Results of Simple Main Effects for Time}

Pairwise Comparisons

\begin{tabular}{|c|c|c|c|c|c|c|c|}
\hline \multirow[b]{2}{*}{ Treatment } & \multirow[b]{2}{*}{ (I)Time } & \multirow[b]{2}{*}{ (J)Time } & \multirow{2}{*}{$\begin{array}{c}\text { Main } \\
\text { Difference } \\
(\mathrm{I}-\mathrm{J})\end{array}$} & \multirow[b]{2}{*}{ Std. Error } & \multirow[b]{2}{*}{ Sig. } & \multicolumn{2}{|c|}{$\begin{array}{l}95 \% \text { Confidence } \\
\text { Interval }\end{array}$} \\
\hline & & & & & & $\begin{array}{l}\text { Lower } \\
\text { Bound }\end{array}$ & $\begin{array}{l}\text { Upper } \\
\text { Bound }\end{array}$ \\
\hline \multirow[t]{2}{*}{ Control } & 1 & 2 & 1.367 & .693 & .053 & -.018 & 2.752 \\
\hline & 2 & 1 & -1.367 & .693 & .053 & -2.752 & .018 \\
\hline \multirow[t]{2}{*}{ Experimental } & 1 & 2 & -2.308 & .848 & $.008 *$ & -4.004 & -.612 \\
\hline & 2 & 1 & 2.308 & .848 & $.008 *$ & .612 & 4.004 \\
\hline
\end{tabular}

Note. $* \mathrm{p}<.05$

Research Question \#3

Is there a significantly positive relationship between students' spatial ability and mathematical understanding of selected multivariate calculus concepts?

To address this question, a Pearson's Correlation Coefficient was be calculated between the groups' knowledge score and spatial ability score before treatment and after treatment. There are some assumptions associated with Pearson's r (Cohen, 2008).

\section{Assumption \#1 Independent Random Sampling}

Random sampling was not achieved since the study is working with intact groups of students who self-registered into the different course sections and thus the reason why 
the present study was denominated quasi-experimental in Chapter 3. However, there is independence of groups since no students was enrolled in more than one of the course sections, and no student appeared in more than one group.

Assumption \#2 Interval/Ratio Scale and Normal Distribution

All four variables (Knowledge Pretest, Knowledge Posttest, Visual Pretest, and Visual Posttest) are measured on interval/ratio scale. Both knowledge variables have a range from $0-100$, while the visual variables have a range from $0-30$. The tests for normality are shown in Table 18.

Table 18 Normality for Knowledge (Pretest and Posttest), and Visual (Pretest and Posttest)

Mean, Standard Deviation, Kurtosis, Skewness, and Shapiro-Wilk Test by Variable

\begin{tabular}{lccccc}
\hline \multicolumn{1}{c}{ Population } & M & SD & Kurtosis & Skewness & Shapiro-Wilk \\
\hline Knowledge Pretest & 29.539 & 15.251 & -.627 & .271 & $.005^{*}$ \\
Knowledge Posttest & 47.692 & 18.352 & -.767 & -.117 & $.023^{*}$ \\
Visual Pretest & 19.169 & 5.859 & -.394 & -.370 & .156 \\
Visual Posttest & 19.277 & 6.592 & -.305 & -.746 & $.001^{*}$ \\
\hline Note. ${ }^{*} \mathrm{p}<.05$ & & & & &
\end{tabular}

To satisfy assumption \#2, all the variables need to be normally distributed in the population. According to the Shapiro-Wilk test, only Visual Pretest is normally distributed with a non-significant $\mathrm{p}$-value $(p=.156)$. However, for all four variables, Kurtosis and Skewness are between -1 and 1, which are typically considered good values to describe normal distribution of a set of data points. Furthermore, upon analysis of their 
histogram (See Fig. 2, Fig. 3, and Fig. 4, respectively), we can conclude that Knowledge Pretest, Knowledge Posttest, have roughly a normal distribution in the population. Visual Posttest deviates more than the other variables from a normal distribution.

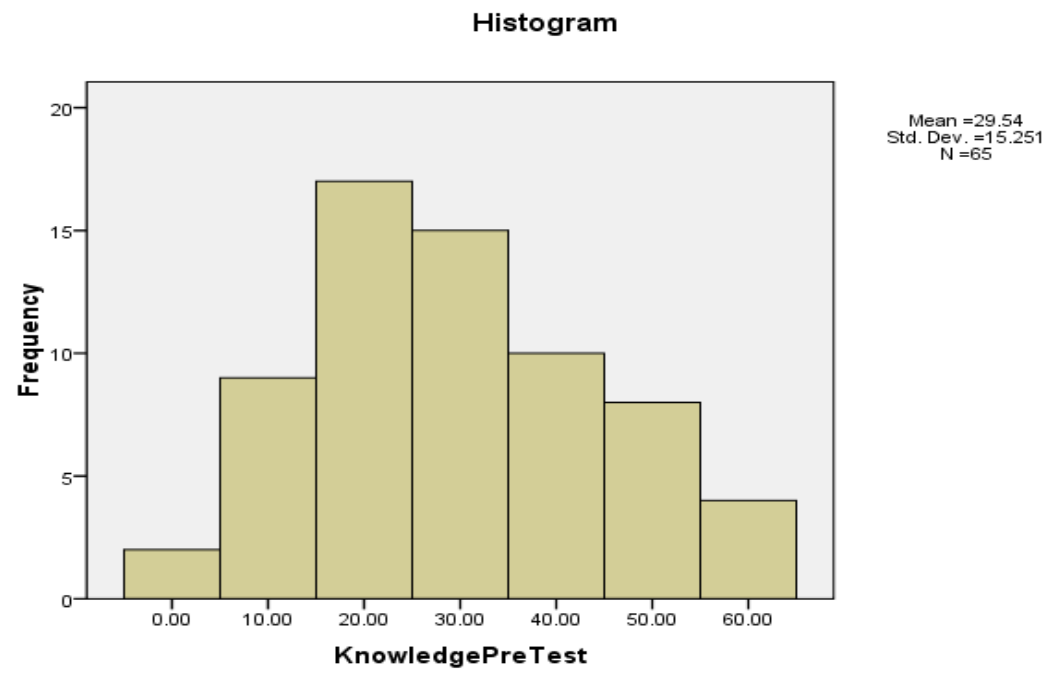

Figure 2. Histogram from Population's Knowledge Pretest

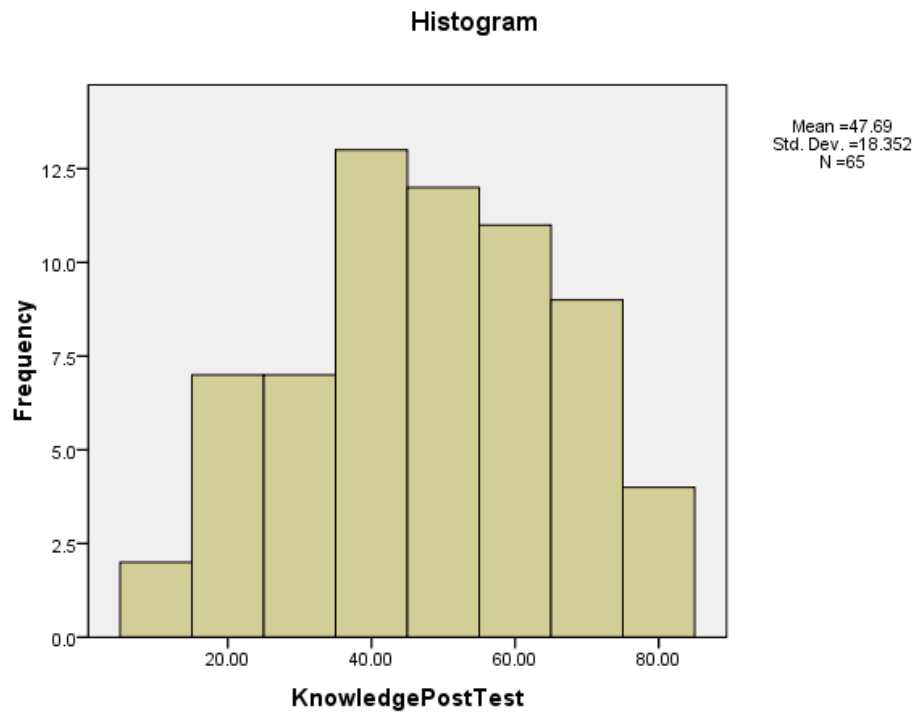

Figure 3. Histogram for Population's Knowledge Posttest 


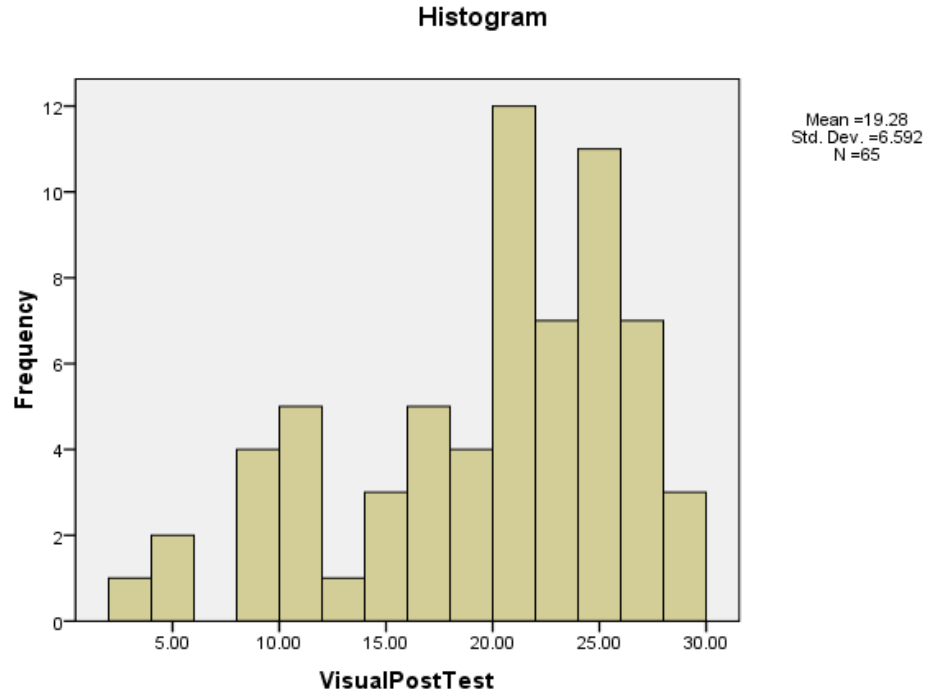

Figure 4. Histogram for Population's Visual Posttest

Assumption \#3 Linearity and Homoscedasticity

Since Pearson's $r$ measures the strength of linear association between two variables, it is important to check whether the two variables in question are related in a linear or nonlinear manner. Moreover, for interpreting the significance of Pearson's $r$ correlation coefficient, the set of data points must show homoscedasticity. To test these assumptions, a scatter/dot diagram was used for each pair of variables.

The scatter/dot plot to observe the linearity and homoscedasticity for visual pretest-visual posttest indicate that there is some linearity between the two variables. Furthermore, we can some heteroscedasticity (See Fig. 5). 


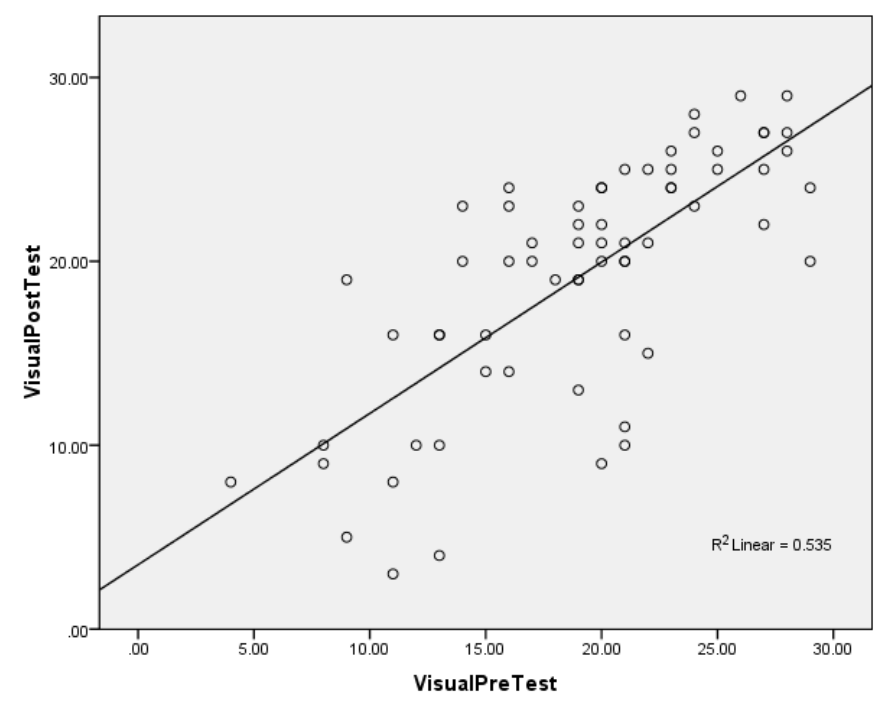

Figure 5. Scatter/Dot Chart of Visual Pretest - Visual Posttest

The scatter/dot plot to observe the linearity and homoscedasticity for visual pretest-knowledge pretest indicate that there is no linearity, if any, between the two variables. Furthermore, we can see some heteroscedasticity (See Fig. 6).

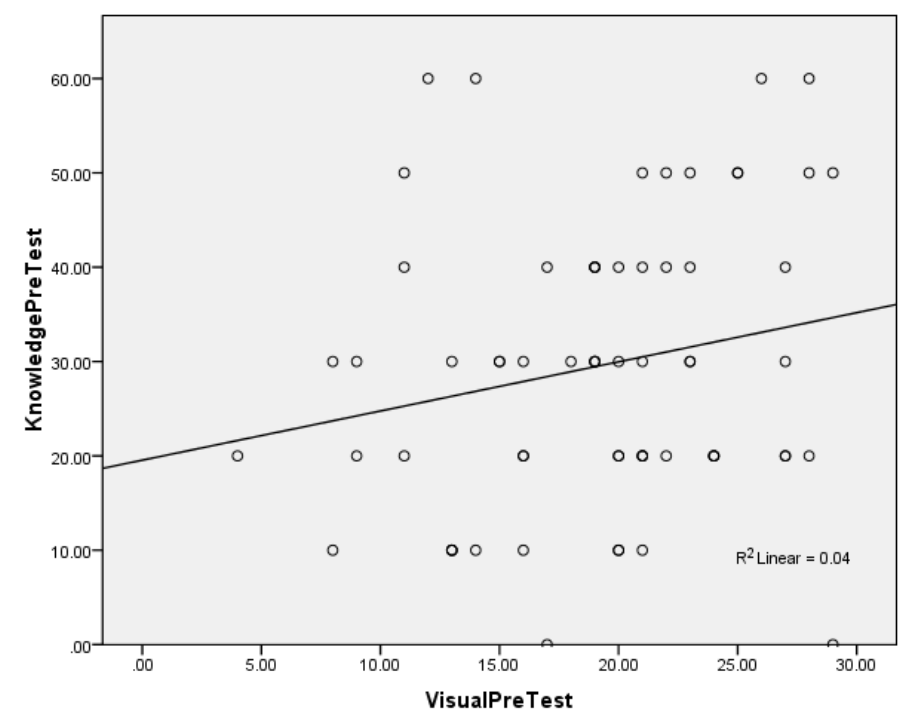

Figure 6. Scatter/Dot Chart for Visual Pretest - Knowledge Pretest 
The scatter/dot plot to observe the linearity and homoscedasticity for visual pretest-knowledge posttest indicate that there is no linearity, if any, between the two variables. Furthermore, we can see some heteroscedasticity (See Fig. 7).

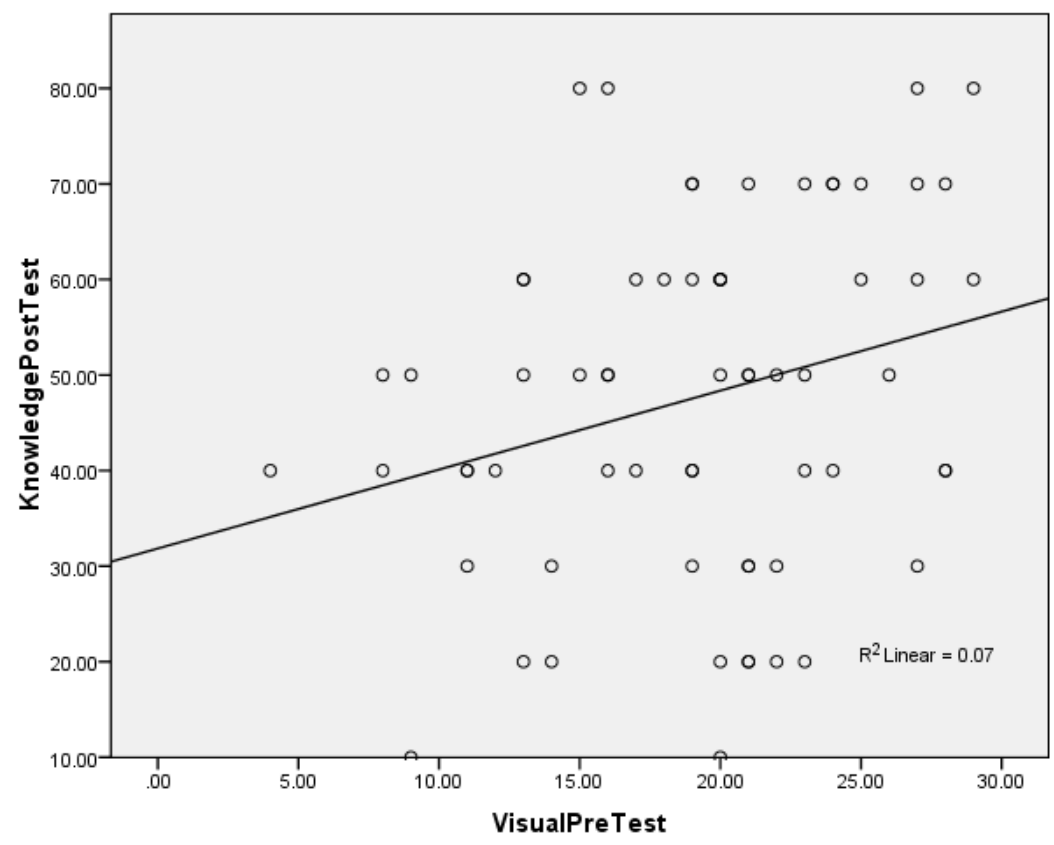

Figure 7. Scatter/Dot Chart for Visual Pretest - Knowledge Posttest

The results for the linearity and homoscedasticity for visual posttest-knowledge pretest indicate that there is no linearity between the two variables, and some heteroscedasticity (See Fig. 8). 


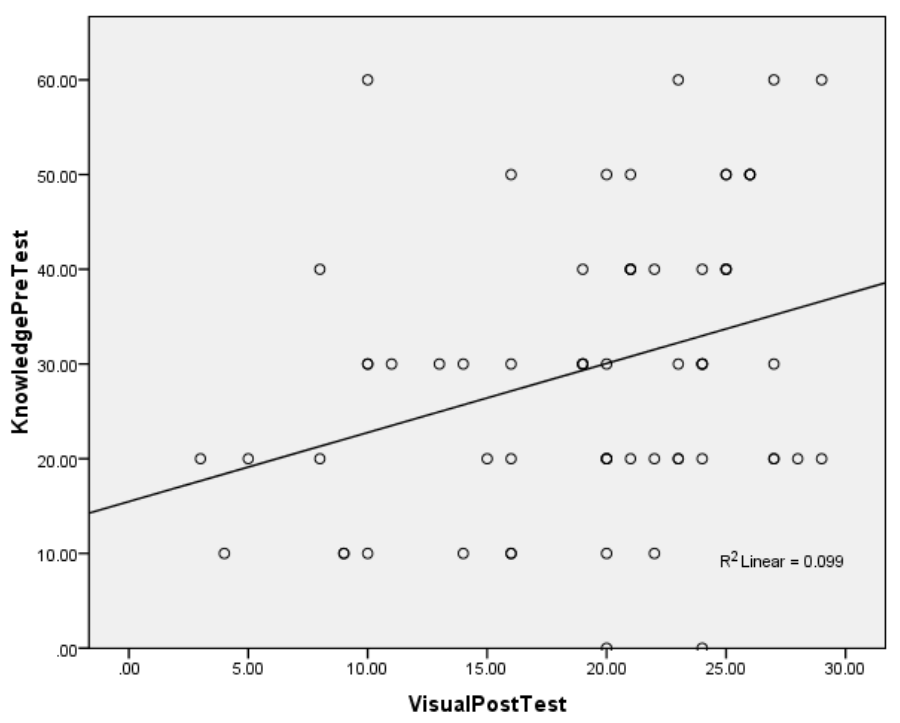

Figure 8. Scatter/Dot Chart for Visual Posttest - Knowledge Pretest

The results for the linearity and homoscedasticity for visual posttest-knowledge posttest indicate that there is not much linearity between the two variables, and some heteroscedasticity (See Fig. 9).

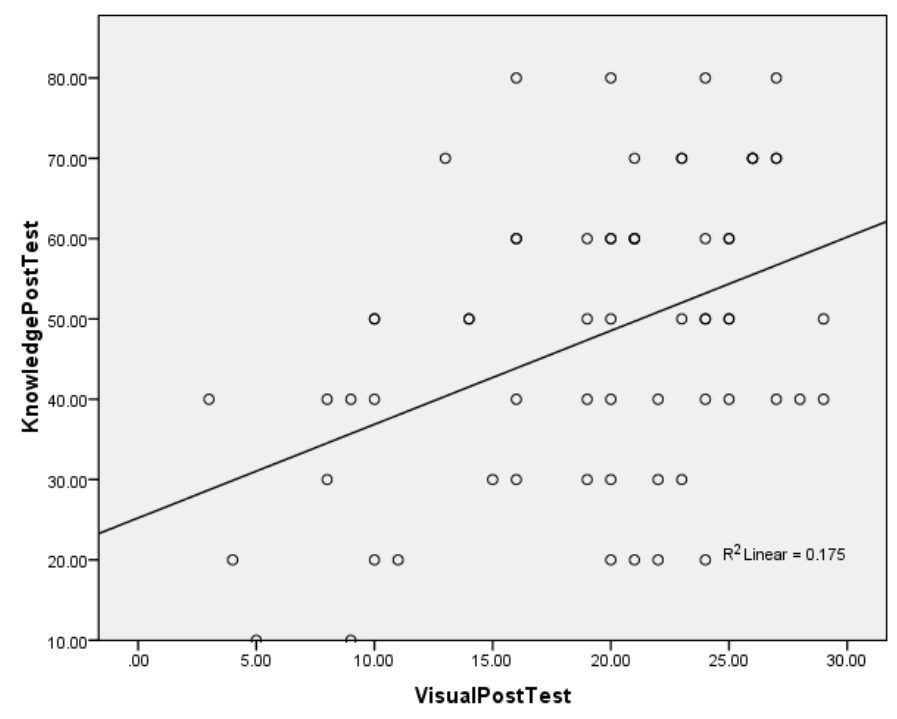

Figure 9. Scatter/Dot Chart for Visual Posttest - Knowledge Posttest 
The results for the linearity and homoscedasticity for knowledge pretestknowledge posttest indicate that there is no linearity between the two variables, and some homoscedasticity (See Fig. 10).

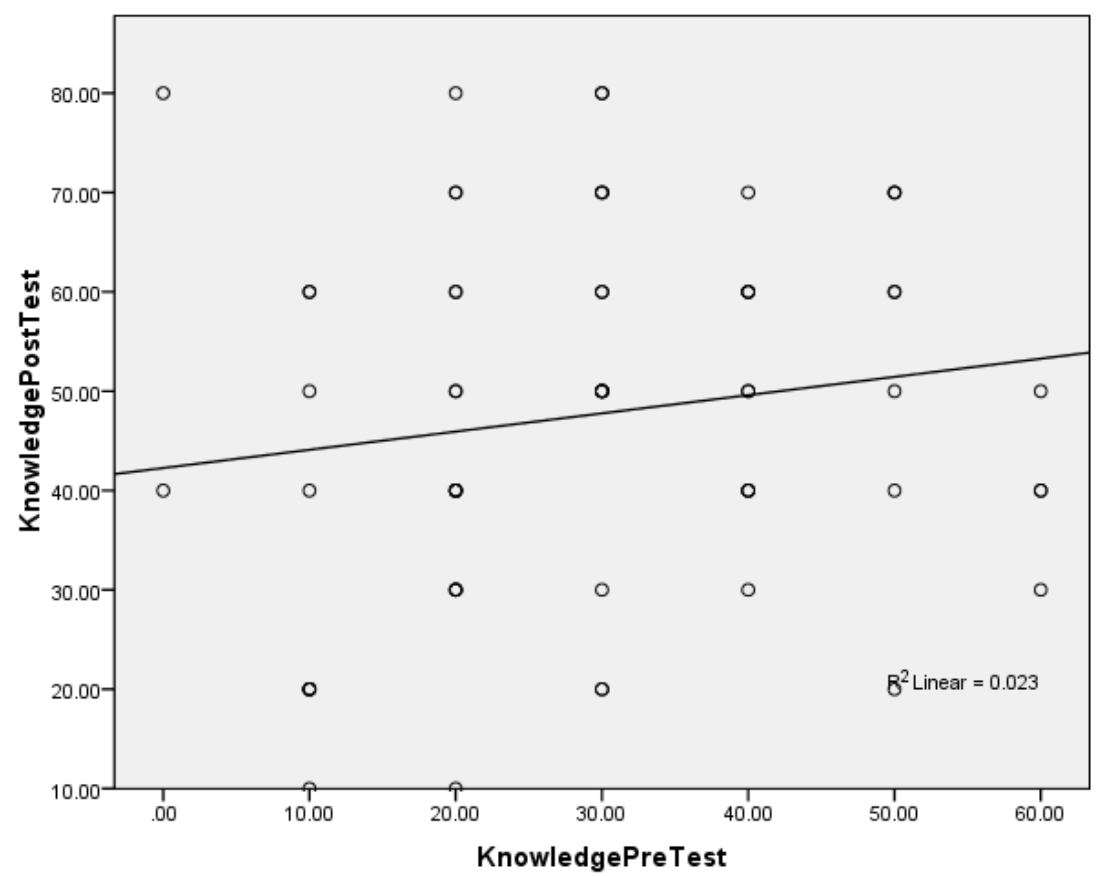

Figure 10. Scatter/Dot Chart for Knowledge pretest - Knowledge Posttest

\section{Outliers}

Although there was one outlier, the data point will be considered in the analysis because it represents the diversity of the population in multivariate calculus in terms of skills and knowledge. 
Pearson's r Correlations Test

To investigate the relationship between students' spatial ability and knowledge of selected multivariate calculus content, a Pearson's $r$ correlation was used. Pearson's $r$ can be used to describe the linear relationship between two continuous variables where "a coefficient of +1 represents perfect positive correlation, -1 represents perfect negative correlation, and 0 represents a total lack of correlation" (Cohen, 2008, p. 256).

Furthermore, Cohen (2008) characterizes correlations as small $(\mathrm{r}=0.1)$, medium $(\mathrm{r}=$ $0.3)$, and large $(\mathrm{r}=0.5)$. The results of the test can be seen in Table 19. Since there are four scores for the two variables being investigated, knowledge and spatial ability, there are then six pairs of scores displayed in the Pearson's $r$ correlation Test. For the purpose of this study, only the correlation between Knowledge Posttest scores and Visual Posttest scores (Pair \#5) were used for interpretation, but the correlation of all possible pairs is reported below.

\section{Pair \#1 Visual Pretest - Visual Posttest}

According to Pearson's r Correlation test, the Visual Pretest scores and Visual Posttest scores have a significant, large strength of association $(r(65)=.731, p=.000)$.

\section{Pair \# 2 Visual Pretest - Knowledge Pretest}

According to Pearson's r Correlation test, the Visual Pretest scores and Knowledge

Pretest scores have a non-significant, low strength of association $(r(65)=.200, p=.110)$.

\section{Pair \#3 Visual Pretest - Knowledge Posttest}

According to Pearson's r Correlation test, the Visual Pretest scores and Knowledge Posttest scores have a significant, low strength of association $(r(65)=.264, p=.034)$. 
Pair \#4 Visual Posttest - Knowledge Pretest

According to Pearson's r Correlation test, the Visual Posttest scores and Knowledge

Pretest scores have a significant, medium strength of association $(r(65)=.315, p=.011)$.

Pair \#5 Visual Posttest - Knowledge Posttest

According to Pearson's r Correlation test, the Visual Posttest scores and Knowledge

Posttest scores have a significant, medium strength of association $(r(65)=.419, p=$ $.001)$.

Pair \#6 Knowledge Pretest - Knowledge Posttest

According to Pearson's r Correlation test, the Knowledge Prettest scores and Knowledge Posttest scores have a non-significant, low strength of association $(r(65)=.152, p=$ $.225)$. 


\section{Table 19 Pearson's r Correlations}

Correlations for Knowledge Pretest, Knowledge Posttest, Visual Pretest, Visual Posttest

\begin{tabular}{|c|c|c|c|c|}
\hline & Visual Pre & Visual Post & Knowledge Pre & $\begin{array}{c}\text { Knowledge } \\
\text { Post }\end{array}$ \\
\hline Visual Pretest & & & & \\
\hline Pearson Correlation & 1 & $.731 * *$ & .200 & $.264 *$ \\
\hline Sig. (2-tailed) & & .000 & .110 & .034 \\
\hline
\end{tabular}

\begin{tabular}{lcccc}
\multicolumn{1}{c}{ Visual Posttest } & & & \\
Pearson Correlation & $.731^{*}$ & 1 & $.315^{*}$ & $.419^{*}$ \\
Sig. (2-tailed) & .000 & & .011 & .001
\end{tabular}

\begin{tabular}{lllll}
\multicolumn{1}{c}{ Knowledge Pretest } & & & & \\
\cline { 1 - 1 } Pearson Correlation & .200 & $.315^{*}$ & 1 & .152 \\
Sig. (2-tailed) & .110 & .011 & & .225
\end{tabular}

$\begin{array}{lllll}\text { Knowledge Posttest } & & & & \\ \text { Pearson Correlation } & .264 & .419^{*} & .152 & 1 \\ \text { Sig. (2-tailed) } & .034^{*} & .001 & .225\end{array}$

Note.

$* * \mathrm{p}<.01$,

$* \mathrm{p}<.05$ 


\section{CHAPTER 5: DISCUSSION}

Introduction

This chapter is divided into five sections which provide a summary of the findings and a discussion of the results, as well as the study's limitations and recommendations. The first section is a summary of the research problem, research questions, and findings of the study. The second section provides an examination of the findings and their implication in the practice and field of study. The third section will address the limitations and delimitations within the context of the study. The fourth section provides recommendations for future research. Lastly, the fifth section delivers the conclusion of the study as framed by the theoretical framework and the literature.

Summary of the Research Problem, Research Questions, and Findings

Multivariate Calculus is one of the first courses where students learn about the geometry of space, the calculus of many variables, and vector fields. It is a course where students' spatial visualization is further developed while contributing to their mathematical understanding. Learning with understanding promotes the creation of autonomous learners and makes subsequent learning easier (NCTM, 200). Tall (1991) proposed that gaps in understanding will not be addressed by making the concepts simpler, but rather more complicated while infusing visualizations and visual reasoning in the presentation of such concepts: "The idea is to appeal to the visual patterning power of the metaphorical right brain, in such a way that it lays down appropriate intuitions to service the logical deductivity of the left" (Tall, 1991, p. 112). Additionally, technology can be used to enhance visualizations with user-controlled dynamic pictures which can provide insights and perceptions of the concepts explored (Sheikh, 2015; Tall et al., 
2008). Furthermore, enhancing students' spatial visualization is critical because it contributes to the development of students' geometric thinking, which in turn contributes to their ability to represent, interpret, and solve problems and real-world situations (NCTM, 2000). A little over 10 year ago, Presmeg (2006) stated: "Effective pedagogy that can enhance the use and power of visualization in mathematics education is perhaps the most pressing research concern at this period" (p. 233). More recently, a similar sentiment has been echoed: "Given the increasing availability and use of technology, more research is needed on technology-enhanced techniques that aid with visualization and representations, and the conditions under which they are effective" (Sheikh, 2015, p. 174)

The purpose of the study was to investigate the effects of a visually-enhanced approach, facilitated by Maple, on students' performance on a multivariate calculus concepts test and a visualization test at a Hispanic Serving Institution. The study took place in five undergraduate classrooms of Multivariate Calculus chosen by convenience sampling. The research design followed a quasi-experimental design with non-equivalent groups where pretest and posttest data for each dependent variable was collected via validated, researcher-made instruments. Some demographic data was collected from the population via a survey. The population was split into two groups: experimental and control. Faculty in the experimental group consisted of two professors who had attained an MS and were familiar with Maple, while the three faculty in the control group had attained PhDs. Although the faculty in the experimental group did not have doctoral degrees like their counterparts in the control group, they were very enthusiastic in using 
technology as an aid to their instruction, and their familiarity with the software facilitated its use in the classroom.

Three research questions were posed by the researcher. First, to what extent does prerequisite knowledge, and a visually-enhanced approach to instruction facilitated by CAS affect college students' mathematical understanding of multivariate calculus concepts in an undergraduate Multivariate Calculus classroom setting at an HSI? Second, to what extent does prerequisite knowledge, and a visually-enhanced approach to instruction facilitated by CAS affect college students' spatial ability in an undergraduate Multivariate Calculus classroom setting at an HSI? Third, is there a significant relationship between college students' spatial ability and mathematical understanding of selected multivariate calculus concepts in an undergraduate Multivariate Calculus classroom setting at an HSI?

Research Question \#1.

To answer this question, a Repeated Measures, Two-Way, Mixed ANOVA was run with two independent, categorical variables (Treatment, Diagnostic Level) and one dependent variable (Knowledge) measured at two time points (before treatment and after treatment). The alternative hypothesis posited that there would be significant differences between the students' gain in understanding of selected multivariate calculus concepts as measured by the researcher-made knowledge assessment.

The results of the test indicated that students in the treatment group experienced statistically significant gains in understanding of selected multivariate calculus concepts versus students in the control group. The finding would suggest that intentionally 
enhancing the visual aspects of some multivariate calculus concepts leads to an improvement in students' understanding of said concepts. Improving student's understanding by enhancing the visual/geometric aspects of the concepts taught in multivariate calculus aligns with Duval's (2017) TRSR where mathematical understanding is understood as the synergy of two or more registers of semiotic representation, with geometric shapes/visualizations being elements of the geometric register. The intentional emphasis on the geometric register coupled with the traditionally emphasized algebraic register should provide the basis for students' improvement in understanding. Such an outcome is echoed in the results found by Cromley et al. (2017) and Shiekh (2015). Although the Cromley et al. (2017) study was conducted with participants who had some knowledge of differential calculus and not multivariate calculus which is the setting for the present study, they found that spatial skills and multiple representations were significant predictors of calculus proficiency as measured by some AP Calculus exam items. Furthermore, multiple representations were strongly correlated with spatial skills and conceptual knowledge as measured by the researchermade CCK test. Additionally, Shiekh's (2015) investigation in a multivariate calculus and dynamic systems course provided evidence of the complementing role visualizations play with analytical thinking to enhance students' understanding of multivariate calculus.

The results of the statistical test performed also indicated that students who scored higher (score $>=50$ ) in the Diagnostic Assessment experienced statistically significant gains when compared with those who scored lower (score $<50$ ). This finding echoes Sheikh's (2015) findings. It is a validation to the general understanding that students who enter a multivariate calculus course better prepared tend to do better than those who are 
under-prepared. However, the interaction effect between Treatment and Diagnostic was not statistically significant. This outcome would suggest that the differences observed in terms of understanding in students with high level diagnostic scores versus low level diagnostic scores in the experimental was also observed in students with high level diagnostic scores versus low level diagnostic scores in the control group.

The results of the statistical test performed also indicated that time was a significant within-subjects factor. The finding is not surprising, and it is congruent with our notion of schooling that students acquire knowledge over time, showing more understanding towards the end of a course than they could have shown at the beginning of the course.

The results from research question \#1 support the use of a visually-enhanced approach facilitated by CAS dynamic worksheets for the teaching and learning of selected multivariable calculus concepts in an undergraduate multivariate calculus course of an HSI.

Research Question \#2.

To answer the second question, a Repeated Measures, Two-Way, Mixed ANOVA was run with two independent, categorical variables (Treatment, Diagnostic Level) and one dependent variable (Spatial Ability) measured at two time points (before treatment and after treatment). The alternative hypothesis posited that there would be significantly positive differences between the students' gains in spatial ability as measured by Yoon's (2011) PSVT: R. The results showed that students who scored higher (score $>=50$ ) in the Diagnostic Assessment experienced statistically significant gains versus those who 
scored lower (score $<50$ ). The finding may seem intuitive. It is a validation to the general understanding that students who enter a multivariate calculus course better prepared tend to do better than those who are under-prepared.

The results of the statistical test performed also showed no statistically significant differences in students' gains in spatial ability in the treatment group versus students in the control group, indicating that the visually-enhanced approach produced no significantly different gains in terms of spatial ability compared to the traditional teaching. However, the statistical test performed showed a statistically significant interaction between time and treatment, and further tests confirmed a statistically significant difference in the spatial ability scores between the pretest and the posttest for students in the experimental group, and a marginally statistically significant difference for students in the control group but in the opposite direction suggesting a decline (see Table 17, page 76). The observed result from the experimental group would be desirable because treatment happened from the first time point to the second time point, therefore observing differences between students' spatial ability from the experimental group versus students from the control group as time changes from time point 1 to time point 2 is precisely the kind of outcome this study was expecting. Furthermore, it is a confirmation of an informal result from Shiekh's (2015) research study where, although no proper statistical test was used, there were statistically significant differences in students' achievement towards the end of the study (Test 3) that were not observed at earlier time points (Test 1 and Test 2). In the present study, the marginally statistically significant difference in the opposite direction between the pretest and the posttest for 
students in the control group suggests that without an intentional effort to enhance the visualizations of the multivariate calculus concepts, students' spatial ability may decline.

Additionally, the results of the statistical test indicated that the interaction between Treatment and Diagnostic produced no statistically significant differences in spatial ability. The finding would suggest that the differences observed in terms of spatial ability in students with high level diagnostic scores versus students with low level diagnostic scores in the experimental group was also observed between students with high level diagnostic scores versus students with low level diagnostic scores in the control group. The results of the statistical test also indicated no main effect of time on spatial ability suggesting that differences in students' visual posttest scores and visual pretest scores is not significant. There was also no interaction effect between time and diagnostic assessment. This finding would suggest that the differences observed in terms of spatial ability scores in the visual pretest between students with high level diagnostic scores versus students with low level diagnostic scores was also observed in the visual posttest between students with high level diagnostic scores versus low level diagnostic scores.

The results from research question \#2 supports the notion that the use of an intentional, visually-enhanced approach facilitated by CAS dynamic worksheets for the teaching and learning of selected multivariable calculus concepts has a positive effect on students' spatial ability as measured by Yoon's (2011) PVST: R. 
Research Question \#3.

To answer this question, a Pearson's Correlation Coefficient was calculated between the groups' knowledge score and spatial ability score before treatment (Knowledge Pretest - Visual Pretest) and after treatment (Knowledge Posttest - Visual Posttest). The alternative hypothesis posited that there would be a significant linear relationship between understanding of selected multivariate calculus concepts and spatial ability. The results of the statistical test showed a non-significant, positive, small strength of association between Knowledge Pretest and Visual Pretest, indicating that student's spatial ability varied across the different levels of their understanding when entering the Multivariate Calculus classroom. The result would not be surprising because visualizations in the space are not seen in previous math courses. It is precisely Multivariate Calculus one of the first courses where spatial visualizations are intentionally taught in relation to the concepts presented during the course.

The results of the statistical test also showed a significant, positive, medium strength of association between Knowledge Posttest and Visual Posttest, indicating that students who did better in the Visual Posttest assessment tended to do better in the Knowledge assessment. The finding is expected because of a students' completion of a multivariate calculus course should improve their understanding and spatial ability for the reasons explained above. With the already strong algebraic nature of the traditional teaching and learning of multivariate calculus concepts, the intentional development of visualizations and geometric thinking and the synergy of these two representations, should provide the basis for mathematical understanding, or as Duval (2017) dubbed it: "semiosis". 


\section{Implications}

The results of the present study support the hypothesis that mathematical understanding of selected multivariate calculus concepts can be improved through an intentional, visually-enhanced approach facilitated by CAS dynamic worksheets for the teaching and learning of said concepts. It provides empirical-based evidence that instruction of multivariate calculus that intentionally enhances the visual/geometric representations of some multivariate calculus concepts to complement the analytical and algebraic representations of said concepts can be beneficial to students' learning and understanding (Cohen \& Hegarty, 2012; Mendezabal \& Tindowen, 2018; Sheikh, 2015). Special attention must be paid to how the technology is integrated to benefit learning without creating an unintentional cognitive overload that may limit learning (Borchelt, 2004; Meagher, 2005; Sheikh, 2015).

Although students' spatial ability showed no statistically significant improvement based on treatment, the interaction effect of time and treatment had a significant impact on students' spatial ability. In particular, a statistically significant difference was found in the experimental group in terms of spatial ability from the pretest score to the posttest score versus no statistically significant differences between the pretest scores and the posttest scores in the control group. The result provides empirically-based evidence supporting the implication that if there is an intentional effort to enhance the visual/geometric representations in multivariate calculus, there could be a growth over time of students' spatial abilities and overall improvement in students' learning and understanding. The proposed suggestion is in line with the results found in other studies (McGee \& Martinez, 2014; McGee \& Moore-Ruso, 2015). Furthermore, there was 
evidence of positive, medium strength of association between visualization and knowledge in the undergraduate Multivariate Calculus classrooms of the HSI.

Multivariate Calculus is a course with strong visual and geometric components, and efforts should be made to enhance these components to foster and develop students' spatial ability and geometric thinking and create the synergy with other representations, such as the algebraic, required to understand concepts taught in the course. Technological advances, including but not limited, to CAS technologies have made it possible to circumvent the natural difficulties associated with visualizing 3D objects in the 2D board found in the typical college mathematics classroom. These newer technologies have the capability of enhancing the visual/geometric aspects of mathematics learning, and instructors should be aware of the possible benefits associated with such use. However, efforts must be made to ensure the proper use of technology in the multivariate calculus classroom. These efforts will require institutional support and professional development/training for faculty, particularly if institutional systematic change affecting the teaching and learning of all students is sought.

\section{Limitations and Delimitations}

\section{Limitations}

Limitations are potential weaknesses or constrains that affect a study which are mostly beyond the researcher's control (Simon \& Goes, 2013). Just like for any other study, the existing limitations in this investigation affected its design and results.

One limitation for the current study was the lack of peer-reviewed, valid and reliable instruments to measure pre-requisite knowledge and knowledge for multivariate 
calculus. As a result, the instruments were researcher-made and although there was an attempt by the researcher to guarantee validity (panel of experts) and reliability (testretest) of the instrument, it is possible the data obtained using the instrument did not efficiently measure the variables in question, diagnostic and knowledge.

Another limitation for the study was the sample size which was used to conduct the study. Several factors played a role in limiting the sample size. First, the number of multivariate calculus course sections available in any given semester is limited because of the specialized content nature of the course and the number of majors required to take it. Secondly, the study was carried out during one semester, thus limiting the number of participating course sections and therefore the number of students available for participation. Third, although the researcher made every attempt to describe the nature of the study, its importance, and the protection of the data and information collected from the participants, some students chose not to participate in the study. Fourth, for those students who chose to participate, absence and attrition played a key role in limiting the participants completion of the necessary assessments.

Another limitation for this study was the use of intact course sections and thus, the lack of random assignment to the experimental and control groups. As a result, causation cannot be claimed for this study. Therefore, the present research is a correlational study. Related to the issue of intact course sections and the limited availability of multivariate calculus course sections, another limitation for this study was the presence of different instructors for both the experimental and control groups. 
Another limitation for the current study might be the participants completion of the assessments in terms of effort and honesty. Although extra-credit points were offered for participation and effort, it may be possible that some participants did not provide their best and honest effort and answered in a random manner to complete the assessment as soon as possible.

Delimitations

"The delimitations of a study are those characteristics that arise from limitations in the scope of the study (defining the boundaries) and by the conscious exclusionary and inclusionary decisions made during the development of the study plan" (Simon \& Goes, 2013, p. 4). Delimitations are the boundaries and constraints imposed by the researcher on the study through conscious, and sometimes, unconscious decisions. Every study has delimitations and this one is no exception. Besides the researcher's decisions about research questions, variables, theoretical framework, and population, other delimitations have played a role in the results of the study.

One delimitation for the study was the choice of concepts selected to be measured by the mathematical understanding instrument. The concepts were chosen based on their geometrical implications and perceived importance of the visual component to its understanding as a mathematical object.

Another delimitation for the current study was the researcher's decision to include outliers in the analysis of the data. Outliers can skew the result of statistical tests, however, for this study, the researcher felt they were accurately representing the population faculty encounters in a multivariate calculus course. The variability of 
students' skills and knowledge in the classroom is not an "outlier" for the HIS where the study was conducted.

Another delimitation for the present study was the violation of some assumptions of the statistical tests used in the study and the researcher's decision to use the test nonetheless. A description of the statistical test assumptions, along with any violation and decision made about how to handle the violation, are fully described in Chapter 4.

\section{Recommendations for Future Research}

There are several recommendations proposed for future studies. One recommendation would be to create validity-tested and reliability-tested instruments to measure the pre-requisite knowledge students bring into the multivariate calculus course, and measure students' knowledge of the multivariate calculus concepts taught. The study can then be replicated to see if it yields the same results.

Another recommendation would be to increase the sample size, either by including more course sections and/or by running the study for at least one academic year, to improve some of the metrics and the internal validity of the different statistical tests performed in this study. Another recommendation would be to control for the instructor factor, either by having the same instructor teach all course sections in the study (might not be feasible) or by rotating the groups assigned to the participating instructors so that all of them have the chance of being part of the control and the experimental group. The last suggestion can be achieved if the same instructors teach the same course sections throughout the semesters. 
Another recommendation for future research would be to investigate whether there is a significant difference in students' gain in mathematical knowledge and spatial visualization in a group taught using dynamic visualizations versus a group taught using static visualizations.

Another recommendation would be to research the institutional support requirements, and faculty development/training required to support faculty wishing to incorporate a CAS to visually-enhance their current approach to the teaching of multivariate calculus.

\section{Conclusion}

The current research study contributed to the field of visualization in the teaching and learning of mathematics by providing empirical-based evidence of the important role that visualizations play in mathematical understanding. The results suggest that the intentional use of a visually-enhanced approach facilitated by CAS dynamic worksheets for the teaching of multivariate calculus is positively associated to better improvements in students' spatial ability and mathematical understanding when compared to a traditional approach. Although there are limitations in the study, its results ratify the findings made by other studies about the importance of visualization/geometry and its complementary, synergistic effect with algebra in the teaching and learning of calculus. 


\section{LIST OF REFERENCES}

Ary, D., Jacobs, L. C., Sorensen, C. K., Walker, D. A., \& Razavieh, A. (2010). Introduction to Research in Education. Wadsworth Cengage Learning. https://doi.org/10.1017/CBO9781107415324.004

Atiyah, M. (2001). Mathematics in the 20th Century. The American Mathematical Monthly, 108(7), 654-666. Retrieved from http://www.jstor.org/stable/2695275

Bagley, S. F. (2014). Improving Student Success in Calculus : A Comparison of Four College Calculus Classes.

Borchelt, N. A. (2004). Effects of a Computer Tool on Students' Cognitive Demand in Undergraduate Calculus.

Carden, J., \& Cline, T. (2015). Problem solving in mathematics: the significance of visualisation and related working memory. Educational Psychology in Practice, 31(3), 235-246. https://doi.org/10.1080/02667363.2015.1051660

Cohen, C. A., \& Hegarty, M. (2012). Inferring cross sections of 3D objects: A new spatial thinking test. Learning and Individual Differences, 22(6), 868-874. https://doi.org/10.1016/j.lindif.2012.05.007

Cromley, J. G., Booth, J. L., Wills, T. W., Chang, B. L., Tran, N., Madeja, M., ... Zahner, W. (2017). Relation of Spatial Skills to Calculus Proficiency: A Brief Report. Mathematical Thinking and Learning, 19(1), 55-68. https://doi.org/10.1080/10986065.2017.1258614

de la Villa, A., García, A., García, F., \& Rodríguez, G. (2017). The new technologies in mathematics: A personal history of 30 years. International Journal for Technology in Mathematics Education, 24(2), 67-74. https://doi.org/10.1564/tme_v24.2.03

Duval, R. (2006). A cognitive analysis of problems of comprehension in a learning of mathematics. Educational Studies in Mathematics.

Duval, R. (2017). Understanding the Mathematical Way of Thinking - The Registers of Semiotic Representation. Springer International Publishing.

Faul, F., Erdfelder, E., Lang, A.-G., \& Buchner, A. (2007). G*Power: A flexible statistical power analysis program for the social, behavioral, and biomedical sciences. Behavior Research Methods, 39(2), 175-191. https://doi.org/10.3758/BF03193146

Habre, S. (2001). Visualization enhanced by technology in the learning of multivariable calculus Reproduced with permission of the copyright owner . Further reproduction prohibited without permission. The International Journal of Computer Algebra in Mathematics Education, 8(2), 115-130. 
Habre, S. (2013). Dynamical mathematical software: Tools for learning and for research. In Enhancing Mathematics Understanding through Visualization: The Role of Dynamical Software (pp. 70-88). https://doi.org/10.4018/978-1-4666-4050-4.ch004

Hallet, D. H. (2000). Calculus at the Start of the New Millennium. Proceedings of the International Conference on Technology in Mathematics Education.

Heid, M. K. (1988). Resequencing Skills and Concepts in Applied Calculus Using the Computer as a Tool. Journal for Research in Mathematics Education, 19(1), 3-25.

Hitt, F. (2002). Representations and mathematics visualization. Proceedings of the 23rd Annual Meeting of the North American Chapter of the International Group for the Psychology of Mathematics Education. Volume 1-2.

July, R. A. (2001). Thinking in Three Dimensions: Exploring Students' Geometric Thinking and Spatial Ability With the Geometer'S Sketchpad.

Karakus, F., \& Aydin, B. (2017). The Effects of Computer Algebra System on Undergraduate Students' Spatial Visualization Skills in a Calculus Course. Malaysian Online Journal of Educational Technology, 5(3), 54-69. Retrieved from http://ezproxy.lib.uconn.edu/login?url=https://search.ebscohost.com/login.aspx?dire $\mathrm{ct}=$ true $\& \mathrm{db}=$ eric $\& \mathrm{AN}=\mathrm{EJ} 1150411 \&$ site $=$ ehost-live

Lavicza, Z. (2007). Factors influencing the integration of computer algebra systems into university-level mathematics education. International Journal for Technology in Mathematics Education, 14, 121-140.

Leopold, C., Gorska, R., \& Sorby, S. (2001). Experiences in Developing the Spatial Visualization Abilities. Journal for Geometry and Graphics, 5(1), 81-91. Retrieved from

http://www.academia.edu/download/42736990/International_experiences_in_develo ping_20160216-11099-13oeqy7.pdf

Marshall, N., Buteau, C., Jarvis, D. H., \& Lavicza, Z. (2012). Do mathematicians integrate computer algebra systems in university teaching? Comparing a literature review to an international survey study. Computers \& Education, 58(1), 423-434. https://doi.org/10.1016/j.compedu.2011.08.020

Martínez-Planell, R., Gaisman, M. T., \& McGee, D. (2015). On students' understanding of the differential calculus of functions of two variables. Journal of Mathematical Behavior, 38, 57-86. https://doi.org/10.1016/j.jmathb.2015.03.003

Martínez-Planell, R., Trigueros Gaismán, M., \& McGee, D. (2017). Students' understanding of the relation between tangent plane and directional derivatives of functions of two variables. Journal of Mathematical Behavior, 46, 13-41. https://doi.org/10.1016/j.jmathb.2017.02.001 
McGee, D. L., \& Martinez-Planell, R. (2014). a Study of Semiotic Registers in the Development of the Definite Integral of Functions of Two and Three Variables. International Journal of Science and Mathematics Education, 12(4), 883-916. https://doi.org/10.1007/s10763-013-9437-5

McGee, D. L., \& Moore-Russo, D. (2015). Impact of Explicit Presentation of Slopes in Three Dimensions on Students' Understanding of Derivatives in Multivariable Calculus. International Journal of Science and Mathematics Education, 13(January), 357-384. https://doi.org/10.1007/s10763-014-9542-0

Meagher, M. (2005). The processes of Learning in a Computer Algebra System (CAS) environment for College students learning Calculus. Retrieved from https://etd.ohiolink.edu/rws_etd/document/get/osu1124113975/inline

Mendezabal, M. J. N., \& Tindowen, D. J. C. (2018). Improving Students' Attitude, Conceptual Understanding and Procedural Skills in Differential Calculus Through Microsoft Mathematics. Journal of Technology and Science Education, 4(8), 385397.

Montiel, M., \& Wilhelmi, M. R. (2009). Using the onto-semiotic approach to identify and analyze mathematical meaning when transiting between different coordinate systems in a multivariate context, 139-160. https://doi.org/10.1007/s10649-009-9184-2

National Council Of Teachers Of Mathematics. (2000a). Principles and Standards for School Mathematics. National Council of Teachers of Mathematics.

National Council Of Teachers Of Mathematics. (2000b). Principles and Standards for School Mathematics. School Science and Mathematics, 47(8), 868-279. Retrieved from www.nctm.org

National Science Board. (2007). A national action plan for addressing the critical needs of the U.S. science, technology, engineering, and mathematics education system. National Science Board, 100. Retrieved from https://www.nsf.gov/pubs/2007/nsb07114/nsb07114.pdf

National Science Board. (2010). Preparing the Next Generation of STEM Innovators: Identifying and Developing our Nation's Human Capital. Chief Executive, 62. Retrieved from http://eric.ed.gov/?id=ED514061

National Science Board. (2018). Science \& engineering indicators 2018. Retrieved from https://www.nsf.gov/statistics/2018/nsb20181/

Newcomer, J. L., Raudebaugh, R. A., McKell, E. K., \& Kelley, D. S. (1999). Visualization, freehand drawing, solid modeling, and design in introductory engineering graphics. Proceedings - Frontiers in Education Conference, 2, 8-13. https://doi.org/10.1109/fie.1999.841659 
Palmiter, J. R. (1991). Effects of Computer Algebra Systems on Concept and Skill Acquisition in Calculus. Journal for Research in Mathematics Education, 22(2), 151-156.

Pea, R. (1987). Cognitive technologies for mathematics education. Cognitive Science and Mathematics Education, 89-122.

Presmeg, N. (2006). Research on Visualization in Learning and Teaching Mathematics. In Handbook of research on the psychology of mathematics education (pp. 205245).

Presmeg, N. C. (1986). Visualisation in High School Mathematics. For the Learning of Mathematics, 6(3), 42-46. https://doi.org/10.2307/40247826

Samuel, J. (2010). The Use Of Technology and Visualization in Calculus Instruction. https://doi.org/10.1017/CBO9781107415324.004

Shadish, W. R., Cook, T. D., \& Campbell, D. T. (2002). Experimental and QuasiExperimental Designs for Generalized Causal inference. Retrieved from https://moodle2.units.it/pluginfile.php/132646/mod_resource/content/1/Estratto_Sha dishCookCampbellExperimental2002.pdf

Sheikh, T. O. (2015). The role of Visualization in the Teaching and Learning of Multivariate Calculus and Systems of Ordinary Differential Equations, (November).

Simon, M. K., \& Goes, J. (2013). Assumptions, limitations, delimitations, and scope of the study. Dissertation Recipies, $1-4$.

Snyder, K. (2006). Students' emerging understanding of the command-driven computer algebra system Maple in a semester calculus course, 318.

Tall, D. (1991). Intuition and rigour : the role of visualization in the calculus. Visualization in Teaching and Learning Mathematics, (19), 105-119.

Tall, D., Smith, D., \& Piez, C. (2008). Technology and calculus. In Research on Technology and the Teaching and Learning of Mathematics: Volume 1. Research Syntheses (Vol. 1, pp. 207-258). Retrieved from http://books.google.com/books?hl=en\&lr=\&id=RGqFJ9inaQQC\&oi=fnd\&pg=PA20 $7 \& \mathrm{dq}=$ david + tall + technology + and + calculus\&ots $=y s E 7 i E f y H k \&$ sig $=\mathrm{dCyB} 9$ evgtoT0 dAfPFaPfAOy11vU\%5Cnhttp://books.google.com/books?hl=en\&lr=\&id=RGqFJ9in aQQC\&oi=fnd\&pg=PA207\&dq=david + tall + technolog

Thomas, M. \& Hong, Y. (2004). Integrating CAS Calculators into Mathematics Learning: Partnership Issues. Proceedings of the 28th Conference on the International Group for the Psychology of Mathematics, 4, 297-304. Retrieved from http://files.eric.ed.gov/fulltext/ED489655.pdf 
Wai, J., Lubinski, D., \& Benbow, C. P. (2009). Spatial Ability for STEM Domains: Aligning Over 50 Years of Cumulative Psychological Knowledge Solidifies Its Importance. Journal of Educational Psychology, 101(4), 817-835. https://doi.org/10.1037/a0016127

White, J. J. (2003). Using Technology to Facilitate Visualization in Multivariable Calculus.

Yoon, S. Y. (2011). Psychometric Properties of the Revised Purdue Spatial Visualization Tests: Visualization of Rotations.

Zazkis, D. (2013). Fostering Students' Understanding of the Connection Between Function and Derivative: A Dynamic Geometry Approach. In Conference for Research in Undergraduate Mathematics Education.

Zotos, K. (2007). Performance comparison of Maple and Mathematica. Applied Mathematics and Computation, 188(2), 1426-1429. https://doi.org/10.1016/j.amc.2006.11.008 
APPENDICES 


\section{Course Competencies:}

\section{Course Competencies:}

\section{Competency 1: $\quad$ The Student will demonstrate knowledge of three-dimensional vectors and surfaces by}

a. computing sums, differences, scalar multiples, and magnitudes of three-dimensional vectors

b. computing dot products and cross products of threedimensional vectors

c. solving applied problems using dot and cross products

d. determining equations of lines and planes in three dimensions

e. determining equations of quadric surfaces

f. representing points and surfaces in cylindrical and spherical coordinates

\section{Competency 2: $\quad$ The Student will demonstrate knowledge of curves in space by}
a. representing curves as vector-valued functions
b. representing curves parametrically
c. representing curves as intersections of two surfaces
d. computing limits, derivatives and integrals of vector-valued functions
e. computing the velocity and the acceleration of a particle moving along a curve in three-space

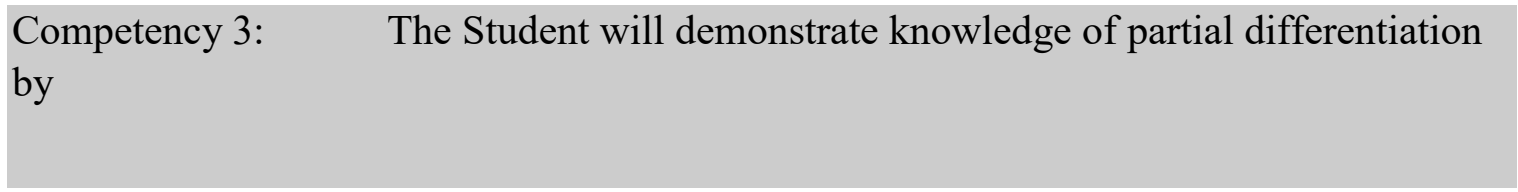

a. computing partial derivatives of any order of functions of two or more variables

b. applying appropriate chain rules to compute partial derivatives and total derivatives

c. computing gradients of functions of two or more variables 

d. computing directional derivatives of functions of two or more variables
e. determining the direction in which the directional derivative of a function at a point is maximized or minimized
f. determining equations of tangent planes and normal lines to a surface at a given point of the surface
g. finding extrema of functions of two or more variables

\section{Competency 4: $\quad$ The Student will demonstrate knowledge of multiple integration by}

a. evaluating double and iterated integrals in rectangular and polar coordinates

b. solving applied problems involving double integrals

c. evaluating triple and iterated integrals in rectangular, cylindrical, and spherical coordinates

d. solving applied problems involving triple integrals

\section{Competency 5: $\quad$ The Student will demonstrate knowledge of vector calculus by}
a. computing the divergence and curl of a vector field
b. determining the potential function of a conservative vector field
c. computing line integrals over oriented curves
d. solving applied problems involving line integrals
e. determining whether a line integral is independent of path
f. evaluating line integrals using Green's Theorem
g. evaluating surface integrals 
APPENDIX B

ADULT CONSENT TO PARTICIPATE IN A RESEARCH STUDY

\begin{abstract}
A VISUALLY-ENHANCED APPROACH TO TEACHING MULTIVARIABLE CALCULUS FACILITATED BY A COMPUTER ALGEBRA SYSTEM
\end{abstract}

\title{
PURPOSE OF THE STUDY
}

You are being asked to be in a research study. The purpose of this study is to investigate whether a visually-enhanced approach to the teaching of selected multivariable calculus (MAC2313) concepts improves students' spatial ability and mathematical understanding.

\section{NUMBER OF STUDY PARTICIPANTS}

If you decide to be in this study, you will be one of 100 people in this research study.

\section{DURATION OF THE STUDY}

This study will last for the entire semester and will require no more than 175 minutes of your time in the following manner:

1. In the ninth week of class you will need to complete a demographic survey (no more than 5 minutes), the Spatial Visualization Pretest (no more 30 minutes), Prerequisite Knowledge Test (no more than 50 minutes), and Mathematical Understanding Pretest (no more than 30 minutes).

2. In the last week of classes you will need to complete the Spatial Visualization Posttest (no more than 30 minutes), and Mathematical Understanding Posttest (no more than 30 minutes).

You will receive extra credit for completing the assessments. If you choose not to participate in the study, alternative assignments requiring the same amount of work and the same content will be provided to you to earn the same extra credit.

\section{PROCEDURES}

If you agree to be in the study, we will ask you to do the following things:

1. In the ninth week of class you will need to complete the Spatial Visualization Pretest, the Prerequisite Knowledge Test, and the Mathematical Understanding 
Pretest

2. In the last week of class you will need to complete the Spatial Visualization Posttest and the Mathematical Understanding Posttest.

\section{RISKS AND/OR DISCOMFORTS}

There are no foreseeable risks or unique discomforts to you for participating in this study.

\section{BENEFITS}

The following benefits may be associated with your participation in this study:

1. Add to the literature and the body of knowledge about students' visualization and mathematical understanding in multivariable calculus at a 2-year institution of higher education (IHE).

2. Provide evidence for institutions when making decisions regarding the use of a computer algebra system (Maple) to enhance the teaching and learning of selected multivariable calculus concepts.

\section{ALTERNATIVES}

There are no known alternatives available to you other than not taking part in this study. However, any significant new findings developed during the course of the research which may relate to your willingness to continue participation will be provided to you.

\section{CONFIDENTIALITY}

The records of this study will be kept private and will be protected to the fullest extent provided by law. In any sort of report we might publish, we will not include any information that will make it possible to identify a subject. Research records will be stored securely and only the researcher will have access to the records. However, your records may be reviewed for audit purposes by authorized University or other agents who will be bound by the same provisions of confidentiality.

\section{COMPENSATION \& COSTS}

There are no compensations associated with this study. You will not be responsible for any costs to participate in this study.

\section{RIGHT TO DECLINE OR WITHDRAW}

Your participation in this study is voluntary. You are free to participate in the study or withdraw your consent at any time during the study. Your withdrawal or lack of 
participation will not affect any benefits to which you are otherwise entitled. The investigator reserves the right to remove you without your consent at such time that they feel it is in the best interest.

\section{RESEARCHER CONTACT INFORMATION}

If you have any questions about the purpose, procedures, or any other issues relating to this research study you may contact Belarmino Gonzalez by phone (305) 237-6216 or via e-mail bgonzal7@mdc.edu. You may also contact Dr. Maria L Fernandez by phone (305) 237-6216.

\section{IRB CONTACT INFORMATION}

If you would like to talk with someone about your rights of being a subject in this research study or about ethical issues with this research study, you may contact the FIU Office of Research Integrity by phone at 305-348-2494 or by email at ori@fiu.edu.

\section{PARTICIPANT AGREEMENT}

I have read the information in this consent form and agree to participate in this study. I have had a chance to ask any questions I have about this study, and they have been answered for me. I understand that I will be given a copy of this form for my records.

Signature of Participant

Date

Printed Name of Participant

Signature of Person Obtaining Consent

Date 


\section{APPENDIX C}

Thomas's Calculus Early Transcendentals $14^{\text {th }}$ Edition

Relevant chapter contents and marked sections $\left({ }^{*}\right)$ with proposed enhanced visualization.

Chapter 12 Vectors and the Geometry of Space

1. Three-Dimensional Coordinate Systems

2. Vectors

3. The Dot Product

4. The Cross Product

5. Lines and Planes in Space

6. Cylinders and Quadric Surfaces

Chapter 13 Vector-Valued Functions and Motion in Space

1. Curves in Space and Their Tangents

2. Integrals of Vector-Valued Functions; Projectile Motion

3. Arc Length in Space

4. Curvature and Normal Vectors of a Curve

5. Tangential and Normal Components of Acceleration

6. Velocity and Acceleration in Polar Coordinates

Chapter 14 Partial Derivatives

1. Functions of Several Variables $\left(^{*}\right)$

2. Limits and Continuity in Higher Dimensions

3. Partial Derivatives $(*)$ 
4. The Chain Rule

5. Directional Derivatives and Gradient Vectors (*)

6. $\quad$ Tangent Planes and Differentials (*)

7. Extreme Values and Saddle Points (*)

8. Lagrange Multipliers

Chapter 15 Multiple Integrals

1. Double and Iterated Integrals over Rectangles (*)

2. Double Integrals over General Regions (*)

3. Area by Double Integration $(*)$

4. Double Integrals in Polar Form

5. Triple Integrals in Rectangular Coordinates (*)

6. Moments and Center of Mass

7. Triple Integrals in Cylindrical and Spherical Coordinates (*)

Chapter 16 Integrals and Vector Fields

1. Line Integrals

2. Vector Fields and Line Integrals

3. Path Independence, Conservative Fields, and Potential Functions

4. Green's Theorem in the Plane

5. Surface Integrals

6. Stokes' Theorem 


\section{APPENDIX D}

Experimental and Control Group: Spring 2019

\begin{tabular}{|c|c|}
\hline Week 1 & Students' Entry Point, \\
\hline Week 1 - Week 4. & $\begin{array}{l}\text { Vectors and the Geometry of Space, } \\
\text { Vector-Valued Functions and Motion in Space }\end{array}$ \\
\hline Week 5 -Week 8 & $\begin{array}{l}\text { Prerequisite Knowledge Test, } \\
\text { Spatial Visualization Pretest, Mathematical Understanding Pretest } \\
\text { Partial Derivatives }\end{array}$ \\
\hline $\begin{array}{c}\text { Week } 9-\text { Week } \\
12 .\end{array}$ & $\begin{array}{l}\text { Partial Derivatives } \\
\text { Multiple Integrals }\end{array}$ \\
\hline $\begin{array}{c}\text { Week } 13-\text { Week } \\
16\end{array}$ & $\begin{array}{l}\text { Multiple Integrals } \\
\text { Integrals and Vector Fields }\end{array}$ \\
\hline Week 16 & $\begin{array}{l}\text { Spatial Visualization Posttest, } \\
\text { Mathematical Understanding Posttest } \\
\text { Students' Exit Point }\end{array}$ \\
\hline
\end{tabular}




\section{APPENDIX E}

From: So Yoon Yoon soyoon@tamu.edu

Sent: Tuesday, October 9, 2018 3:07 PM

To: $\quad$ Gonzalez, Belarmino (InterAmerican)

Subject: RE: About the Revised Purdue Spatial Visualization Test: Visualization of Rotations (Revised PSVT:R)

Attachments: Yoon2011.Revised PSVT-R+AswrSheet.V4.pdf; Yoon2011.Revised PSVT-R.DemographicSurvey for Undergraduate Students.doc

Dear Professor Belarmino Gonzalez,

I appreciate the introduction about the research project. Now, I understand the need of the Revised PSVT:R for your research.

Attached is the final version of the Revised PSVT:R with the answer key. You can also create an online version of the Revised PSVT:R using this paper-and-pencil based version. Based on the three-parameter IRT modeling, the 30 items were ordered from the easiest to hardest, so please do NOT consider any modification or altering of the Revised PSVT:R in your project to warrant its' validity and reliability evidence.

The use of the Revised PSVT:R is limited to the intended project as you informed to me. Please do not distribute the test to others and keep the copies of the test strictly confidential after your administration of the test. This is for the integrity of future projects by other researchers.

If you agree on the condition for the use of the Revised PSVT:R, then reply back to me.

Here is the citation for the instrument.

Yoon, S. Y. (2011). Revised Purdue Spatial Visualization Test: Visualization of Rotations

(Revised PSVT:R) [Psychometric Instrument]. 


\section{APPENDIX F}

Treatment

\section{Case Processing Summary}

\begin{tabular}{|c|c|c|c|c|c|c|c|c|}
\hline & \multirow[b]{3}{*}{ Treatment } & \multicolumn{7}{|c|}{ Cases } \\
\hline & & \multicolumn{2}{|c|}{ Valid } & \multicolumn{3}{|c|}{ Missing } & \multicolumn{2}{|c|}{ Total } \\
\hline & & $\mathrm{N}$ & Percent & $\mathrm{N}$ & & Percent & $\mathrm{N}$ & Percent \\
\hline \multirow[t]{2}{*}{ Diagnostic } & Control & 39 & $100.0 \%$ & & 0 & $.0 \%$ & 39 & $100.0 \%$ \\
\hline & Experimental & 26 & $100.0 \%$ & & 0 & $.0 \%$ & 26 & $100.0 \%$ \\
\hline
\end{tabular}

Tests of Normality

\begin{tabular}{lllllllll}
\hline \hline & \multicolumn{3}{c}{ Kolmogorov-Smirnov $^{\mathrm{a}}$} & \multicolumn{3}{c}{ Shapiro-Wilk } \\
\cline { 3 - 8 } & Treatment & Statistic & $\mathrm{df}$ & Sig. & Statistic & $\mathrm{df}$ & \multicolumn{1}{c}{ Sig. } \\
\hline Diagnostic & Control & .085 & 39 & $.200^{*}$ & .959 & 39 & .171 \\
& & & & & & & & \\
& Experimental & .119 & 26 & $.200^{*}$ & .956 & 26 & .317 \\
\hline \hline
\end{tabular}

a. Lilliefors Significance Correction

*. This is a lower bound of the true significance. 


\section{Descriptives}

\begin{tabular}{|c|c|c|c|c|c|}
\hline & Treatment & & & Statistic & Std. Error \\
\hline \multirow[t]{26}{*}{ Diagnostic } & Control & & Mean & 48.2692 & 2.97900 \\
\hline & & 95\% Confidence & Lower Bound & 42.2386 & \\
\hline & & Interval for Mean & Upper Bound & 54.2999 & \\
\hline & & & $\begin{array}{l}5 \% \text { Trimmed } \\
\text { Mean }\end{array}$ & 47.3718 & \\
\hline & & & Median & 45.0000 & \\
\hline & & & Variance & 346.103 & \\
\hline & & & Std. Deviation & 18.60385 & \\
\hline & & & Minimum & 20.00 & \\
\hline & & & Maximum & 100.00 & \\
\hline & & & Range & 80.00 & \\
\hline & & & $\begin{array}{l}\text { Interquartile } \\
\text { Range }\end{array}$ & 25.00 & \\
\hline & & & Skewness & .652 & .378 \\
\hline & & & Kurtosis & .478 & .741 \\
\hline & Experimental & & Mean & 50.9615 & 3.86074 \\
\hline & & 95\% Confidence & Lower Bound & 43.0102 & \\
\hline & & Interval for Mean & Upper Bound & 58.9129 & \\
\hline & & & $\begin{array}{l}5 \% \text { Trimmed } \\
\text { Mean }\end{array}$ & 51.6453 & \\
\hline & & & Median & 47.5000 & \\
\hline & & & Variance & 387.538 & \\
\hline & & & Std. Deviation & 19.68600 & \\
\hline & & & Minimum & 5.00 & \\
\hline & & & Maximum & 80.00 & \\
\hline & & & Range & 75.00 & \\
\hline & & & $\begin{array}{l}\text { Interquartile } \\
\text { Range }\end{array}$ & 28.75 & \\
\hline & & & Skewness & -.193 & .456 \\
\hline & & & Kurtosis & -.365 & .887 \\
\hline
\end{tabular}




\section{Diagnostic}

\section{Histograms}

\section{Histogram}

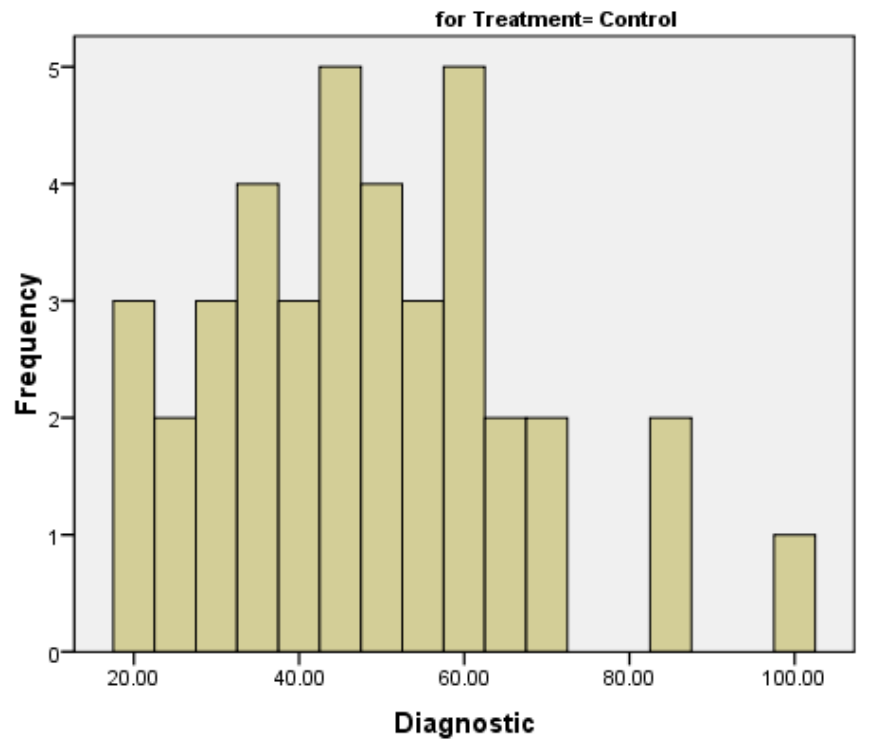

$\begin{aligned} \text { Mean } & =48.27 \\ \text { Std } \text { Dev } & =18.604\end{aligned}$

$\mathrm{N}=39$

Histogram

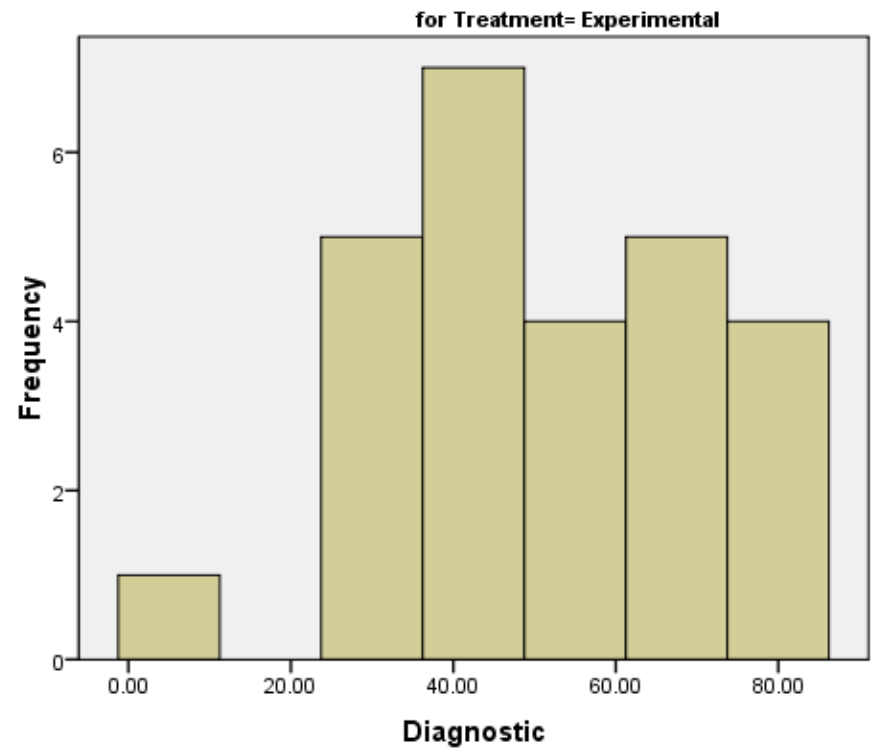

Mean $=50.96$

Std. Dev. $=19.686$
$N=26$

$N=26$ 


\section{Boxplot}

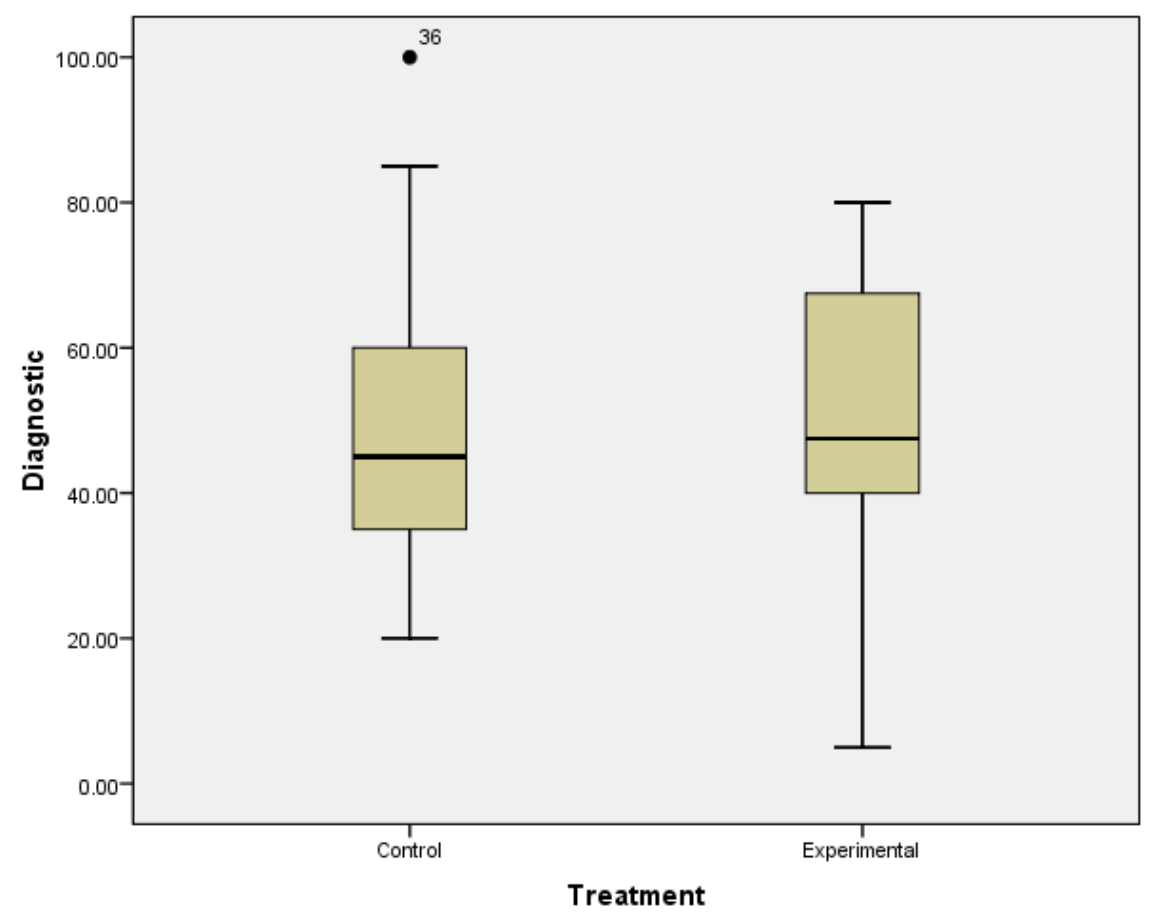

Treatment * HighLow Crosstabulation

Count

\begin{tabular}{|c|c|c|c|c|c|}
\hline & & \multicolumn{3}{|c|}{ HighLow } & \multirow[b]{3}{*}{ Total } \\
\hline & & \multicolumn{3}{|c|}{ Low(Diagnostic < High (Diagnostic } & \\
\hline & & $50)$ & $>=50)$ & & \\
\hline Treatment & Control & 20 & & 19 & 39 \\
\hline & Experimental & 13 & & 13 & 26 \\
\hline Total & & 33 & & 32 & 65 \\
\hline
\end{tabular}


APPENDIX G

\section{The Cartesian Coordinate System (Normal View)}

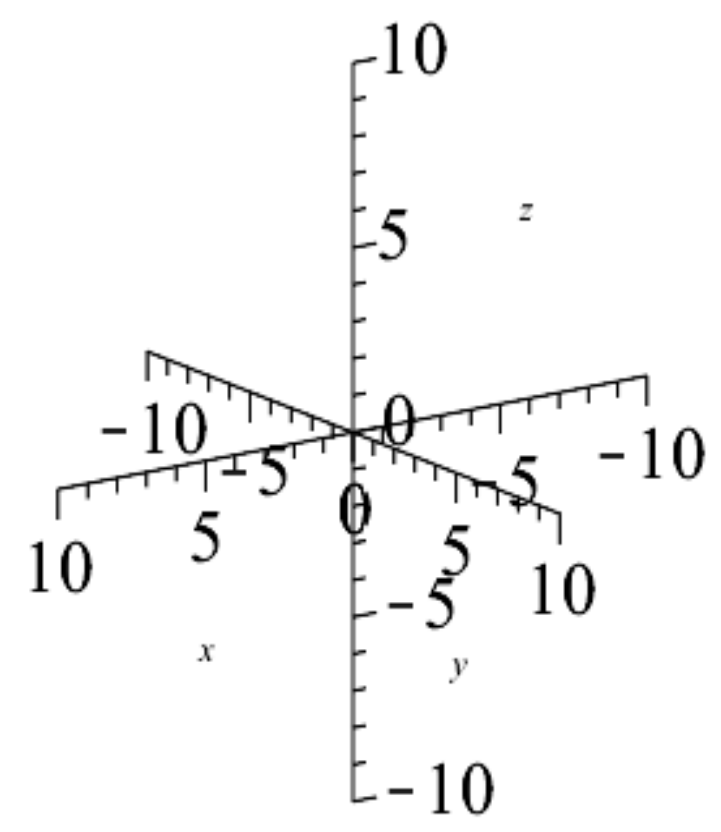

$-10 \leq \mathrm{x} \leq 10,-10 \leq \mathrm{y} \leq 10,-10 \leq \mathrm{z} \leq 10$ 


\section{The Cartesian Coordinate System (Normal View)}

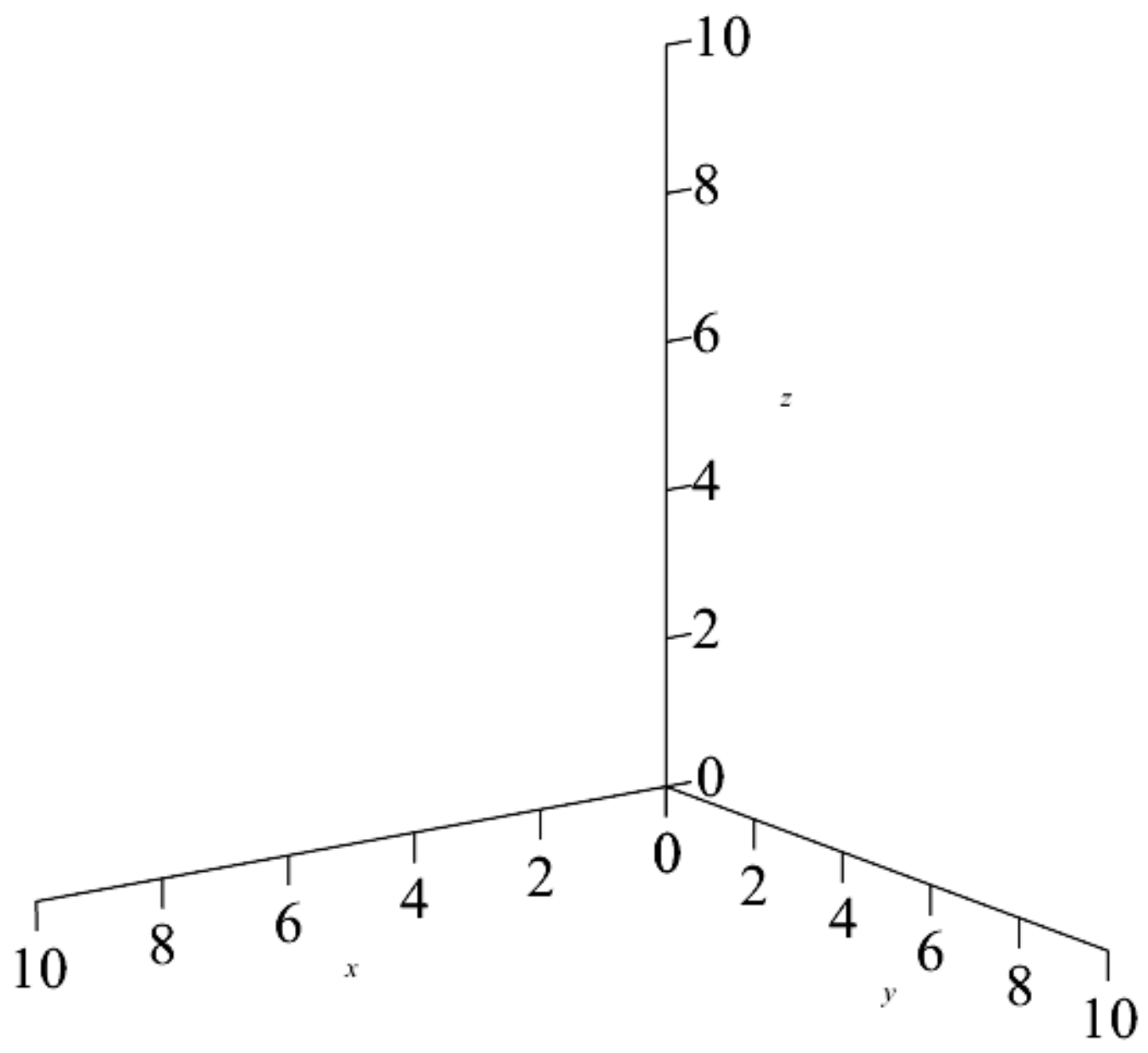

$$
0 \leq \mathrm{x} \leq 10,0 \leq \mathrm{y} \leq 10,0 \leq \mathrm{z} \leq 10
$$




\section{The Cartesian Coordinate System (Framed View)}

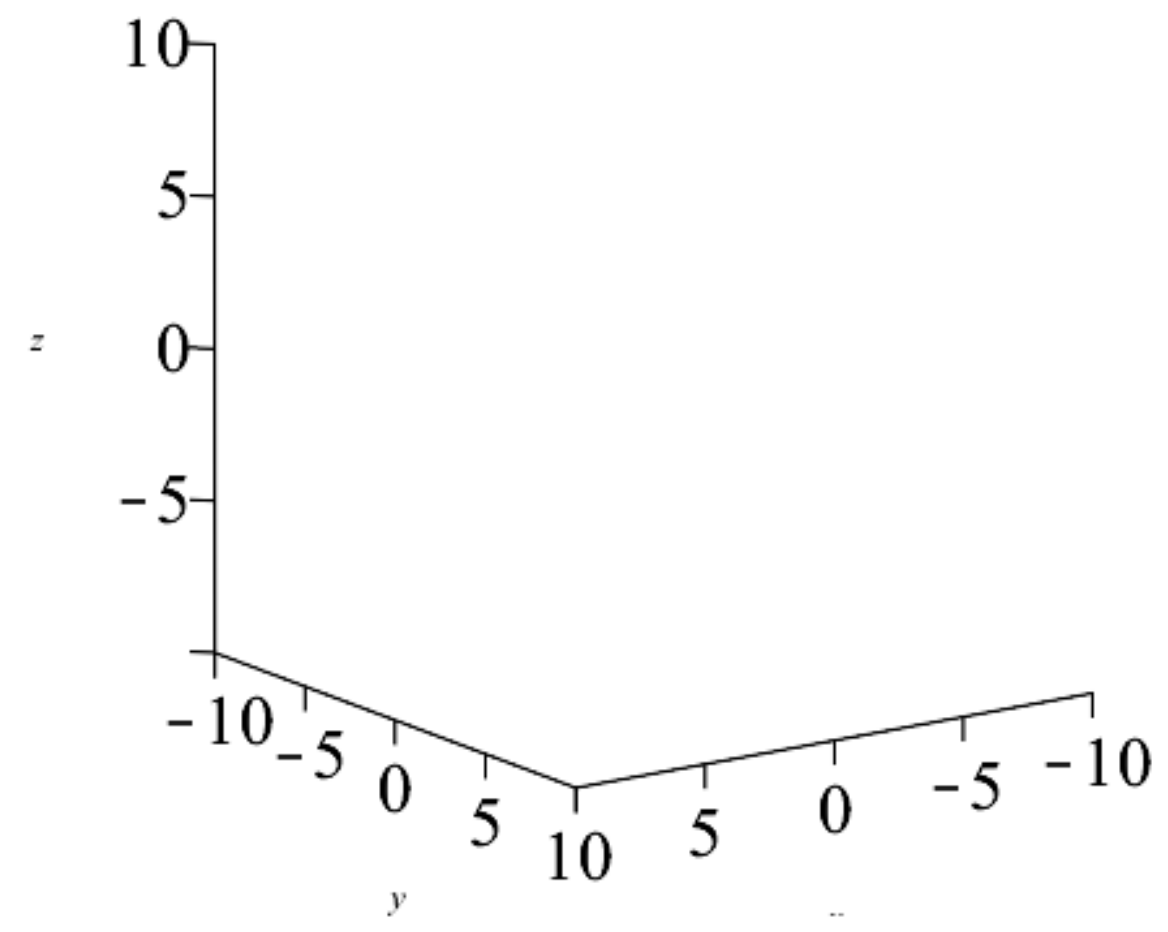




$$
t=10.000
$$

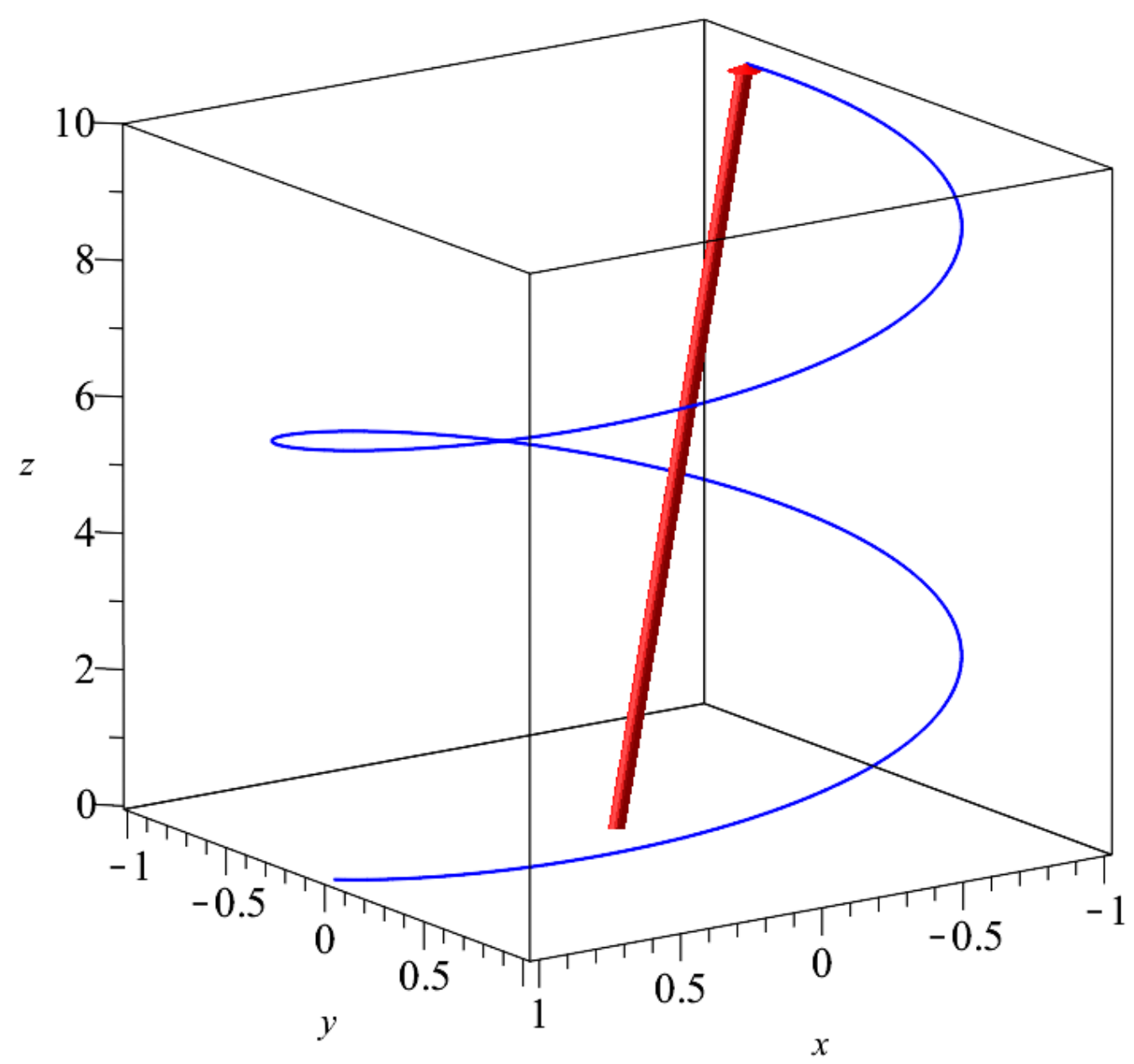




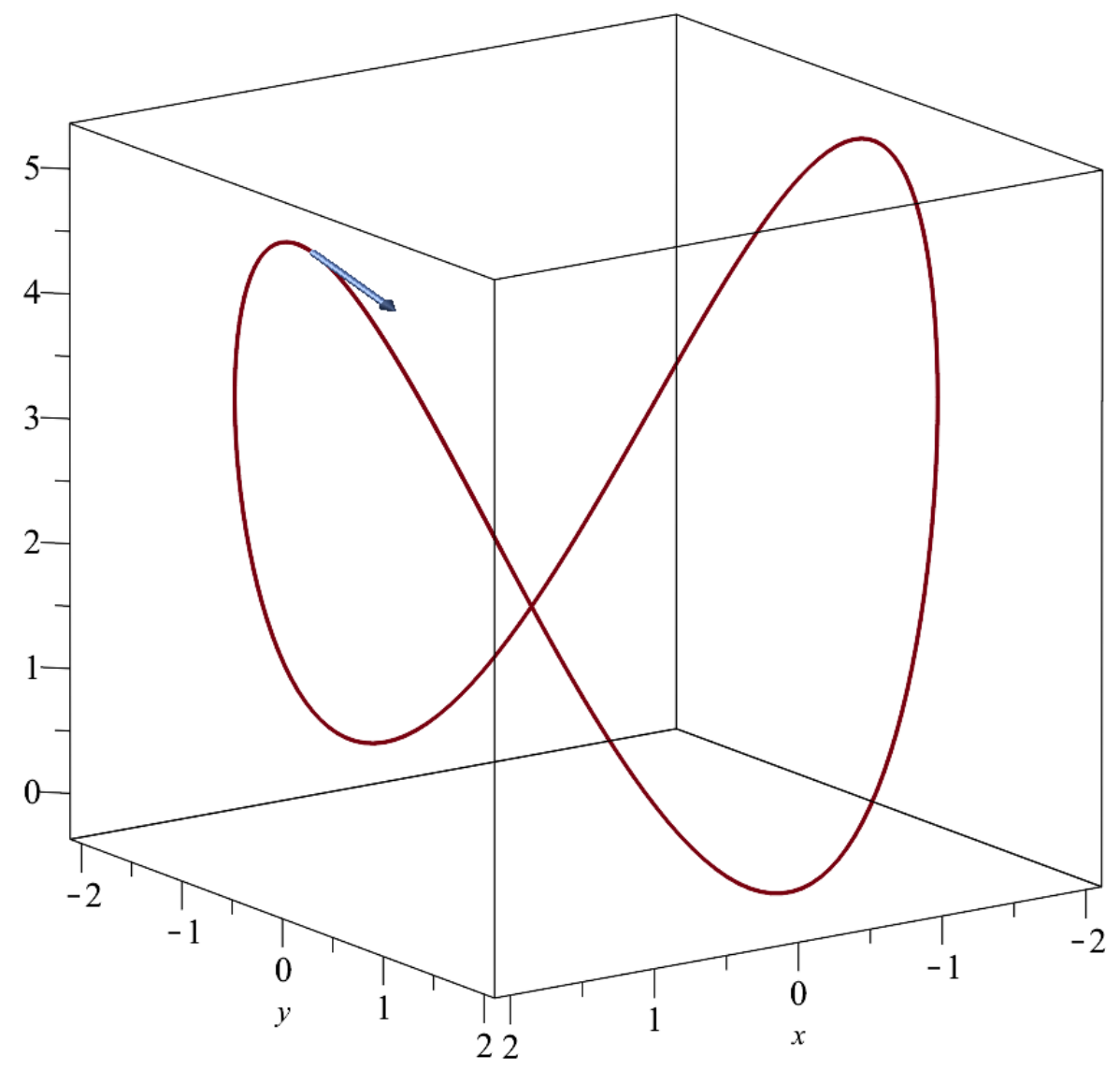

Animation of the tangent vector along the curve defined by the given vector 


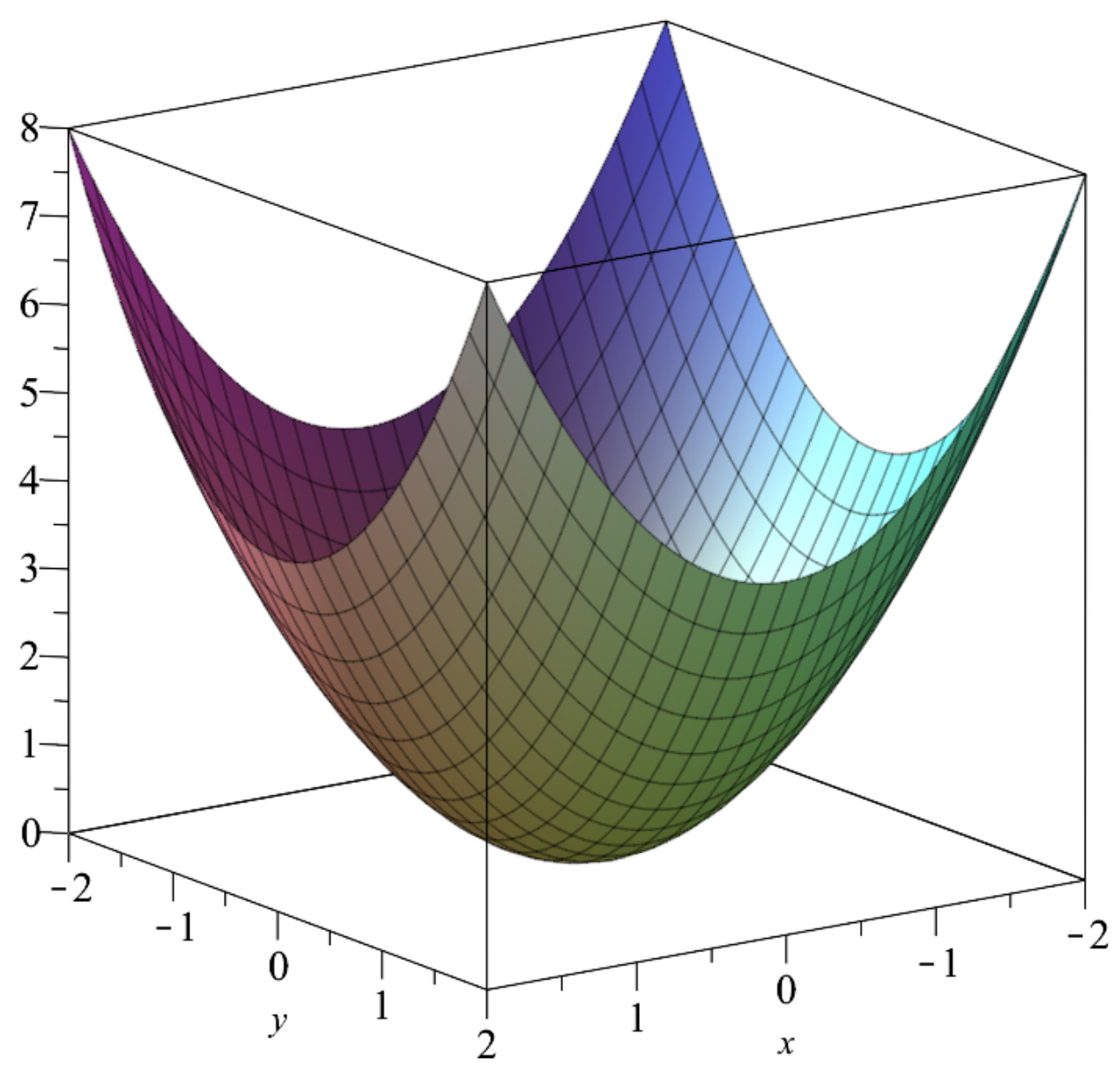




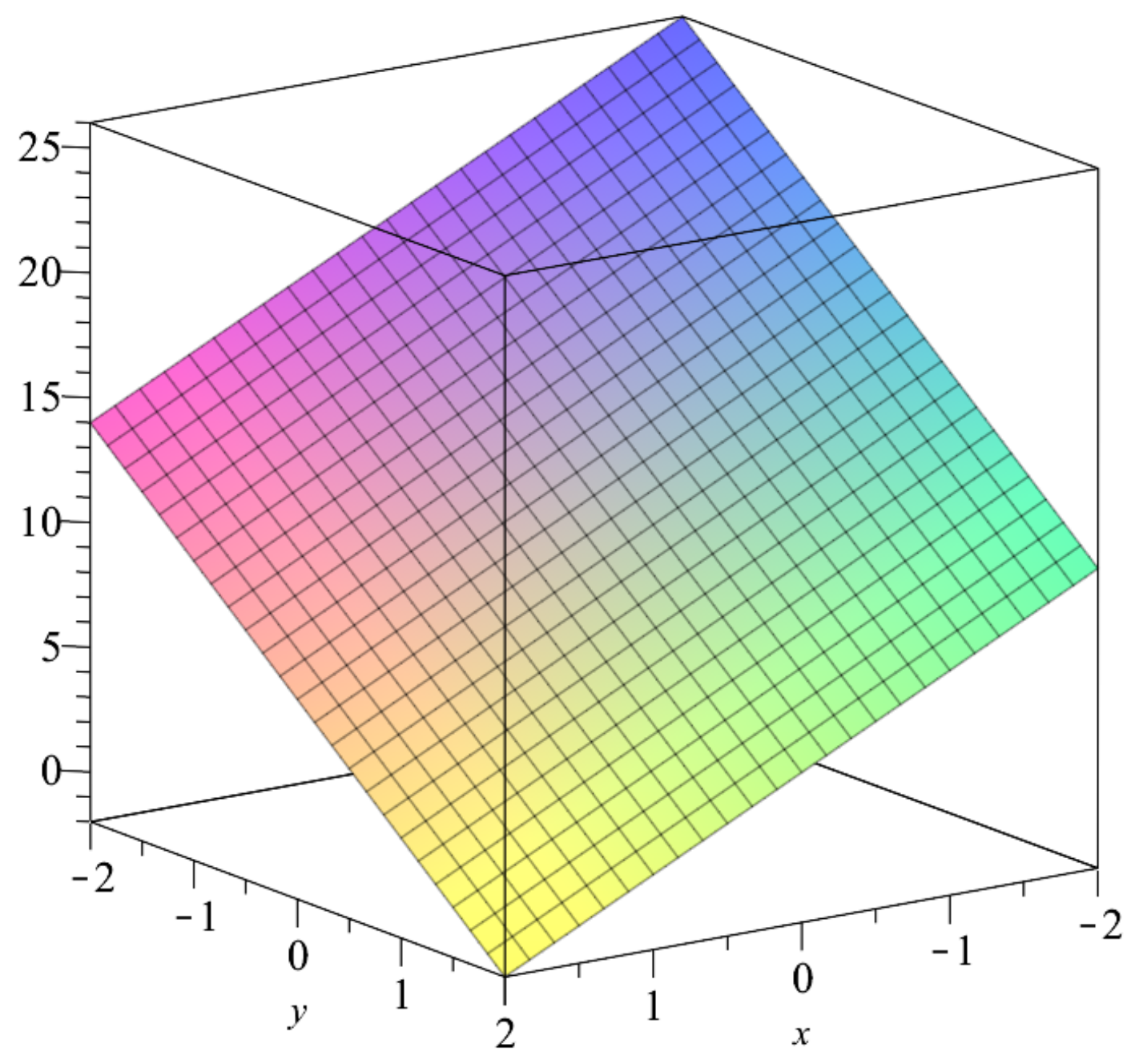




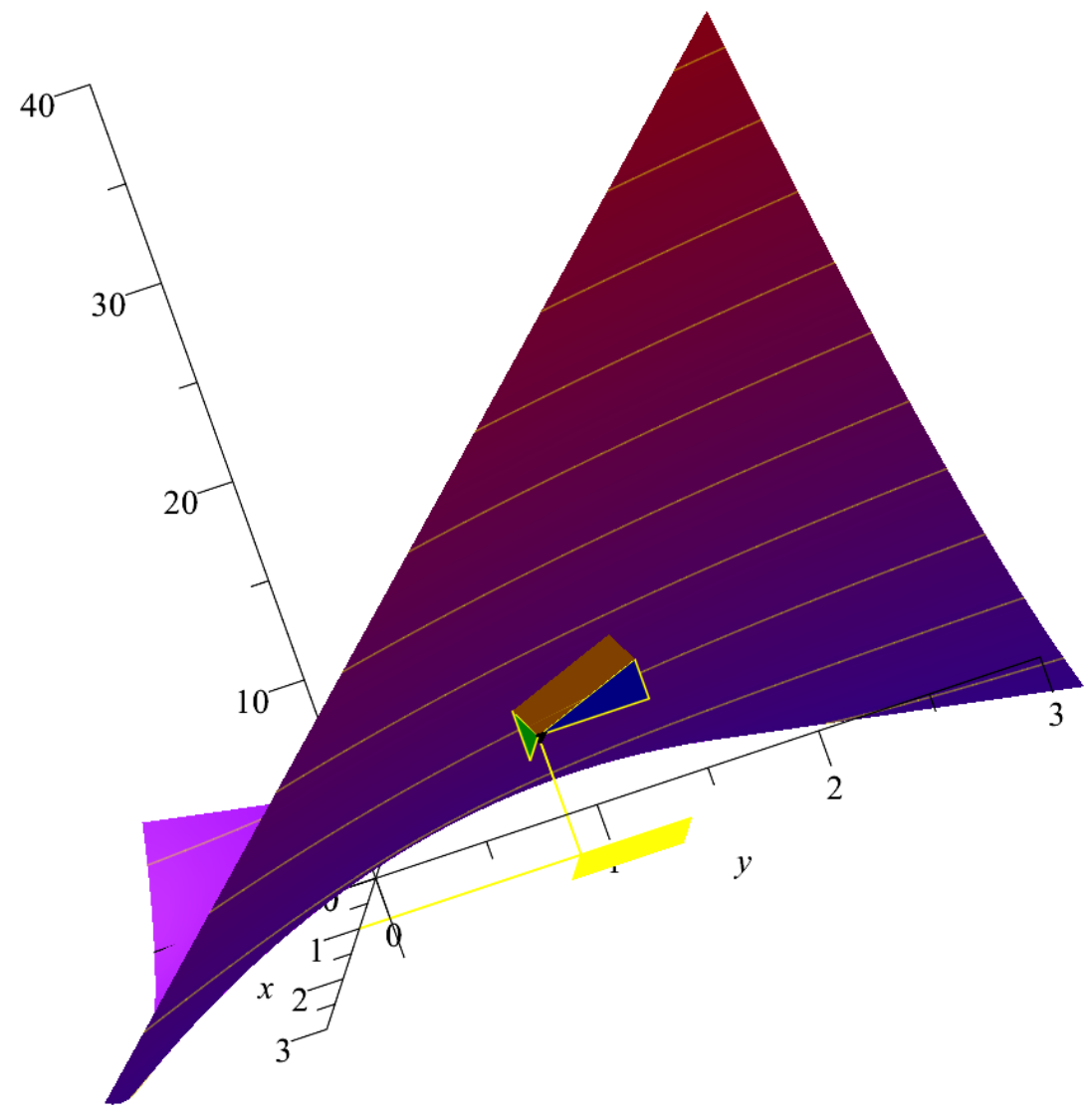

The green traingle represents the partial with respect to $\mathrm{x}$, and its hypotenuse is the tangent line to the plane $\mathrm{y}=\mathrm{b}$. The blue triangle represents the partial with respect to $y$, and its hypotenuse is a tangent line in the plane $\mathrm{x}=\mathrm{a}$. The orange quadrilateral represents the tangent plane at $(a, b)$.

The yellow square in the xy-plane is the projection of the tangent plane on the xy-plane. 


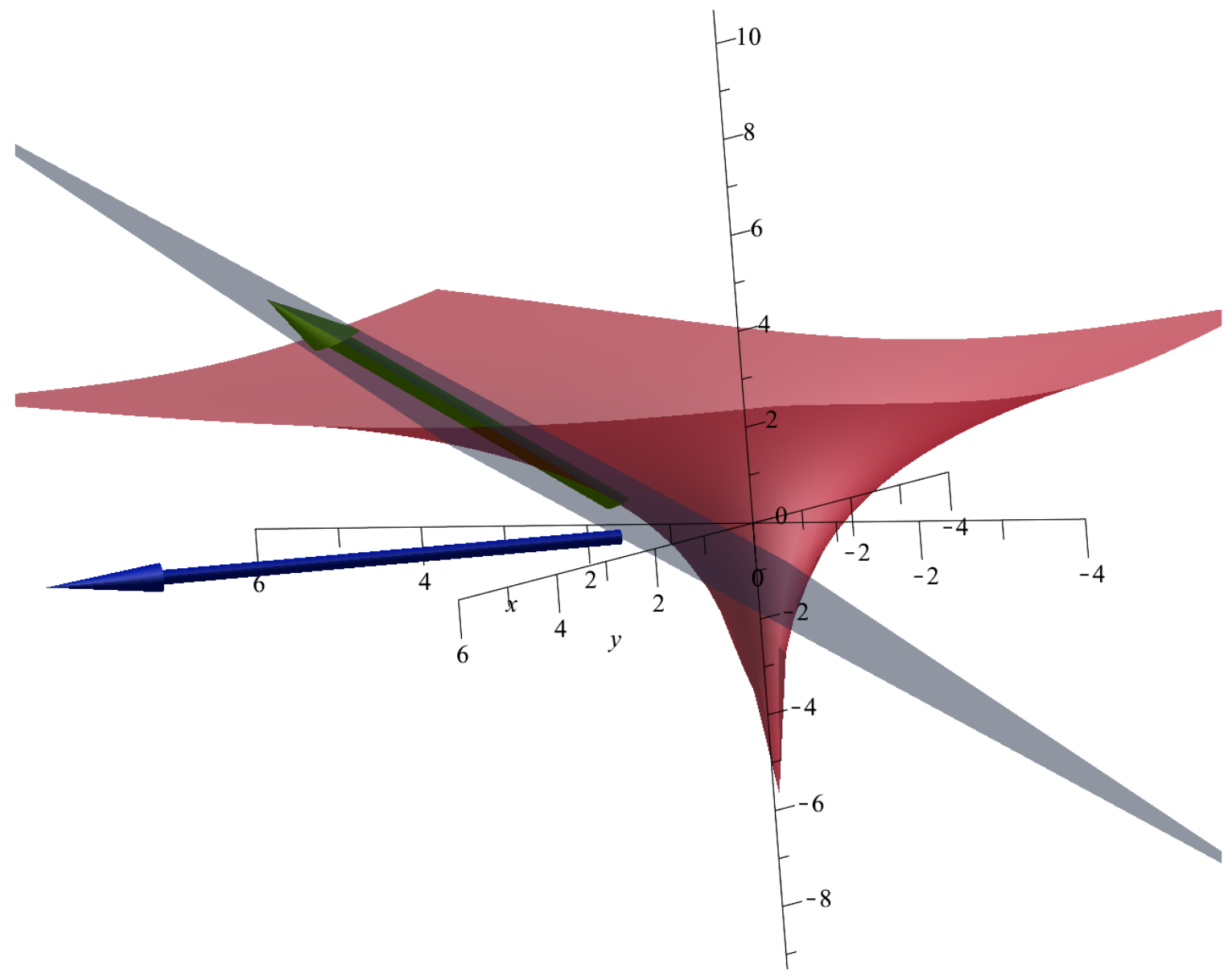

At $(x, y)=(1,1)$, the directional derivative of $f(x, y)=\ln \left(x^{2}+y^{2}\right)$, computed in the direction $\frac{4}{5} i+\frac{3}{5} j$. The direction vector is projected onto the tangent plane at the evaluation point. 


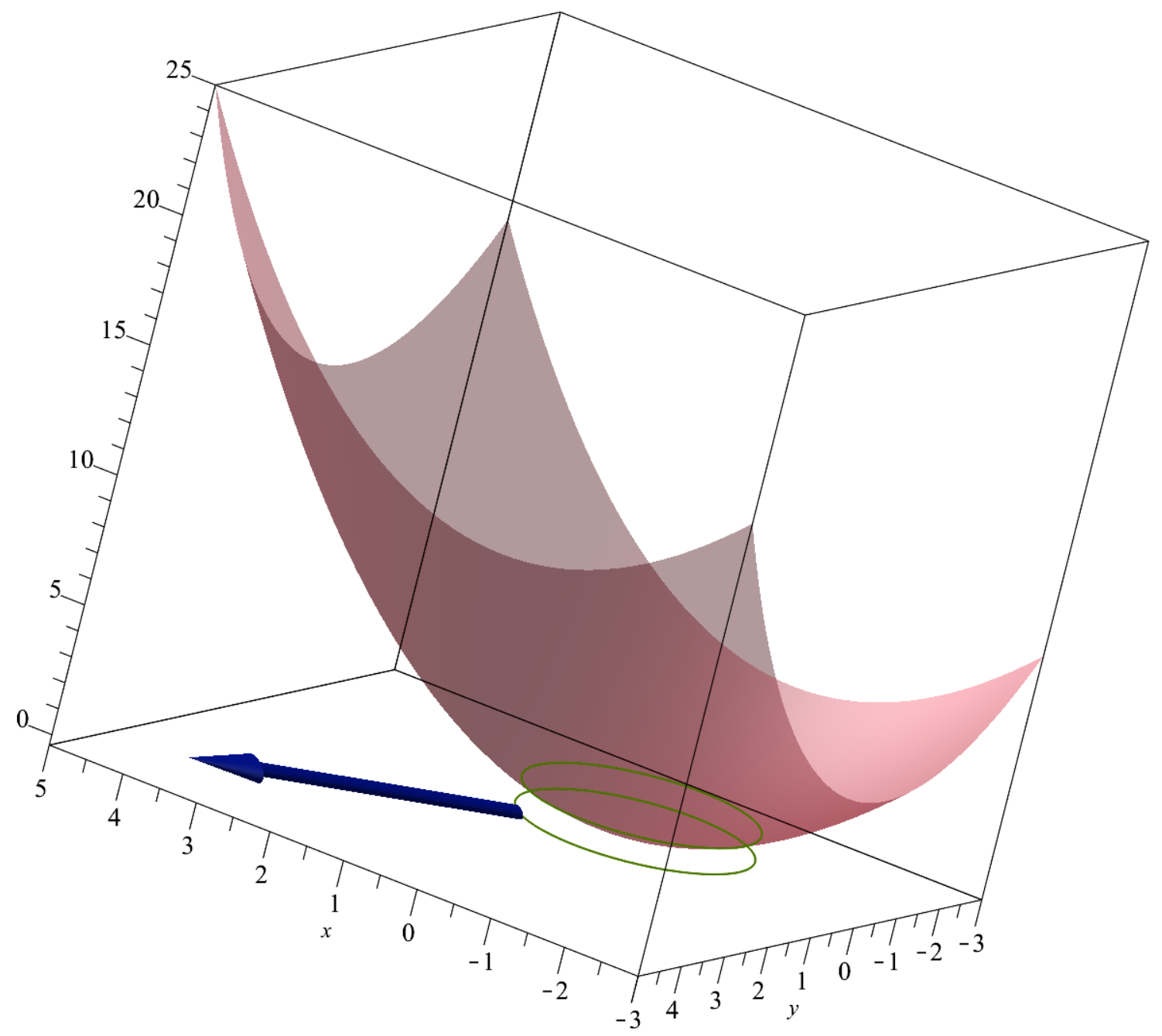

For the function $f(x, y)=\frac{1}{2} x^{2}+\frac{1}{2} y^{2}$, level curve, and gradient vector at the point $(1,1)$. 


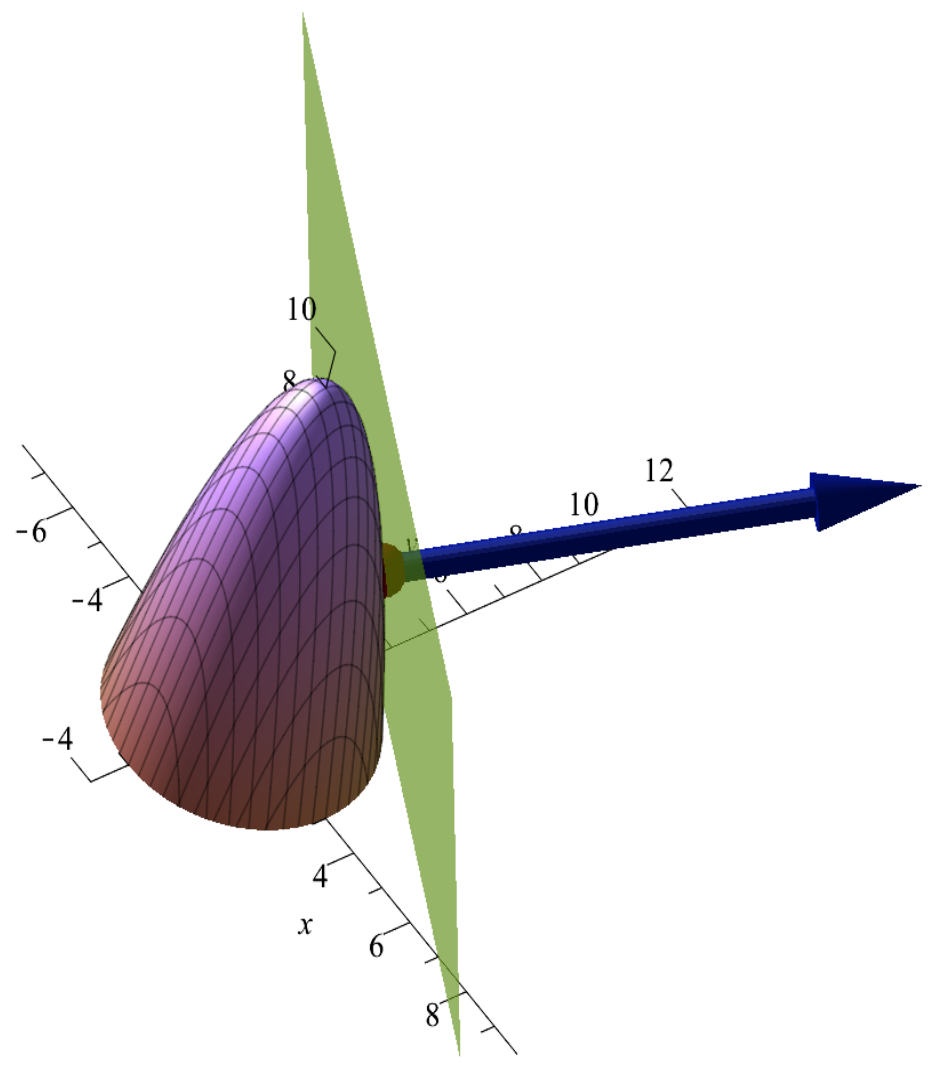

The plane (green) $2 x+4 y+z=14$ tangent to the surface at the point (red). The vector (blue) normal to the surface. 


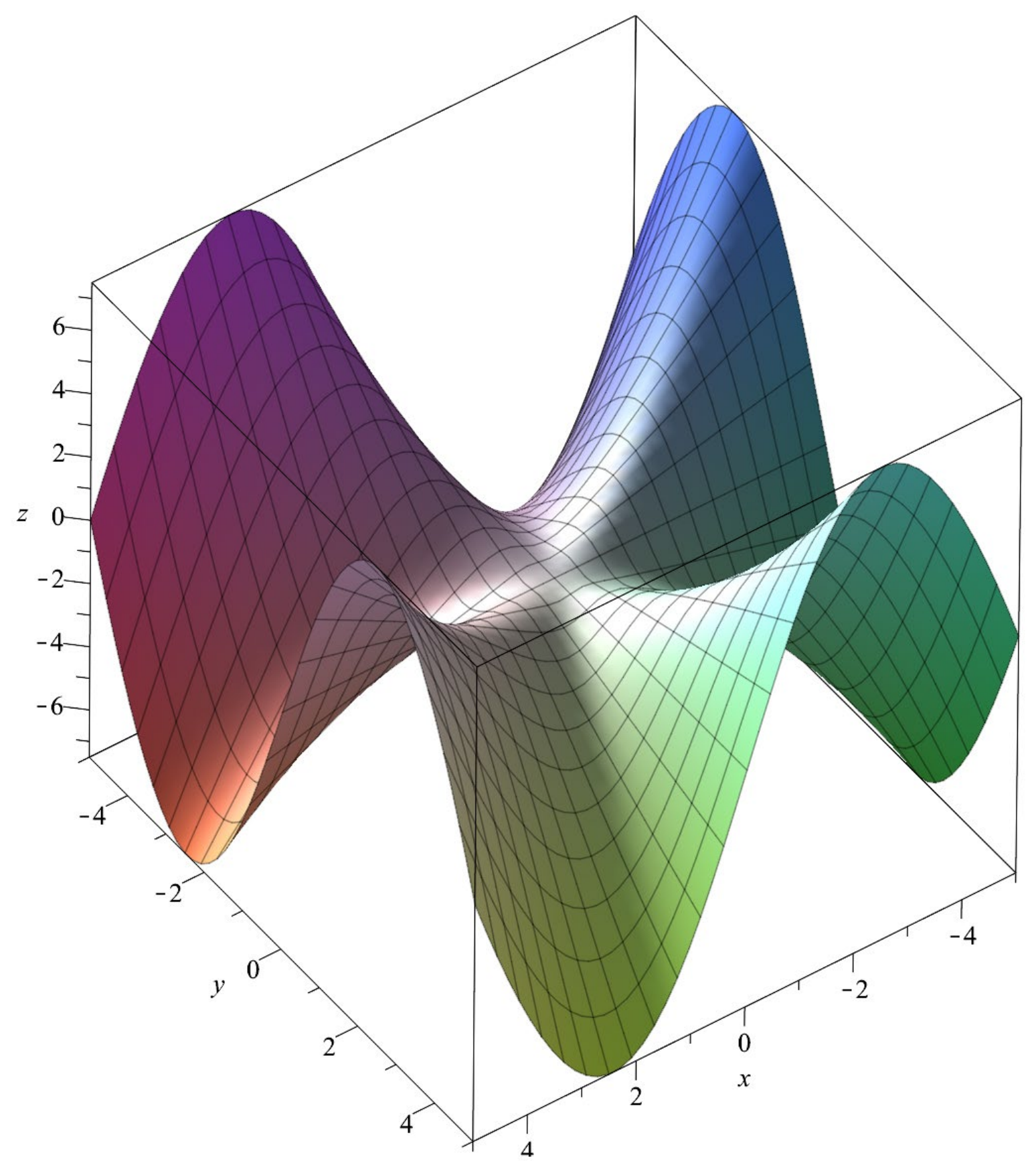




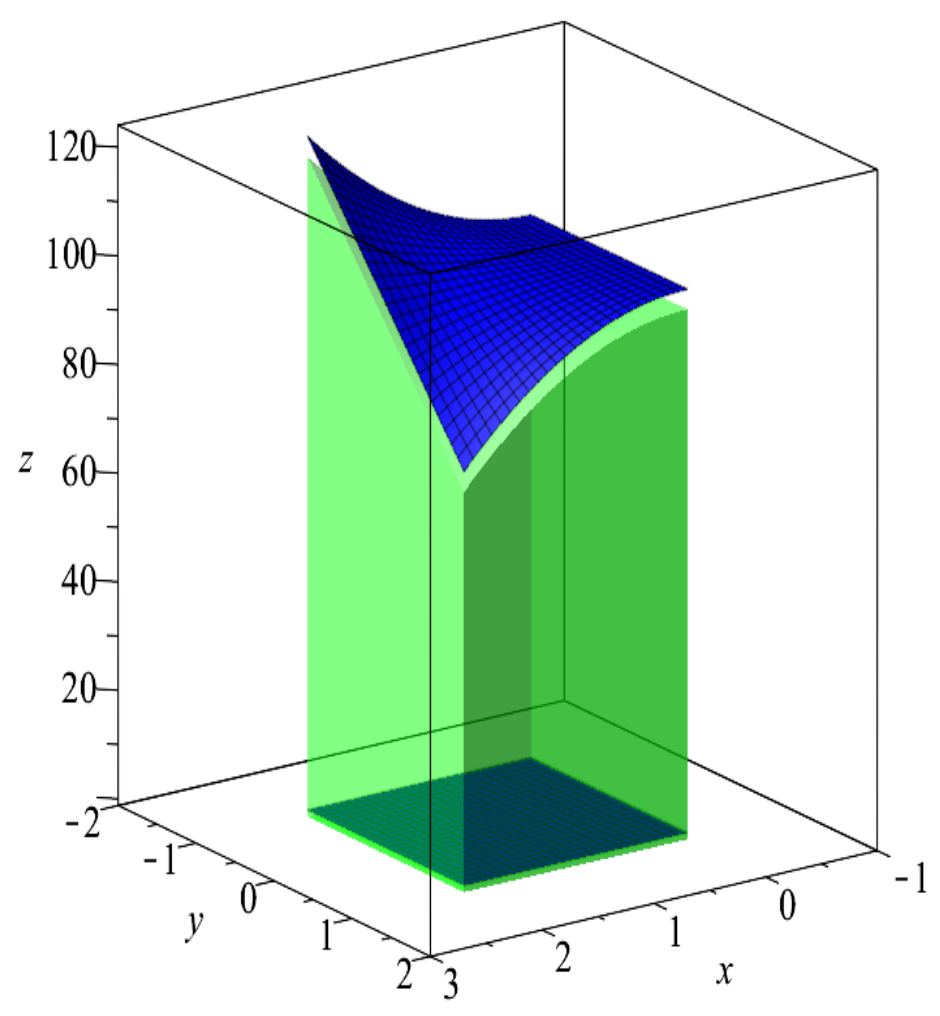




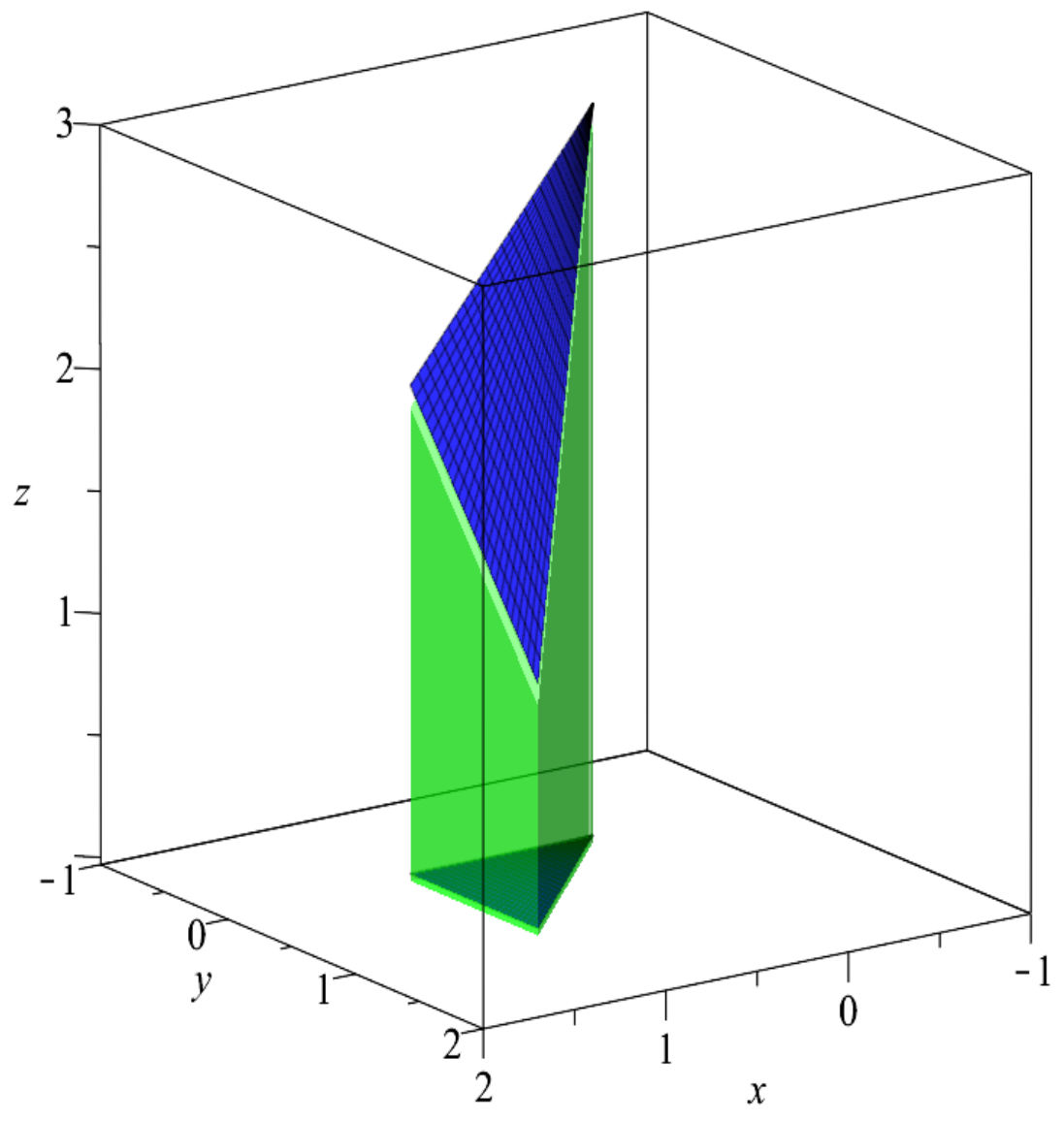




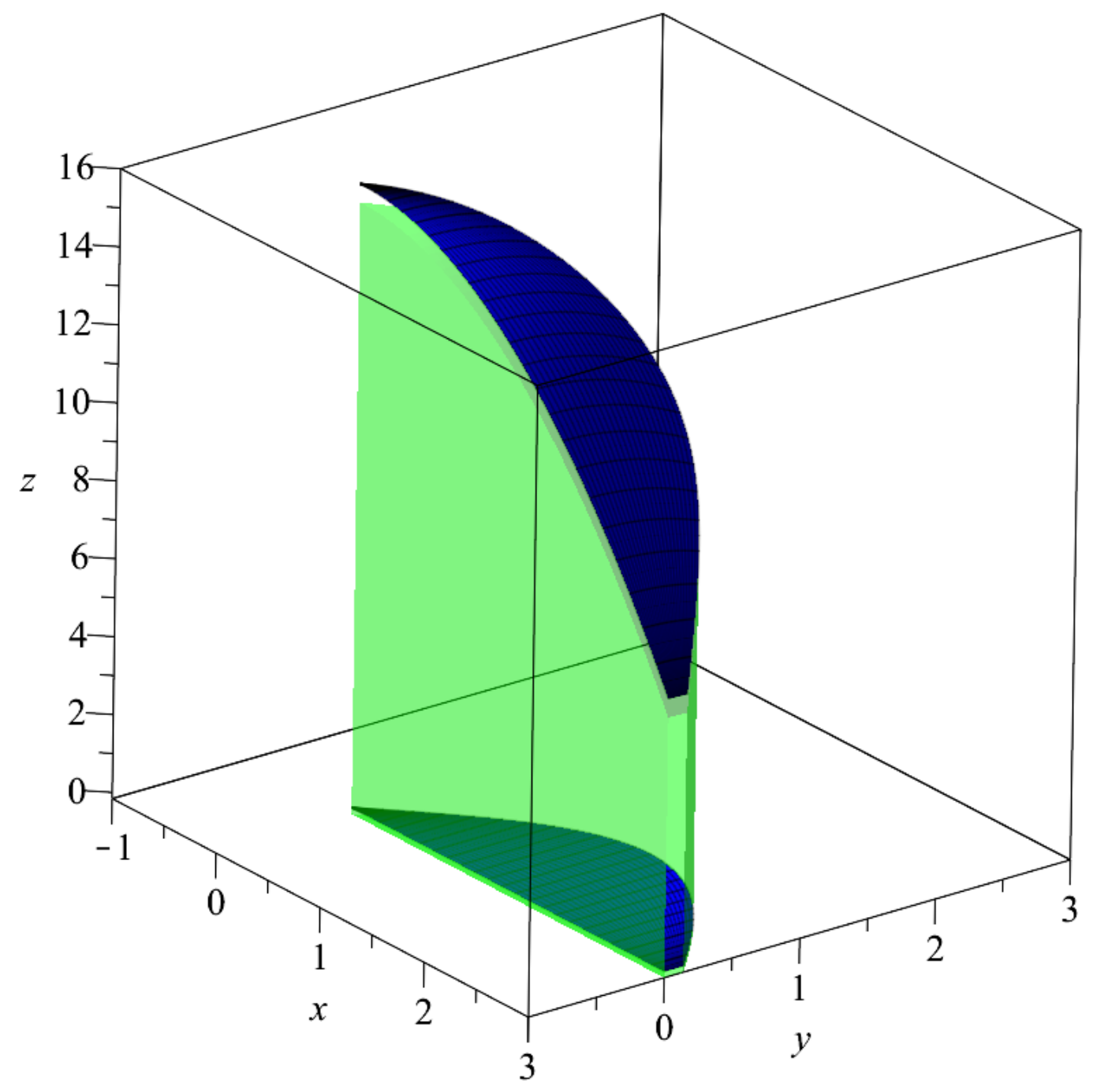




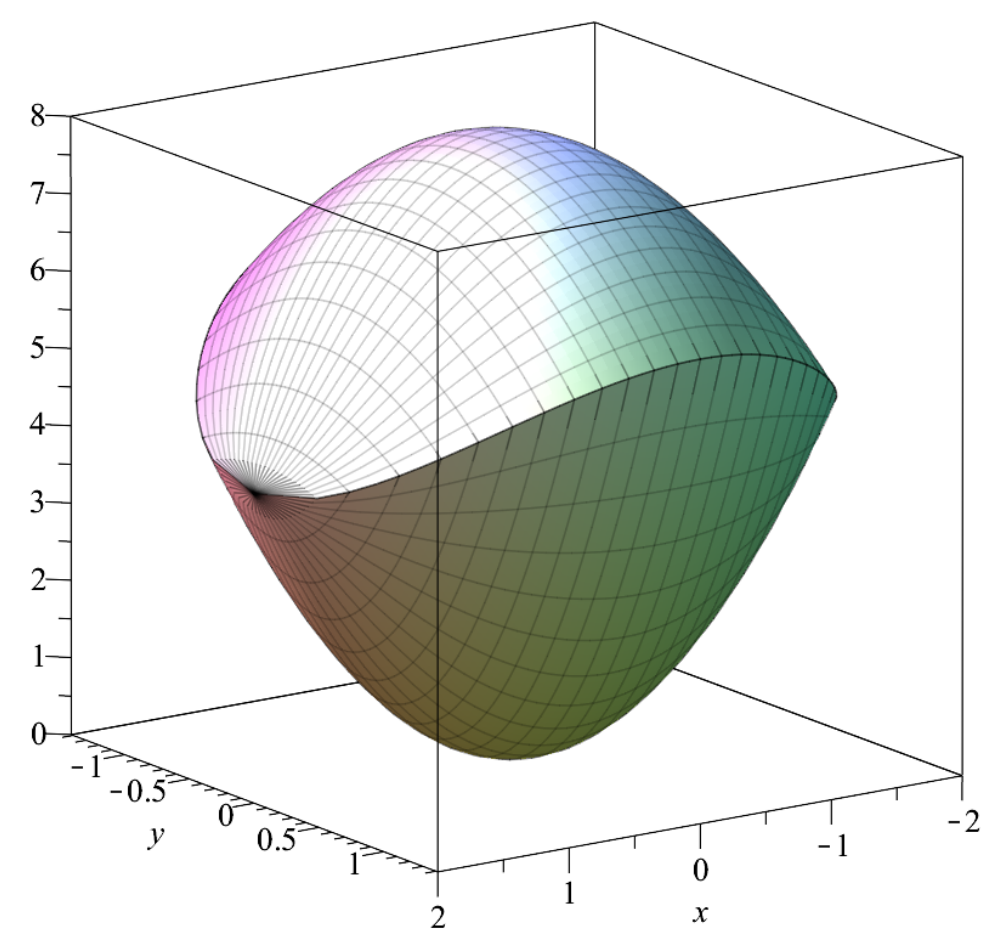

Space enclosed by two surfaces 
VITA

\section{BELARMINO GONZALEZ}

Born, Santiago de Cuba, Cuba

$2001-2005$

B.S. Computer Science

Florida International University

Miami, Florida

$2005-2007$

M.S. Computer Science

Florida International University

Miami Florida

$2008-2011$

Instructor

Department of Mathematics

Miami Dade College

InterAmerican Campus

$2011-2014$

$2014-2017$

Assistant Professor

Department of Mathematics

Miami Dade College

InterAmerican Campus

Associate Professor

Department of Mathematics

Miami Dade College

InterAmerican Campus

2017 - Present

Associate Professor, Sr.

Department of Mathematics and Natural Sciences

Miami Dade College

Padron Campus

Expected 2019

Ed. D. Curriculum and Instruction

Florida International University

Miami, Florida 